\title{
Convergent architecture of the transcriptome in human cancer
}

\author{
Lihua Zou ${ }^{1}$
}

\begin{abstract}
S
Despite large-scale efforts to systematically map the cancer genome, little is known about how the interplay of genetic and epigenetic alternations shapes the architecture of the tumor's transcriptome. With the goal of constructing a system-level view of the deregulated pathways in cancer cells, we systematically investigated the functional organization of the transcriptomes of 10 tumor types using data sets generated by The Cancer Genome Atlas project (TCGA). Our analysis indicates that the human cancer transcriptome is organized into well-conserved modules of co-expressed genes. In particular, our analysis identified a set of conserved gene modules with distinct cancer hallmark themes involving cell cycle regulation, angiogenesis, innate and adaptive immune response, differentiation, metabolism and regulation of protein phosphorylation. We applied a network inference approach to nominate candidate drivers of these conserved gene modules. The predicted drivers have consistent cancer-relevant functions related to the specific hallmarks and are enriched with cancer consensus genes and significantly mutated genes. We showed genetic alternations of TP53 and other cell cycle drivers have major downstream transcriptional impact on cell cycle regulation. Collectively, our analysis provided global views of convergent transcriptome architecture of human cancer. The result of our analysis can serve as a foundation to link diverse genomic alternations to common transcriptomic features in human cancer.
\end{abstract}

1, The Broad Institute of Harvard and MIT, Boston, MA, 02115

* Correspondence: lihuazou@gmail.com 


\section{INTRODUCTION}

The evolutionary history of a cancer cell has documented the accumulation of random 'passenger' mutations along with a few rate-limiting 'driver' events which confer fitness benefit to the cell. The cumulative effect of acquired driver events eventually set cancerous cells into uncontrolled state of proliferation, immortality, angiogenesis, cell death, invasion and metastasis. However, how the genetic and epigenetic effects propagate through intricate gene and biochemical circuits to cause deregulated cellular states within a cancer cell is still largely unknown. A promising approach is to decompose the oncogenic state of tumor cells directly in terms of the activity of sets of conserved biological features that has been described as the hallmarks of cancers ${ }^{1}$.

The comprehensive multi-dimensional genomic data provided by TCGA datasets across many tumor types offers an unprecedented opportunity to deepen our understanding of cancer biology and the discovery of new therapeutic and diagnostic targets. Gene expression analyses using unsupervised clustering approaches have been widely used in cancer research. Although informative, these methods analyzed gene level information and are prone to intrinsic noise caused by various biological and experimental factors. During the last decade, studies ${ }^{2-5}$ showed that gene modules consisting of co-regulated or co-expressed genes can be considered as higher-order building blocks of the global transcriptomic network and have been successfully applied to detect gene-disease association by improving the statistical power beyond the level of individual genes. Systematic data-driven approaches ${ }^{6-10}$ have also been developed to identify co-expressed gene modules in order to elucidate patterns of transcriptome organization across tissues and species.

We adopt the data-driven strategy to investigate the co-expression networks across 10 TCGA human cancer data sets including glioblastoma multiforme (GBM), ovarian carcinoma (OV), colon and rectal cancer (COADREAD), lung squamous cell carcinoma (LUSC), breast invasive carcinoma (BRCA), head and neck squamous cell carcinoma (HNSC), kidney renal 
clear cell carcinoma (KIRC), bladder urothelial carcinoma (BLCA), uterine corpus endometrioid carcinoma (UCEC) (Supplementary Table 1). Our analysis pipeline has four components: 1) construction of the co-expression network for each cancer data set and decomposition of the network into Co-expressed Gene Modules (CGMs) (Figure 1a); 2) identification of 'conserved' (or overlapping) CGMs across multiple tumor types (Figure 1b); 3) extraction of the core genes of conserved CGMs and classification of CGMs by cancer hallmark themes (Figure 1c); and 4) nomination of putative drivers of CGMs based on analysis of the human protein interaction network (Figure 1d).

Overall, we identified a set of conserved cancer CGMs across multiple tissue lineages. These conserved cancer CGMs are enriched with distinct gene ontology and cancer hallmark themes. Predicted module drivers have consistent cellular functions with their corresponding hallmarks and are enriched with cancer consensus genes and significantly mutated genes.

\section{RESULTS}

\section{Co-expression network analysis reveals conservation of gene modules}

We followed a previously described $\operatorname{method}^{9}$ and constructed gene co-expression networks on the basis of Pearson correlation between the RNA-seq expression profiles for the 10 TCGA cancer data sets (Supplementary Methods). For each cancer data set, co-expressed gene modules (CGMs) were identified in two steps: First, we performed unsupervised hierarchical clustering of the gene expression profiles using the topological overlap ${ }^{8,11}$ as a pair-wise distance measure; and then applied the dynamic tree cut method ${ }^{12}$ to decompose the dendrogram at different height and merge the clusters to form stable CGMs iteratively (Supplementary Methods). We defined 12 CGMs in GBM, 5 in OV, 10 in COADREAD, 8 in LUSC, 7 in BRCA, 9 in HNSC, 11 in BLCA, 8 in KIRC, and 9 in UCEC. In total, 79 cancer CGMs were identified by this analysis. 
Next we tested whether these CGMs can be validated using data from other experimental platforms and in independent data sets. We first compared the TCGA GBM expression data (syn1446212) measured by RNA-seq and by Affymetrix microarrays. We applied the same procedures to both data sets and were able to detect the majority of the CGMs defined using Affymetrix microarray when using RNA-seq data, suggesting that CGMs are reproducible across technical platforms (Supplementary Figure 1). We performed a similar comparison using 2 independently published GBM expression data sets (GSE4271, GSE13041) and reassuringly, as above, the majority of CGMs detected in the TCGA data were also detected in the external data sets demonstrating the robustness of the CGMs (Supplementary Figure 1).

To determine whether CGMs from different cancer data sets were composed of overlapping genes, we enumerated all pair-wise CGMs $(n=2,756)$ from any two different cancer data sets and identified 509 pairs of CGMs with significant mutual overlap (Bonferroni corrected hypergeometric test, $p<0.05$, Supplementary Materials). The list of overlapping pairs of CGMs is provided in Supplementary Table 2. Surprisingly, 63 out of 79 (82\%) CGMs showed significant overlap with CGMs detected in at least two different tumor types (Figures 2 and 3). Taken together, our analysis suggests that the human cancer transcriptome is organized into modules of co-expressed genes that are conserved across tumor types.

\section{Hierarchical organization of co-expressed gene modules}

To better understand their global organization, we sought to define the relationships between these CGMs through the construction of a module-module network. The resulting network has 79 nodes, each represents one CGM, and 509 edges between significantly overlapping CGMs. Many module nodes appear to be closely connected on the resulting network (Figure $3 b$ ). To visualize the multi-level relationship among the CGMs, we transformed the module-module network into a hierarchical tree (Figure $3 a$ ) based on the random walk distance ${ }^{13}$. We 
partitioned the hierarchical tree into subtrees or module groups based on network modularity ${ }^{14}$ (modularity threshold=0.37, Supplementary Materials), a graph structure measure reflecting the enrichment of edges among nodes within a group (or cluster) relative to the nodes between the groups.

As shown in Figure 3b, our analysis revealed 11 groups of CGMs comprised of the 63 CGMs with high degree of mutual overlap (Figures 2 and 3). The 11 CGM groups have a median of 5 CGMs representing at least 3 different tumor types in each group. This implies that these CGM groups capture common or 'conserved' cellular processes across cancer types. The 11 CGM groups are shown as distinct subtrees on the transformed hierarchical tree of CGMs (Figure 3a). Notably, the red, turquoise, and orange CGMs fall within one branch delineated by the green square on Figure 3a which mostly involves immune response. The blue, purple, and magenta modules fall within another branch (enclosed by the blue square on Figure 3a) which primarily involves angiogenesis, epithelial-mesenchymal transformation (EMT) and muscle development. The hierarchical tree of identified gene modules suggests convergent functional organization of cellular programs of tumor independent of their tissue lineage.

To test whether genes belonging to each of the CGM groups are indeed co-expressed across their tumor types, we calculated the Pearson correlation for all gene pairs between their expression levels in the relevant tumor types. We confirmed the gene-gene correlation within the overlapping CGMs is significantly higher than expected from a random gene set of the same size (Kolmogorov-Smirnov test $p<2.6 \times 10^{-16}$, Figure 3c).

\section{Conserved expression modules are enriched with cancer hallmarks}

To assess possible biological functions of the CGMs, we calculated gene ontology enrichment for individual CGM (Figure 4, Supplementary Materials). We also extract core module genes (Supplementary Materials) for each of the 11 CGM group and calculate its functional enrichment 
using DAVID tools (http://david.niaid.nih.gov/david/). We classified the CGMs into 7 functional categories based on their specific enrichment of gene ontology ${ }^{15}$ and cancer hallmarks (Supplementary Table 3): (i) cell cycle (FDR $<2.2 \times 10^{-51}$, black modules of Figure 2-4); (ii) innate immune response (FDR $<7 \times 10^{-14}$, red modules of Figure 2-4); (iii) adaptive immune response (FDR $<5.6 \times 10^{-109}$, turquoise and orange modules of Figure 2-4); (iv) differentiation $\left(\right.$ FDR $<9 \times 10^{-10}$, brown modules of Figure 2-4); (v) angiogenesis/EMT $\left(\right.$ FDR $<2 \times 10^{-7}$, blue, purple, and magenta modules of Figure 2-4); (vi) metabolism (FDR $<0.1$ green and pink modules of Figure 2-4); (vii) phosphorylation (FDR<0.3, yellow modules). We referred to these classified CGMs as "hallmark gene modules" and highlighted their core module genes below. We provide the full list of core module genes in Supplementary Table 4.

The cell cycle modules (class i, black modules of Figure 2-4) are enriched with genes involving chromosome instability (i.e. CENPA, BUB3, NUF2 $2^{16-18}$ ) and DNA replication (i.e. $C D C 45, M C M 10^{19}$ ). Other notable genes in this module include transcription factors $M Y B L 2$, FOXM1, E2F2 and mitotic regulators such as CCNB2, CDK1, AURKB, CDC25A and CDC25C. The innate immune modules (class ii, red modules of Figure 2-4) include multiple INF-signaling and virus-response pathway genes including IFI27, IFI6, IRF9 and several MHC class I genes including $H L A-B, H L A-H, H L A-L$. Mutations and somatic copy number alternations (SCNAs)(doi:10.7303/syn300013) in several HLA gene family members affect about $10 \%$ of total TCGA cancer patients (Supplementary Figure 2). The adaptive immune modules (class iii, turquoise and orange modules of Figure 2-4) are present in all 10 TCGA cancer data sets for this analysis. The core adaptive immune genes include multiple inflammatory response genes CD163, CPVL, FPR3 and members of MHC class II genes including HLA-DOA, HLA-DPA1, HLA-DPB1.

The angiogenesis/EMT modules (class iv, blue modules of Figure 2-4) are present across all 10 TCGA data sets in this study. Core genes of the angiogenesis/EMT modules 
include FN1, MMP2, TWIST1, and WNT5A that are involved with cell adhesion, embryonic development, angiogenesis and TGF-beta mediated signaling ${ }^{1}$. Somatic mutations and SCNAs in members of angiogenesis and TGF-beta pathway are shown to affect $37 \%$ of human cancers (Supplementary Figure 2). The differentiation modules (class v, brown modules of Figure 2-4) appear to be specific to squamous carcinoma including LUSC, HNSC and BLCA. The core genes of the differentiation module contains multiple tissue differentiation genes, for example, SOX2, TP63, KRT5, KRT16, HOXA10 and WNT signaling pathway genes WNT4 and WNT7B ${ }^{20,21}$. SOX2 is reported previously as lineage-survival proto-oncogene with essential roles in the differentiation and development of normal squamous cell ${ }^{22}$. SOX2 is located on 3q26, a frequent amplified region in HNSC and LUSC ${ }^{23}$. The mutual exclusivity between SOX2 and TP63 mutations (Supplementary Figure 2) suggests a convergent mechanism driving the differentiation transcriptional programs among a subset of squamous carcinoma.

\section{Functions of imputed module drivers reflect hallmark themes}

We next sought to nominate candidate drivers of the conserved CGMs. Previous studies suggest that disease genes in close proximity on the protein interaction network (PIN) will likely be functionally related ${ }^{24,25}$. We compiled a joint human PIN dataset from various resources including HPRD ${ }^{26}, \mathrm{NCl}-\mathrm{PID}^{27}$, Cancer Cell Map from (http://cancer.cellmap.org/cellmap/), and REACTOME $^{28}$ (Supplementary Material). For each of the CGM groups, we applied a networkbased driver inference algorithm (NetSig, Supplementary Materials) to prioritize putative module drivers based on their proximity to the core module genes on the PIN. Figure 5 shows examples of protein subnetworks comprised of the direct protein interactions between the top candidate module drivers (red node, Figure 5) and the most connected core module genes (Supplementary Materials).

Our analysis identified a total of 318 candidate module drivers (doi:10.7303/syn1960770). Many of the top candidate drivers identified by NetSig have 
consistent oncogenic roles relevant to the functional classes of their CGMs. For example, top candidate drivers (red nodes, Figure 5a) of the cell cycle modules (black modules, Figure 5) include TP53, BRCA1, CDKN1A, CDK2, CDC6, PCNA and BUB1A, all of which have wellknown roles in the regulation of cell cycle and genomic stability ${ }^{1}$. Notably, non-synonymous mutations and foal SCNAs of TP53 and other cell cycle drivers are present in $55 \%$ of the human cancers (Figure 6d). This highlights the role of DNA repair and genomic instability as the key enabling hallmarks of human cancer. Tumor patients carrying genetic alternations of TP53 and other cell cycle drivers tend to have increased number of SCNA events (especially deletions) (Figure 6b), which is in agreement with the observation made independently by Zack et al. Submitted. To assess the downstream transcriptional impact of the genetic alternations to the cell cycle drivers, we defined the pathway activity of a gene set in terms of the coefficient of the first principle component of the expression matrix of the pre-defined gene set ${ }^{29}$. Then we calculated the pathway activity for the cell cycle modules and the knowledge-based KEGG cell cycle pathway ${ }^{30}$. The activity profile of the cell cycle modules and the KEGG cell cycle pathway (Figure 6e) are concordant with each other and both highly up-regulated among tumor patients with genetic changes of cell cycle drivers (student t-test, $p<2.2 \times 10^{-16}$ ). In addition, the cell cycle module genes are expressed at much higher level than adjacent non-tumor tissues across 6 TCGA tumor types with such comparison available (Figure 6f).

The protein subnetworks of the angiogenesis/EMT modules (blue and purple modules, Figure 5) share several common candidate drivers including CTNNB1, SMAD4, SRC, and ITGB1, which have known regulatory and signaling roles in TCF-beta signaling, angiogenesis and $\mathrm{EMT}^{1,31,32}$. Other notable candidate drivers in the subnetworks include RAC1, EP300, EGFR which have been shown to be frequently mutated in human cancer (doi:10.7303/syn1715784.2). The top predicted drivers of the closely related module group 
(magenta modules, Figure $5 f$ and Figure 3) include several muscle development genes including $D M D, D M N, S G C D$ and $S R C$ among others.

The top predicted drivers of the innate immune modules (red modules, Figure $5 \mathrm{~g}$ ) include STAT2 and RNASEL among others. STAT2 is reported to mediate the innate immunity and host defense mechanism via the Type I Interferon receptor ${ }^{33}$. RNASEL contributes in many ways to the interferon anti-virus system ${ }^{34}$. The top candidate drivers of the adaptive immune modules (turquoise and orange module, Figure 5) include LCK, CD4, CBL, PTPN11 (also known as SHP2) with important roles in diverse immune response through the antigen recognition by the $\mathrm{T}$ cell receptor $(\mathrm{TCR})^{35}$. The top predicted drivers of the phosphorylation modules (yellow modules, Figure $5 \mathrm{c}$ ) are linked to members of several major signaling pathways including AR, ESR1, PIK3R1, HSP9OAA1, JAK1, STAT3, SMAD4 1 .

The top predicted drivers of the metabolism modules (green modules, Figure $5 \mathrm{~b}$ ) include multiple members of the cohesin complex SMC1A, SMC1B, SMC3, RAD21, STAG1 and STAG2. Cohesin complex are frequently mutated in acute myeloid leukemia $(A M L)^{36}$ and defects in cohesin complex may underlie chromosomal instability of human cancers ${ }^{37,38}$. Other notable candidates of the subnetwork include H2AFX, HIST3H3, RHOA, MAPK8 and MAPK14. $H 2 A F X$ is frequently mutated in the Pan-Cancer data by MutSig algorithm ${ }^{39}$ (doi:10.7303 /syn1715784.2).

We next asked whether the module drivers are enriched with cancer genes targeted by genomic alternations. We compared the predicted module drivers with the mutation drivers identified by the MutSig algorithm in the Pan-Cancer data (doi:10.7303/syn1715784.2). There are 29 out of 318 predicted modules drivers (Supplementary Table 3) overlapping with mutation drivers (hypergeometric test $p<8 \times 10^{-26}$ ). There are 41 out of 318 module drivers (Supplementary Table 5) overlapping with the Cancer Consensus Genes (CCG $)^{4038}$ (hypergeometric test $p<1 \times 10^{-20}$ ). Overall, the result suggests that the predicted module 
drivers likely capture aspects of the biology and shed new light on the functional context of the cancer drivers discovered via mutation analysis.

\section{DISCUSSION}

To our knowledge, this is the first extensive investigation of human cancer transcriptome to date. Our study defined the global transcriptome architecture of human cancer. We identified 11 groups of CGMs conserved across multiple tumor types. These conserved CGMs display distinct gene ontologies and cancer hallmark themes. The highly conserved CGMs across tumor types suggest the existence of selective force shaping the cancer transcriptome. Such conserved CGMs can be viewed as 'building blocks' of the cancer transcriptiome and be used as surrogate for the common cellular functions of human cancer. We noticed these conserved CGMs are significantly correlated with a large collection of published gene signatures (data not shown) although they are derived directly from the data and not dependent on any prior knowledge. As an example, we showed that the activity profile of the cell cycle modules is highly concordant with the knowledge-based KEGG cell cycle pathway (Figure 6e).

As a starting point to understand the common genetic and regulatory mechanism of these conserved CGMs, we integrated cancer transcriptome and interactome to nominated drivers for the conserved CGMs. We showed the predicted module drivers recapitulate known tumor biology and have consistent cancer-relevant functions with the hallmark themes of the conserved CGMs. Our analysis support that the cell cycle regulation and chromatin maintenance are the key system hallmarks of human cancer. Genetic alternations of TP53 and other cell cycle drivers have major downstream transcriptional impact on the cell cycle regulation from our Pan-Cancer analysis. We anticipate future studies to elucidate mechanism leading to the deregulation of the hallmark gene modules would have direct implications for the design of new drug targets and contribute to novel pathway-focused therapeutic paradigm. 


\section{METHODS SUMMARY}

The 10 TCGA Pan-Cancer data sets used for our study are available from Sage Bionetworks (doi:10.7303/syn300013). The RNAseq molecular profiling was based on IlluminaHiSeq_RNAseqV2. The RNAseq data preprocessing was carried out using the SeqWare Pipeline project, version 0.7.0. The normalized level 3 RNAseq expression was based on RSEM ${ }^{41}$. Significantly recurrent SCNAs were identified using GISTIC $2.0^{42,43}$ on relative total copy-number data after correction for sample purity. Significantly mutated genes were identified using MutSig ${ }^{39}$. Co-expression network analysis was based on WGCNA package ${ }^{44}$.

\section{FIGURE LEGENDS}

Figure 1. Overview of Pan-Cancer hallmark module analysis. a, For RNAseq data of each cancer data set, we construct the co-expression network based on the pair-wise Pearson correlation of gene expression profile. In total, 79 CGMs were identified by dynamic tree cut algorithm $^{12}$. b, We enumerate all possible pairs of CGMs from any two different cancer data sets to find 11 groups of conserved CGMs across tumor types. c, We extract core module genes for each of the conserved CGM groups. We also classify the conserved CGMs into 7 functional categories by their enriched cancer hallmarks. d, We map the core module genes onto a human protein interaction network and apply NetSig to nominate module drivers (Supplementary Methods).

Figure 2. Detection of conserved co-expressed gene modules. a-i, Each dendrogram corresponds to the co-expression network of one of the 10 cancer data set (COAD and READ are combined into one cancer data set) produced by average linkage hierarchical clustering of genes on the basis of topological overlap ${ }^{11}$. The vertical scale of the dendrogram is the measure 
of distance i.e. $1-\|d\|$, where $d$ is Pearson correlation of a pair of expression profile. CGMs in each cancer data set are assigned unique color to distinguish different modules and numbered uniquely (e.g. M1,M2 ..) within the set. The M2 module of OV (indicated by *) is at the borderline of modularity cutoff (Supplementary Materials) and is manually assigned to the pink group. We merged the M7 module of COADREAD with two close neighbors $M 3, M 9$ as indicated within the brackets. Conserved CGMs from different cancer data sets with significant gene overlap were assigned the same color as indicated by the horizontal bar beneath each dendrogram. For clarity, only CGMs conserved in at least 3 different tumor types are shown. The remaining non-conserved or poorly connected genes are colored white. The color key at the bottom shows the function categories of the conserved CGMs.

Figure 3. Hierarchical organization of conserved co-expressed gene modules. a, The leafs of the hierarchical tree represent a CGM. Groups of highly conserved CGMs are shown as distinct subtrees of the hierarchical tree corresponding to the module-module network shown below. The dotted line represents modularity threshold. b, Each node in the module-module network represents a CGM. Each edge represents the gene overlap between two CGMs of different tumor types. The color circles indicate the conserved CGM groups. The node color matches the leaf color of the tree. c, Each colored histogram shows the Pearson correlation of all possible gene pairs from one of the conserved module group. The overlapping grey histogram to the left shows the Pearson correlation of all genes pairs from a random gene set which has the same size of the conserved module group.

Figure 4: Gene ontology of co-expressed gene modules. The columns of the matrix are the conserved CGMs. Examples of core genes (indicated within the colored square) for each of the conserved CGMs are shown below the matrix. The color rectangulars along the diagonal 
indicate the conserved CGM groups (columns) and their most significantly associated gene ontology terms (rows). The color intensity of the matrix cell represents the level of association by one-sided hypergeometric test. Columns are ordered so the modules of the same group are together. The rows are grouped so the most significantly enriched gene ontology terms for a module group are together.

Figure 5: Examples of protein subnetworks connecting conserved module genes. a-i, The red round shaped nodes in each protein subnetwork indicate top candidate drivers of one of the conserved CGM group. The red square shaped nodes represent the predicted drivers that are also SMGs according to MutSig analysis. The edges connecting two nodes represent the human protein-protein interactions. The predominate cellular functions of the predicted module drivers are indicated next to each protein subnetwork. The functional classes of the predicted module drivers are shown at the bottom.

Figure 6: Transcriptional impact of genetic alternations of cell cycle drivers. a, The color keys for different tumor types used in this study. b, The stacked barplot shows sample-bysample counts of broad amplification (red) and deletion events (blue) across tumor types (horizontal axis). c, The heatmap shows the SCNAs in each cancer sample (horizontal axis) plotted by chromosomal locations (vertical axis). d, The heatmap shows the somatic mutations of key cell cycle drivers sample-by-sample across tumor types. e, The pathway activity profile ${ }^{29}$ of the core cell cycle modules and the KEGG cell cycle pathway. The color key of somatic mutations and SCNA, the scale of pathway activity and copy number value based on GISTIC2 ${ }^{43}$ are shown below the activity profile from left to right. $\mathbf{f}$, The boxplots show the comparison between the expression level (vertical axis) of the core cell cycle genes in adjacent normal tissue versus tumor tissue in 6 different TCGA data sets. 


\section{Reference}

1. Hanahan, D. \& Weinberg, R. A. Hallmarks of cancer: the next generation. Cell $144,646-674$ (2011).

2. Mootha, V. K., Lindgren, C. M. \& Eriksson, K. F. PGC-1a-responsive genes involved in oxidative phosphorylation are coordinately downregulated in human diabetes. Nature (2003).

3. Segal, E., Friedman, N., Koller, D. \& Regev, A. A module map showing conditional activity of expression modules in cancer. Nat Genet 36, 1090-1098 (2004).

4. Subramanian, A. et al. Gene set enrichment analysis: a knowledge-based approach for interpreting genome-wide expression profiles. Proc. Natl. Acad. Sci. U.S.A. 102, 1554515550 (2005).

5. Segal, E., Friedman, N., Kaminski, N., Regev, A. \& Koller, D. From signatures to models: understanding cancer using microarrays. Nat Genet 37, S38-S45 (2005).

6. Stuart, J. M., Segal, E., Koller, D. \& Kim, S. K. A gene-coexpression network for global discovery of conserved genetic modules. Science 302, 249-255 (2003).

7. Snel, B., van Noort, V. \& Huynen, M. A. Gene co-regulation is highly conserved in the evolution of eukaryotes and prokaryotes. Nucleic Acids Res. 32, 4725-4731 (2004).

8. Zhang, B. \& Horvath, S. A General Framework for Weighted Gene Co-Expression Network Analysis. Statistical Applications in Genetics and Molecular Biology 4, (2005).

9. Zhang, B. et al. Integrated Systems Approach Identifies Genetic Nodes and Networks in LateOnset Alzheimer's Disease. Cell 153, 707-720 (2013).

10. Oldham, M. C., Horvath, S. \& Geschwind, D. H. Conservation and evolution of gene coexpression networks in human and chimpanzee brains. Proc. Natl. Acad. Sci. U.S.A. 103, 17973-17978 (2006). 
11. Ravasz, E. Hierarchical Organization of Modularity in Metabolic Networks. Science 297, $1551-1555$ (2002).

12. Langfelder, P., Zhang, B. \& Horvath, S. Defining clusters from a hierarchical cluster tree: the Dynamic Tree Cut package for R. Bioinformatics (2008).

13. Pons, P. \& Latapy, M. in Lecture Notes in Computer Science 3733, 284-293 (Springer Berlin Heidelberg, 2005).

14. Newman, M. Fast algorithm for detecting community structure in networks. Physical review $E(2004)$.

15. Berardini, T. Z. \& Khodiyar, V. K. The Gene Ontology in 2010: extensions and refinements. Nucleic acids Res. 38, D331-D335 (2010).

16. Amato, A., Schillaci, T., Lentini, L. \& Di Leonardo, A. CENPA overexpression promotes genome instability in pRb-depleted human cells. Mol Cancer (2009).

17. Johnson, V. L., Scott, M. I. F., Holt, S. V., Hussein, D. \& Taylor, S. S. Bub1 is required for kinetochore localization of BubR1, Cenp-E, Cenp-F and Mad2, and chromosome congression. (2004).

18. Nabetani, A., Koujin, T., Tsutsumi, C., Haraguchi, T. \& Hiraoka, Y. A conserved protein, Nuf2, is implicated in connecting the centromere to the spindle during chromosome segregation: a link between the kinetochore function and the spindle checkpoint. Chromosoma 110, 322-334 (2001).

19. Sawyer, S. L., Cheng, I. H., Chai, W. \& Tye, B. K. Mcm10 and Cdc45 Cooperate in Origin Activation in Saccharomyces cerevisiae. Journal of Molecular Biology 340, 195-202 (2004).

20. MacDonald, B. T., Tamai, K. \& He, X. Wnt/B-catenin signaling: components, mechanisms, and diseases. Developmental cell (2009).

21. Pongracz, J. E. \& Stockley, R. A. Wnt signalling in lung development and diseases. Respir. Res. 7, 15 (2006). 
22. Bass, A. J. et al. SOX2 is an amplified lineage-survival oncogene in lung and esophageal squamous cell carcinomas. Nat Genet 41, 1238-1242 (2009).

23. Cancer Genome Atlas Research Network. Comprehensive genomic characterization of squamous cell lung cancers. Nature 489, 519-525 (2012).

24. Pujana, M. A. et al. Network modeling links breast cancer susceptibility and centrosome dysfunction. Nat Genet 39, 1338-1349 (2007).

25. Barabási, A. L. \& Oltvai, Z. N. Network biology: understanding the cell's functional organization. Nature Reviews Genetics (2004).

26. Baolin, L. \& Bo, H. HPRD: a high performance RDF database. Network and Parallel Computing (2007).

27. Schaefer, C. F., Anthony, K., Krupa, S. \& Buchoff, J. PID: the pathway interaction database. Nucleic acids Res. 37, D674-D679 (2009).

28. Croft, D. et al. Reactome: a database of reactions, pathways and biological processes. Nucleic Acids Res. 39, D691-D697 (2010).

29. Tomfohr, J., Lu, J. \& Kepler, T. B. Pathway level analysis of gene expression using singular value decomposition. BMC Bioinformatics 6, 225 (2005).

30. Kanehisa, M., Goto, S., Sato, Y., Furumichi, M. \& Tanabe, M. KEGG for integration and interpretation of large-scale molecular data sets. Nucleic Acids Res. 40, D109-D114 (2011).

31. Eliceiri, B. P. et al. Selective requirement for Src kinases during VEGF-induced angiogenesis and vascular permeability. Mol. Cell 4, 915-924 (1999).

32. Park, H. et al. Homeobox D1 regulates angiogenic functions of endothelial cells via integrin $\beta 1$ expression. Biochem. Biophys. Res. Commun. 408, 186-192 (2011).

33. Perry, S. T., Buck, M. D., Lada, S. M., Schindler, C. \& Shresta, S. STAT2 mediates innate immunity to Dengue virus in the absence of STAT1 via the type I interferon receptor. PLoS Pathog. 7, e1001297 (2011). 
34. Chakrabarti, A., Jha, B. K. \& Silverman, R. H. New insights into the role of RNase L in innate immunity. J. Interferon Cytokine Res. 31, 49-57 (2011).

35. Pardoll, D. M. The blockade of immune checkpoints in cancer immunotherapy. Nat Rev Cancer 12, 252-264 (2012).

36. Cancer Genome Atlas Research Network. Genomic and epigenomic landscapes of adult de novo acute myeloid leukemia. N. Engl. J. Med. 368, 2059-2074 (2013).

37. Solomon, D. A. et al. Mutational inactivation of STAG2 causes aneuploidy in human cancer. Science 333, 1039-1043 (2011).

38. Barber, T. D. et al. Chromatid cohesion defects may underlie chromosome instability in human colorectal cancers. Proc. Natl. Acad. Sci. U.S.A. 105, 3443-3448 (2008).

39. Lawrence, M. S. et al. Mutational heterogeneity in cancer and the search for new cancerassociated genes. Nature (2013). doi:10.1038/nature12213

40. Futreal, P. A. et al. A census of human cancer genes. Nat Rev Cancer 4, 177-183 (2004).

41. Li, B. \& Dewey, C. RSEM: accurate transcript quantification from RNA-Seq data with or without a reference genome. BMC Bioinformatics (2011).

42. Beroukhim, R. et al. The landscape of somatic copy-number alteration across human cancers. Nature 463, 899-905 (2010).

43. Mermel, C. H. et al. GISTIC2.0 facilitates sensitive and confident localization of the targets of focal somatic copy-number alteration in human cancers. Genome Biol. 12, R41 (2011).

44. Langfelder, P. \& Horvath, S. WGCNA: an R package for weighted correlation network analysis. BMC Bioinformatics 9, 559 (2008). 


\section{ACKNOWLEDGEMENTS}

The authors would like to acknowledge TCGA and Sage Bionetworks for the collaborative atmosphere to generate and make the PanCan12 data freeze public available and the support of all institutions involved. We would like to thank Gad Getz, Lynda Chin, Chip Stewart for the commenting on the preliminary draft of the manuscript. We would like to thank our Broad Institute colleagues Gordon Saksena, Mike Lawrence, Andrew Cherniack and members of the Broad GDAC team for their contribution to the generation of the PanCan12 data freeze during construction of the study.

\section{Author Contributions}

LZ conceived the study and performed the analysis and wrote the paper. 
bioRxiv preprint doi: https://doi.org/10.1101/028415; this version posted October 5, 2015. The copyright holder for this preprint (which was not certified by peer review) is the author/funder, who has granted bioRxiv a license to display the preprint in perpetuity. It is made available under aCC-BY-NC-ND 4.0 International license.

\section{Zou_Fig.1}



a) construct co-expression networks and identify Co-expressed Gene Modules (CGMs)

\section{CGMs}

10 tumor types


b) find groups of conserved CGMs across tumor types

c) extract core module genes of conserved CGMs and classify by functional classes

11 CGM groups

63 conserved CGMs
11 core signatures

7 hallmark classes



d) nominate module drivers on the human PIN

318 modules drivers 


\section{Zou_Fig.2}


Genes

Color keys of conserved Co-expressed Gene Modules (CGMs):
i) Cell Cycle
iii) $\square$ Adaptive Immune
v) Differentiation
vii) Phosphorylation 
bioRxiv preprint doi: https://doi.org/10.1101/028415; this version posted October 5, 2015. The copyright holder for this preprint (which was not certified by peer review) is the author/funder, who has granted bioRxiv a license to display the preprint in perpetuity. It is made available under aCC-BY-NC-ND 4.0 International license.

\section{Zou_Fig.3}

a

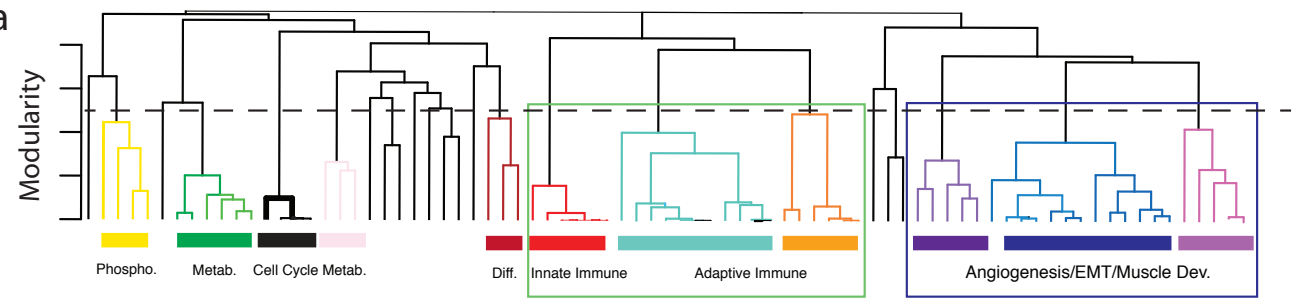

b
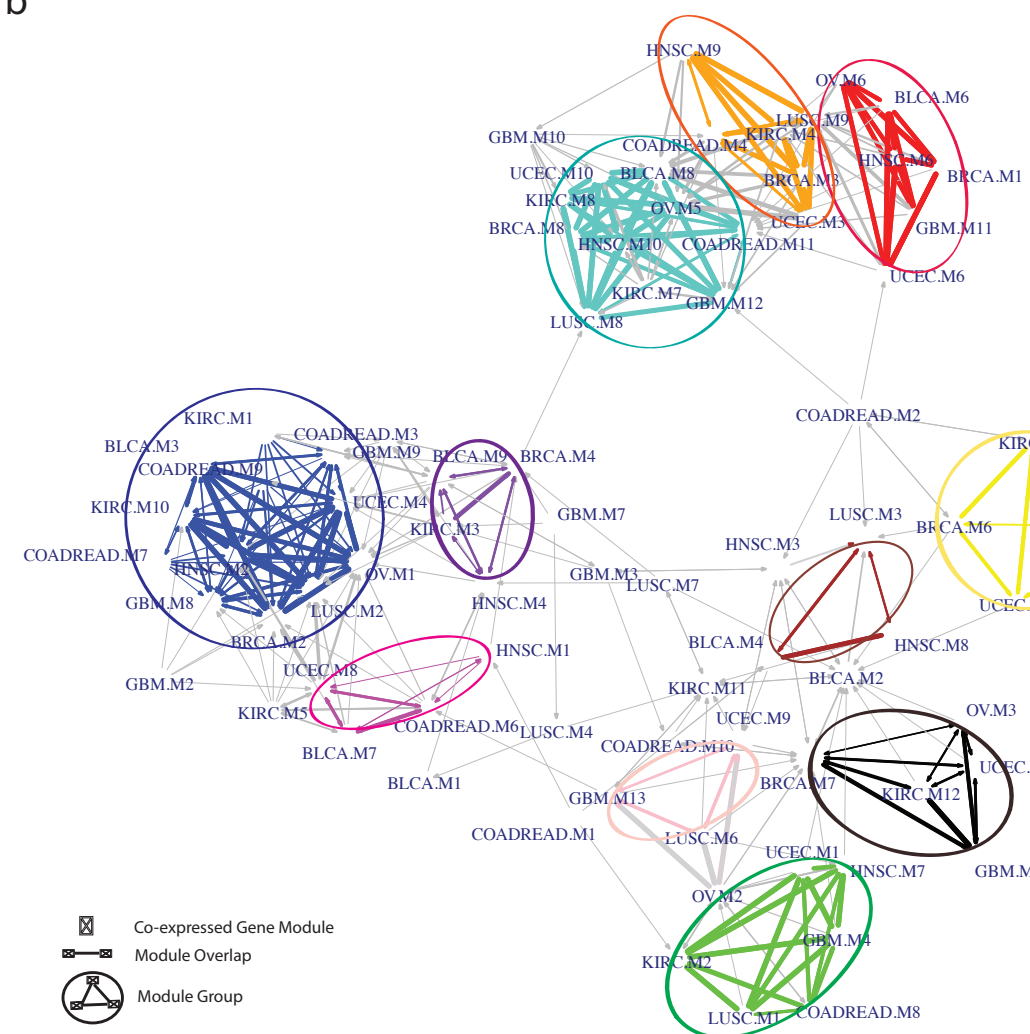

C
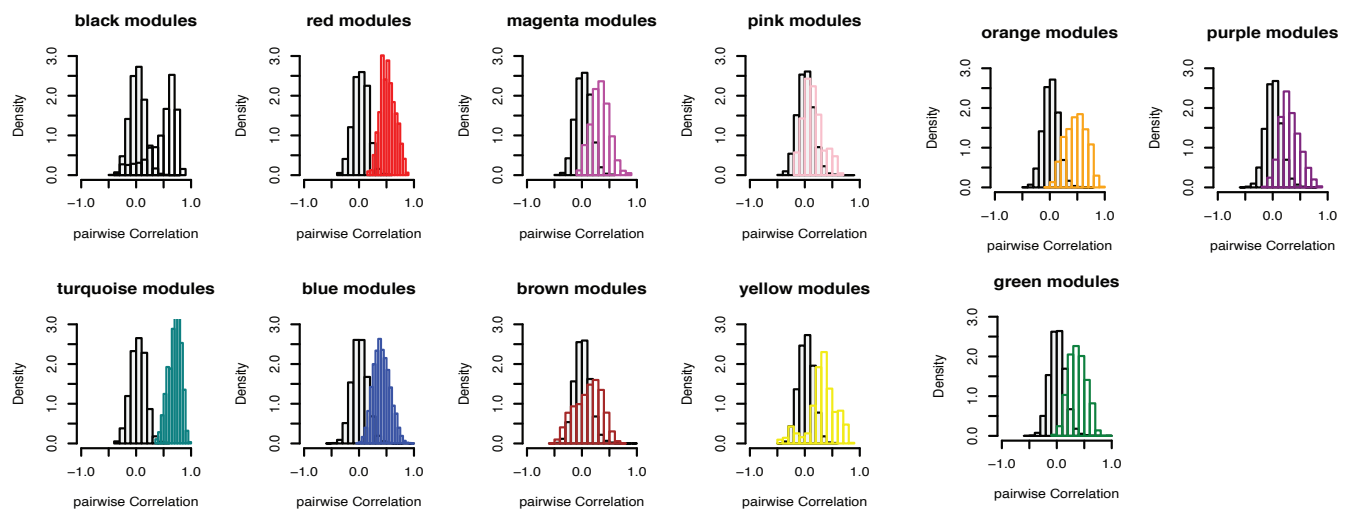
bioRxiv preprint doi: https://doi.org/10.1101/028415; this version posted October 5, 2015. The copyright holder for this preprint (which was not certified by peer review) is the author/funder, who has granted bioRxiv a license to display the preprint in perpetuity. It is made available under aCC-BY-NC-ND 4.0 International license.

\section{Zou_Fig.4}




bioRxiv preprint doi: https://doi org/10 1101/028415; this version posted October 5, 2015. The copyright holder for this preprint (which was not certified by peer review) is the author/funder, who has granted bioRxiv a license to display the preprint in perpetuity. It is made available under aCC-BY-NC-ND 4.0 International license.

\section{Zou_Fig.5}

a black modules
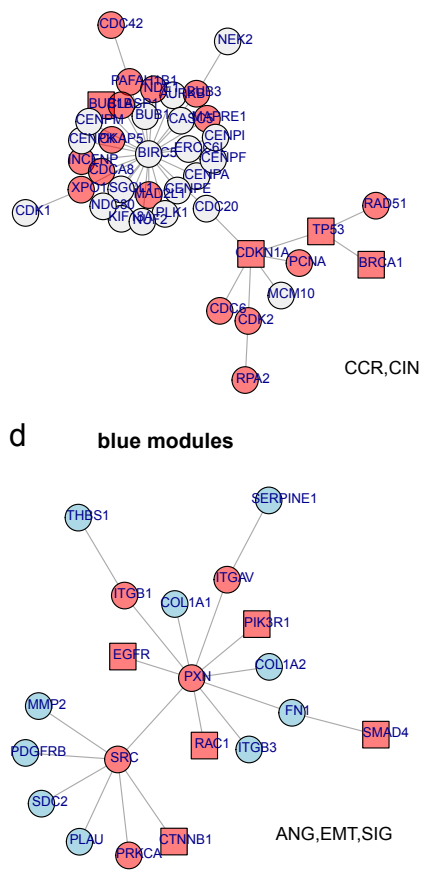

g red modules

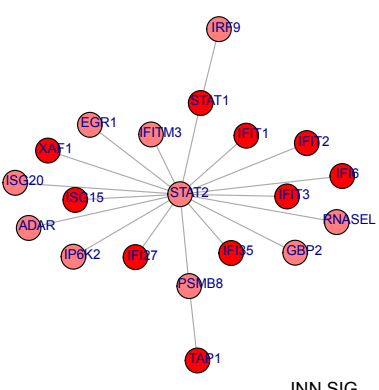

b

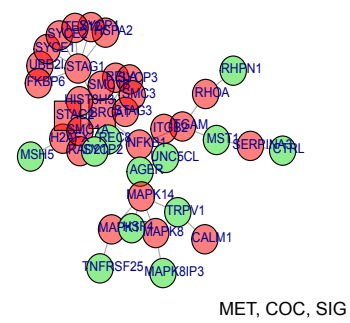

e

purple modules

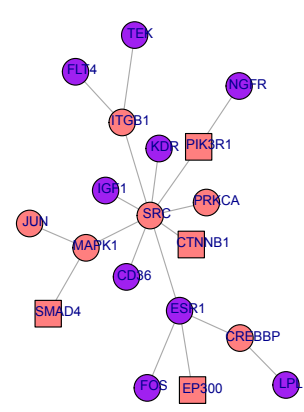

h

turquoise modules

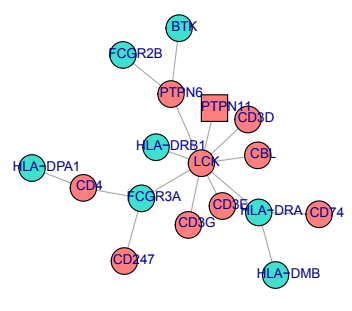

AIM
C yellow modules

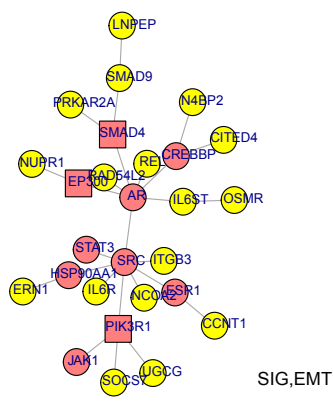

f

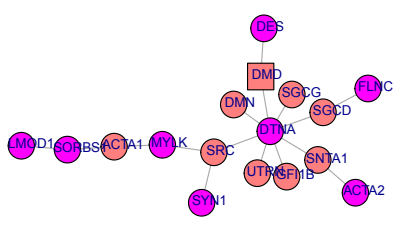

ANG,EMT,SIG

MUS,EMT

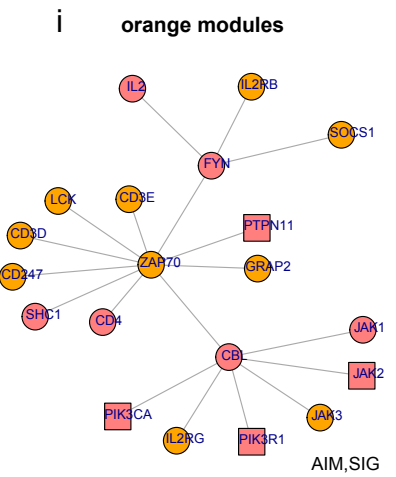

\footnotetext{
$\bigcirc$ Predicted Module Driver $\square$ SMG

(CCR) Cell cycle/Replication/Prolif. (SIG) Signaling/phosphorylation

(CIN) Genome Instablility $\quad(\mathrm{INN})$ Innate imm./virus response

(COC) Cohesin complex (AIM) Adaptive immune

(ANG) Angiogenesis/ (MET) Metabolism

(EMT) Epithelial Mes. Transform

(MUS) Muscle development
} 
bioRxiv preprint doi: https://doi.org/10.1101/028415. this version posted October 5,2015 . The copyright holder for this preprint (which was not certified by peer review) is the author/funder, who has granted bioRxiv a license to display the preprint in perpetuity. It is made available under aCC-BY-NC-ND 4.0 International license.

\section{Zou_Fig.6}

a

$\square$ GBM $\square$ OV $\square$ COADREAD $\square$ LUSC $\square$ BRCA $\square$ HNSC $\square$ KIRC $\square$ BLCA $\square$ UCEC

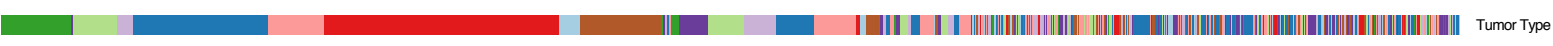

b

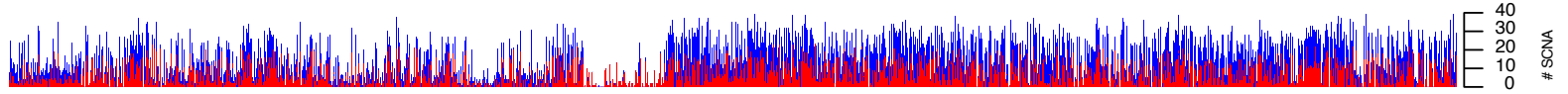

c

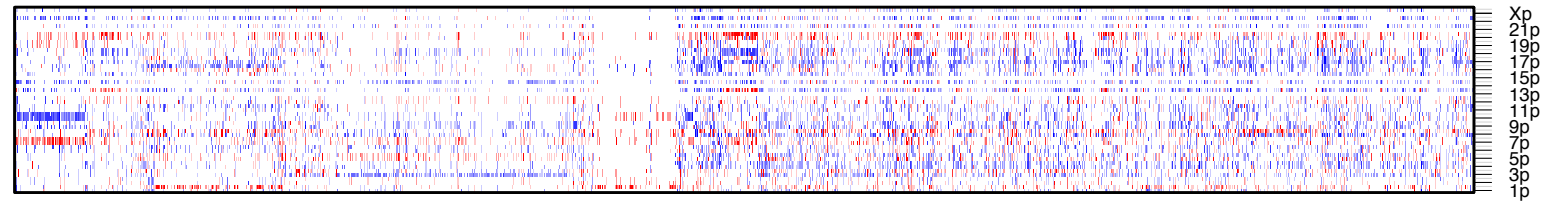

d

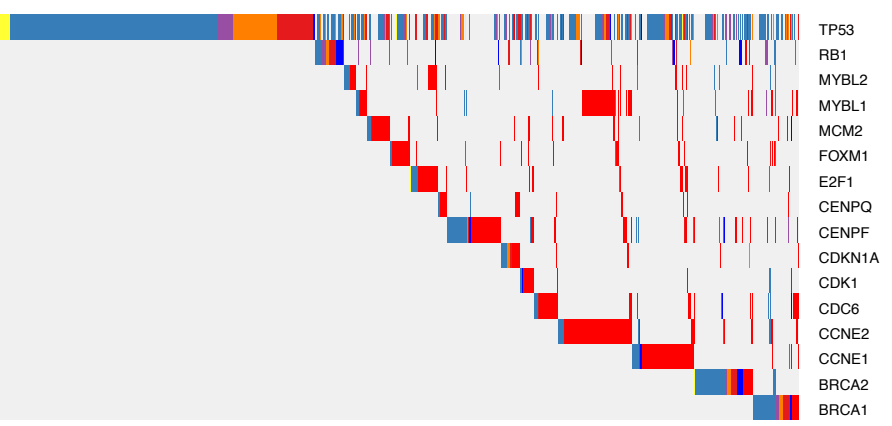

e $\quad$ e .

$\begin{array}{ll}\text { - Syn. } & \text { Frame shift } \\ \text { Missense } & \text { In frame indel } \\ \text { Splice site } & \text { Other non syn }\end{array}$

- Splice site

Other non syn.

- focal amplication

f
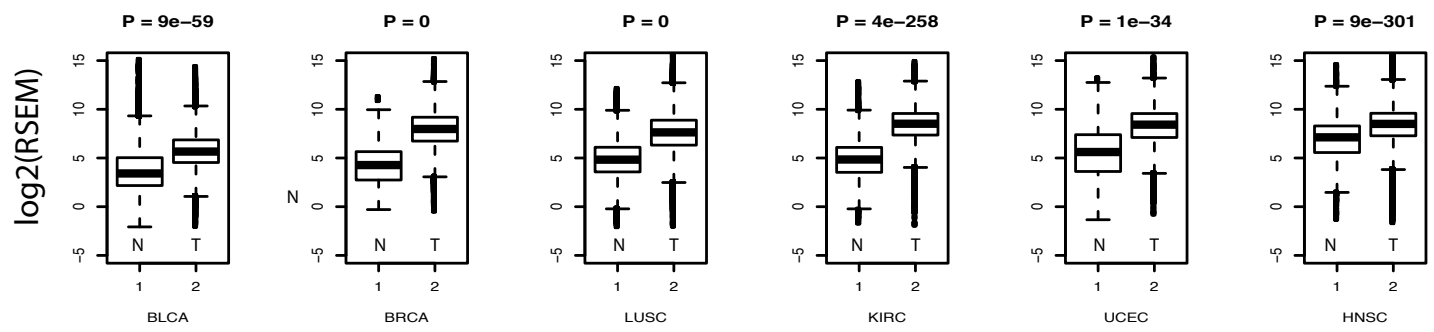

LUSC

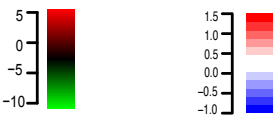




\section{Zou_Suppl_Fig.1}
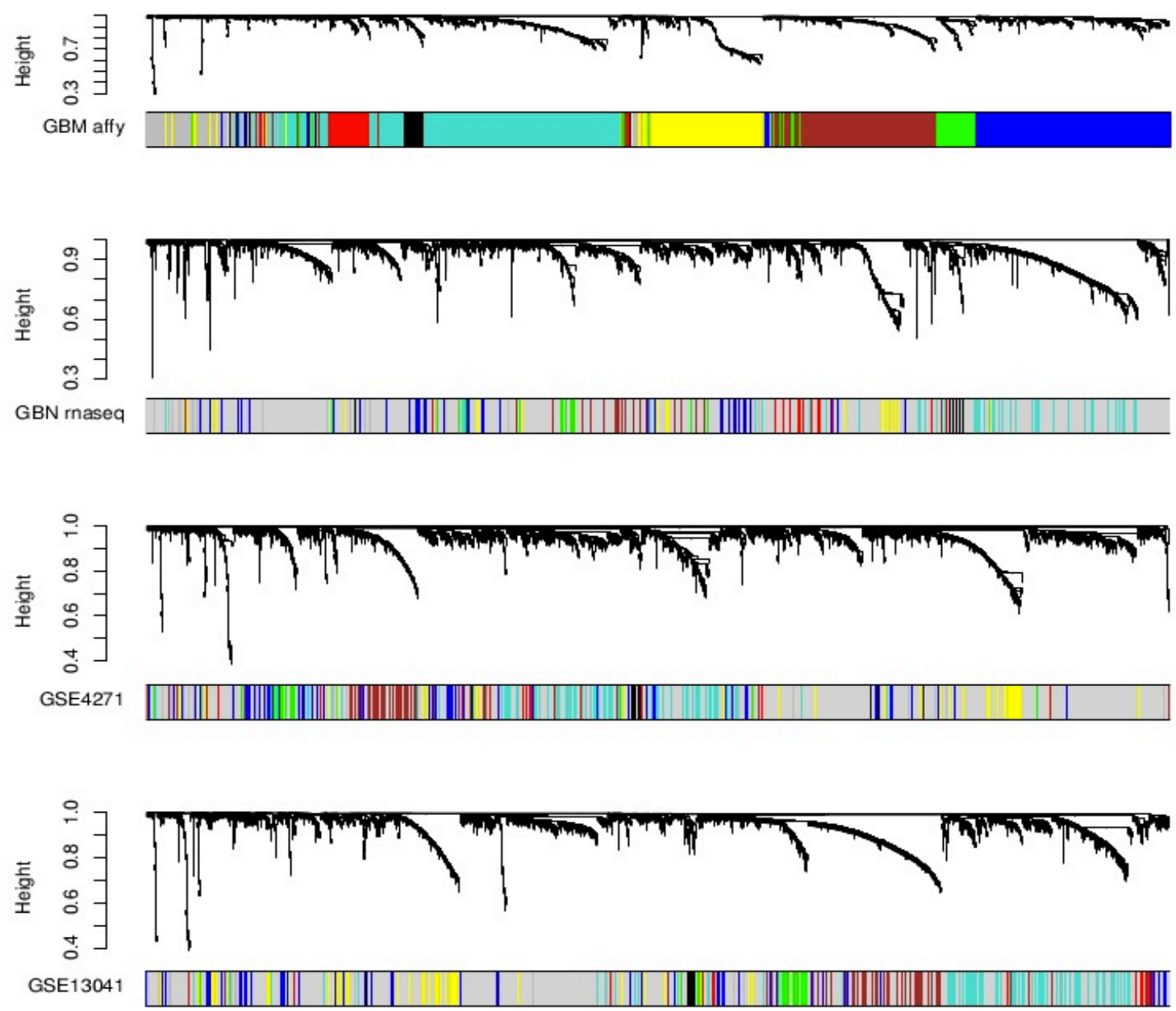
bioRxiv preprint doi: https://doi.org/10.1101/028415: this version posted October 5,2015 . The copyright holder for this preprint (which was not certified by peer review) is the author/funder, who has granted bioRxiv a license to display the preprint in perpetuity. It is made available under aCC-BY-NC-ND 4.0 International license.

\section{Zou_Suppl_Fig.2}

GBM OV $\square$ COADREAD $\square$ LUSC $\square$ BRCA $\square$ HNSC $\square$ KIRC $\square$ BLCA $\square$ UCEC

a

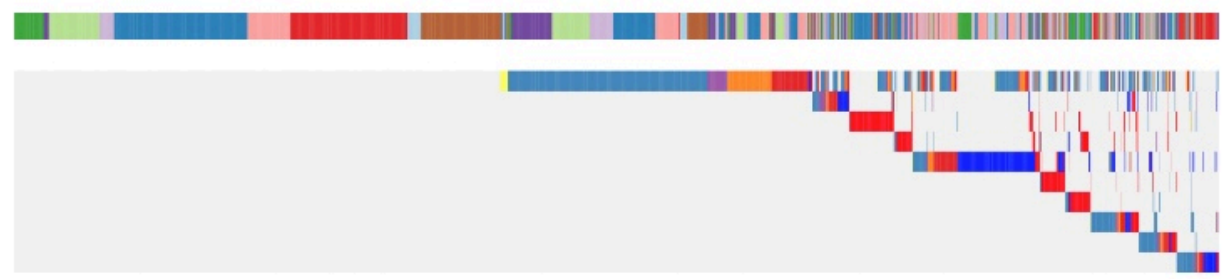

53/DNA repair

TP53

AB1

MOMU

MDNR
CDKN2A

CDKE
CDK4

CDK4

BACACA1
BAP1

b

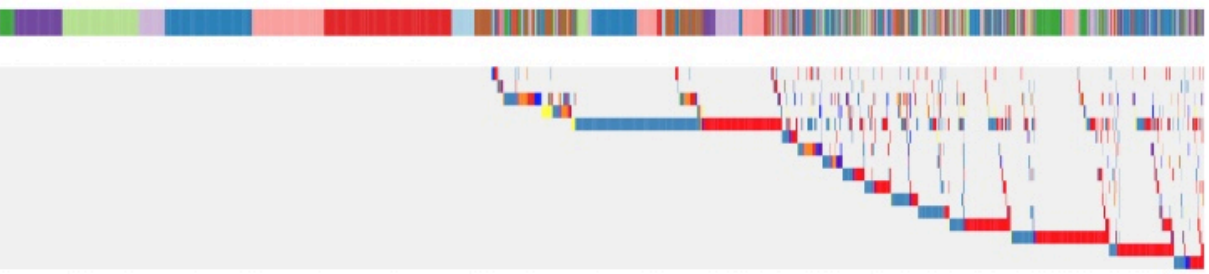

c

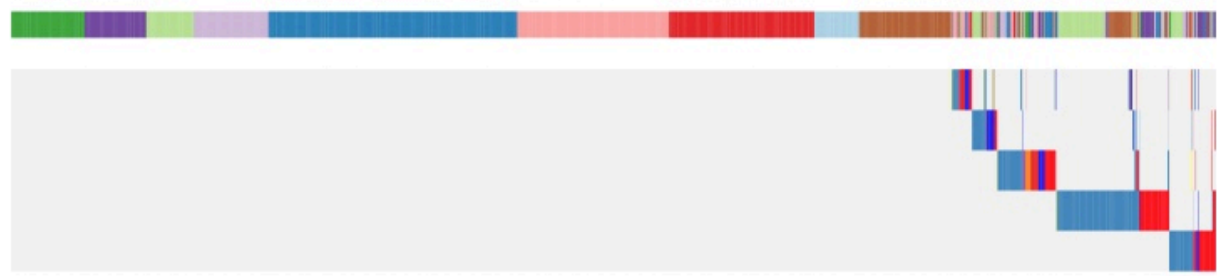

d

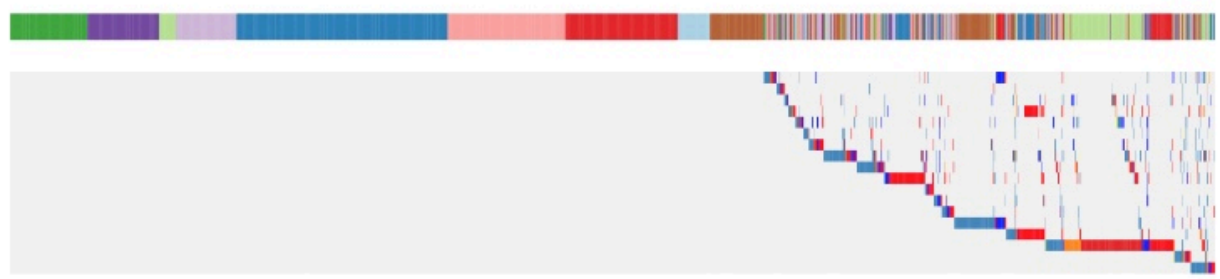

e

PIK3CA

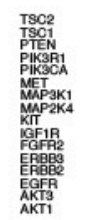

RAS

RAsA1

NRAS

NF1

kPas

BRAF

TGF-beta

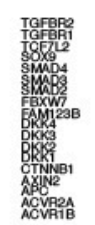

SOX2/NFE2L2/HLA
ㅁ Syn.

- Missense

․ Splice site

Nonsense

In shift

In frame inde

- Other non syn

- focal del

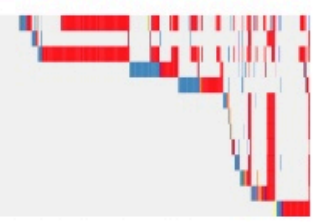




\section{Zou_Suppl_Fig.3}
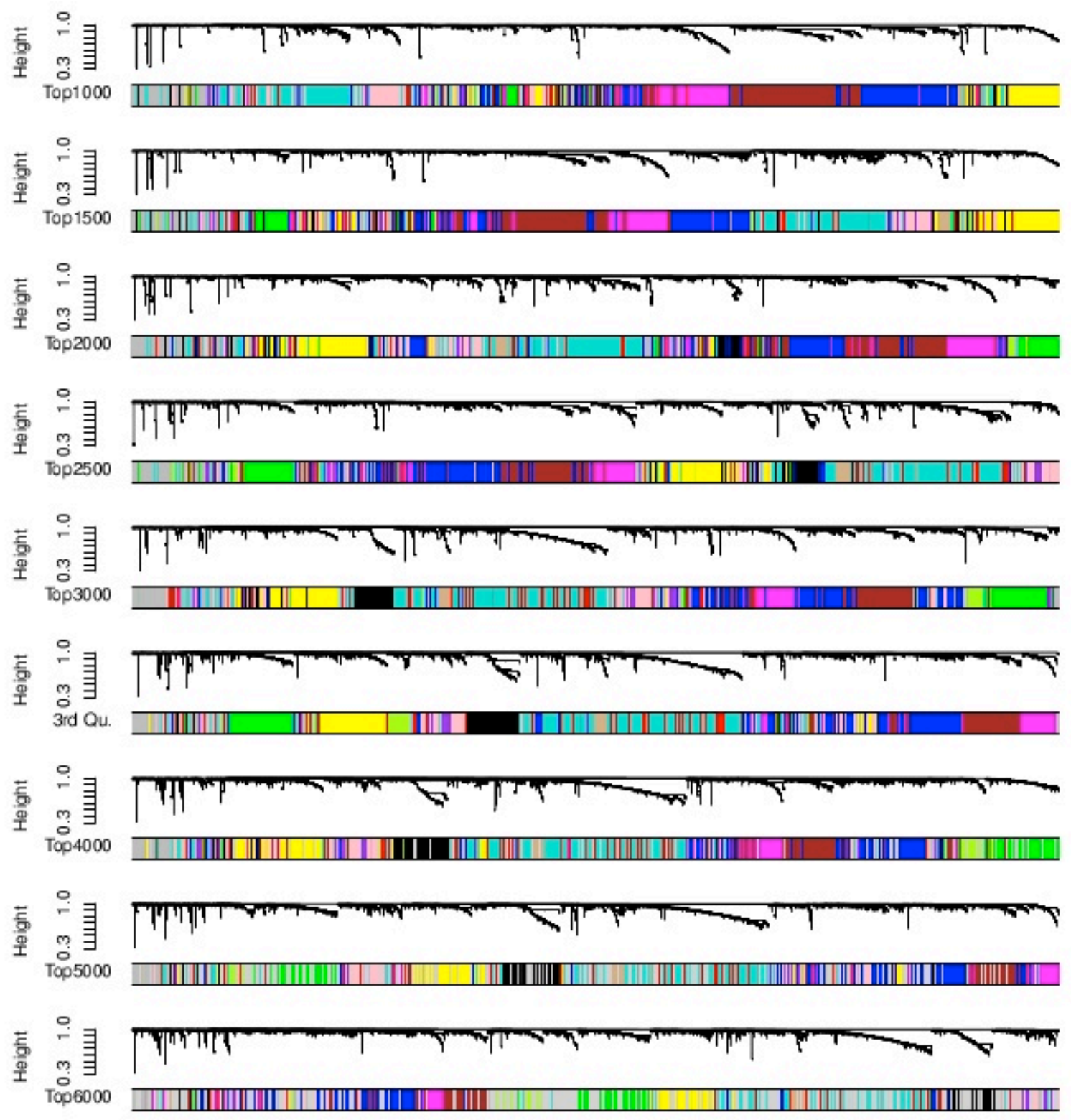
bioRxiv preprint doi: https://doi.org/10.1101/028415; this version posted October 5, 2015. The copyright holder for this preprint (which was not certified by peer review) is the author/funder, who has granted bioRxiv a license to display the preprint in perpetuity. It is made available under aCC-BY-NC-ND 4.0 International license.

Zou_Suppl_Table_1

\begin{tabular}{|l|l|l|l|l|l|l|l|l|}
\hline Cancer & SynapselD & $\begin{array}{l}\text { Number of } \\
\text { Samples }\end{array}$ & $\begin{array}{l}\text { Number of } \\
\text { Exome }\end{array}$ & $\begin{array}{l}\text { Number of } \\
\text { CNV }\end{array}$ & $\begin{array}{l}\text { Number of } \\
\text { MIR }\end{array}$ & $\begin{array}{l}\text { Number of } \\
\text { RPPA }\end{array}$ & $\begin{array}{l}\text { Number of } \\
\text { Co-expr. } \\
\text { Modules }\end{array}$ & $\begin{array}{l}\text { Gene Size of } \\
\text { Co-expr } \\
\text { Network }\end{array}$ \\
\hline GBM & syn1461183 & 154 & 563 & 112 & 491 & 214 & 12 & 3526 \\
\hline OV & syn1461171 & 262 & 559 & 582 & 568 & 332 & 5 & 3487 \\
\hline COADREAD & $\begin{array}{l}\text { syn1461155 } \\
\text { snd }\end{array}$ & 264 & 575 & 350 & 551 & 399 & 10 & 2712 \\
\hline LUSC & syn1461168 & 220 & 343 & 226 & 332 & 195 & 8 & 3499 \\
\hline BRCA & syn1461151 & 841 & 866 & 575 & 868 & 408 & 7 & 3268 \\
\hline HNSC & syn1461156 & 303 & 306 & 310 & 309 & 212 & 9 & 3394 \\
\hline KIRC & syn1461159 & 469 & 493 & 283 & 480 & 453 & 11 & 3363 \\
\hline BLCA & syn1461149 & 96 & 135 & 138 & 124 & 54 & 8 & 3380 \\
\hline UCEC & syn1461180 & 333 & 492 & 383 & 485 & 200 & 9 & 3251 \\
\hline
\end{tabular}


bioRxiv preprint doi: https://doi.org/10.1101/028415; this version posted October 5, 2015. The copyright holder for this preprint (which was not certified by peer review) is the author/funder, who has granted bioRxiv a license to display the preprint in perpetuity. It is made available under aCC-BY-NC-ND 4.0 International license.

\section{Zou_Suppl_Table_2}

\begin{tabular}{|c|c|c|}
\hline Module.1 & Module.2 & Adjusted.P-value \\
\hline GBM.black & OV.green & $3.60 \mathrm{E}-38$ \\
\hline GBM.black & BRCA.turquoise & $2.87 \mathrm{E}-31$ \\
\hline GBM.black & KIRC.yellow & $3.91 \mathrm{E}-54$ \\
\hline GBM.black & UCEC.blue & $1.81 \mathrm{E}-25$ \\
\hline GBM.blue & LUSC.blue & 0.001955469 \\
\hline GBM.blue & BRCA.blue & 0.00028959 \\
\hline GBM.blue & HNSC.blue & $8.68 \mathrm{E}-07$ \\
\hline GBM.blue & KIRC.red & 0.02992095 \\
\hline GBM.blue & UCEC.red & 0.002824684 \\
\hline GBM.brown & COADREAD.turquoise & 0.02830111 \\
\hline GBM.brown & HNSC.brown & 0.00147624 \\
\hline GBM.brown & KIRC.brown & 0.004390626 \\
\hline GBM.brown & BLCA.yellow & $2.06 \mathrm{E}-05$ \\
\hline GBM.green & OV.brown & $1.45 \mathrm{E}-11$ \\
\hline GBM.green & COADREAD.purple & $6.96 \mathrm{E}-46$ \\
\hline GBM.green & LUSC.black & $1.09 \mathrm{E}-63$ \\
\hline GBM.green & BRCA.turquoise & 0.002820383 \\
\hline GBM.green & HNSC.pink & $4.29 \mathrm{E}-50$ \\
\hline GBM.green & KIRC.blue & $1.23 \mathrm{E}-88$ \\
\hline GBM.green & UCEC.black & $1.13 \mathrm{E}-61$ \\
\hline GBM.greenyellow & BRCA.red & $2.40 \mathrm{E}-18$ \\
\hline GBM.greenyellow & KIRC.purple & $1.05 \mathrm{E}-29$ \\
\hline GBM.greenyellow & UCEC.pink & $9.97 \mathrm{E}-33$ \\
\hline GBM.magenta & LUSC.green & 0.0136676 \\
\hline GBM.magenta & BRCA.green & 0.006473287 \\
\hline GBM.magenta & KIRC.brown & 0.01165685 \\
\hline GBM.pink & OV.blue & $3.41 \mathrm{E}-34$ \\
\hline GBM.pink & COADREAD.brown & $1.94 \mathrm{E}-08$ \\
\hline GBM.pink & LUSC.blue & $3.51 \mathrm{E}-34$ \\
\hline
\end{tabular}


bioRxiv preprint doi: https://doi.org/10.1101/028415; this version posted October 5, 2015. The copyright holder for this preprint (which was not certified by peer review) is the author/funder, who has granted bioRxiv a license to display the preprint in perpetuity. It is made available under aCC-BY-NC-ND 4.0 International license.

\begin{tabular}{|c|c|c|}
\hline GBM.pink & BRCA.blue & $9.83 E-31$ \\
\hline GBM.pink & HNSC.blue & $2.54 \mathrm{E}-22$ \\
\hline GBM.pink & KIRC.red & $3.92 \mathrm{E}-25$ \\
\hline GBM.pink & BLCA.brown & $3.03 E-14$ \\
\hline GBM.pink & UCEC.green & $2.36 \mathrm{E}-22$ \\
\hline GBM.purple & OV.blue & $2.68 \mathrm{E}-07$ \\
\hline GBM.purple & COADREAD.brown & $8.20 \mathrm{E}-06$ \\
\hline GBM.purple & LUSC.blue & 8.82E-05 \\
\hline GBM.purple & BRCA.green & 0.000226317 \\
\hline GBM.purple & HNSC.blue & 0.000124524 \\
\hline GBM.purple & KIRC.brown & 4.09E-12 \\
\hline GBM.purple & BLCA.yellow & 0.02121653 \\
\hline GBM.purple & UCEC.green & $5.95 \mathrm{E}-08$ \\
\hline GBM.red & OV.turquoise & $8.97 \mathrm{E}-13$ \\
\hline GBM.red & COADREAD.green & $9.66 \mathrm{E}-06$ \\
\hline GBM.red & LUSC.turquoise & $5.50 \mathrm{E}-11$ \\
\hline GBM.red & BRCA.yellow & $5.99 \mathrm{E}-14$ \\
\hline GBM.red & HNSC.yellow & $3.92 \mathrm{E}-06$ \\
\hline GBM.red & KIRC.pink & $1.10 \mathrm{E}-20$ \\
\hline GBM.red & BLCA.turquoise & 7.33E-12 \\
\hline GBM.red & UCEC.yellow & $3.84 \mathrm{E}-13$ \\
\hline GBM.tan & OV.yellow & $2.51 \mathrm{E}-40$ \\
\hline GBM.tan & COADREAD.yellow & $9.95 \mathrm{E}-14$ \\
\hline GBM.tan & LUSC.yellow & $3.41 \mathrm{E}-31$ \\
\hline GBM.tan & BRCA.black & $5.00 \mathrm{E}-45$ \\
\hline GBM.tan & HNSC.magenta & $6.00 \mathrm{E}-49$ \\
\hline GBM.tan & KIRC.green & $2.85 \mathrm{E}-16$ \\
\hline GBM.tan & BLCA.pink & $4.51 \mathrm{E}-36$ \\
\hline GBM.tan & UCEC.magenta & $1.68 \mathrm{E}-60$ \\
\hline GBM.turquoise & OV.turquoise & $9.89 \mathrm{E}-63$ \\
\hline GBM.turquoise & COADREAD.yellow & $2.50 \mathrm{E}-22$ \\
\hline GBM.turquoise & LUSC.turquoise & 4.56E-37 \\
\hline GBM.turquoise & BRCA.yellow & $3.25 \mathrm{E}-35$ \\
\hline GBM.turquoise & HNSC.yellow & 1.93E-51 \\
\hline
\end{tabular}


bioRxiv preprint doi: https://doi.org/10.1101/028415; this version posted October 5, 2015. The copyright holder for this preprint (which was not certified by peer review) is the author/funder, who has granted bioRxiv a license to display the preprint in perpetuity. It is made available under aCC-BY-NC-ND 4.0 International license.

\begin{tabular}{|c|c|c|}
\hline GBM.turquoise & KIRC.pink & $3.10 \mathrm{E}-26$ \\
\hline GBM.turquoise & BLCA.turquoise & $1.72 \mathrm{E}-39$ \\
\hline GBM.turquoise & UCEC.yellow & $9.09 \mathrm{E}-38$ \\
\hline GBM.yellow & OV.brown & 5.97E-48 \\
\hline GBM.yellow & COADREAD.magenta & 0.00554752 \\
\hline GBM.yellow & LUSC.pink & $7.30 \mathrm{E}-31$ \\
\hline GBM.yellow & BRCA.turquoise & $2.05 \mathrm{E}-05$ \\
\hline GBM.yellow & KIRC.turquoise & $6.07 \mathrm{E}-06$ \\
\hline GBM.yellow & UCEC.turquoise & $5.97 \mathrm{E}-23$ \\
\hline OV.blue & GBM.pink & $1.39 \mathrm{E}-29$ \\
\hline OV.blue & COADREAD.brown & $5.15 \mathrm{E}-24$ \\
\hline OV.blue & LUSC.blue & $8.16 \mathrm{E}-140$ \\
\hline OV.blue & BRCA.blue & $1.55 \mathrm{E}-109$ \\
\hline OV.blue & HNSC.blue & 4.75E-77 \\
\hline OV.blue & KIRC.red & $4.62 E-43$ \\
\hline OV.blue & BLCA.brown & $5.69 \mathrm{E}-73$ \\
\hline OV.blue & UCEC.green & $2.74 \mathrm{E}-90$ \\
\hline OV.brown & GBM.yellow & $2.77 \mathrm{E}-47$ \\
\hline OV.brown & COADREAD.purple & $5.77 \mathrm{E}-14$ \\
\hline OV.brown & LUSC.pink & $3.09 \mathrm{E}-62$ \\
\hline OV.brown & BRCA.turquoise & $3.08 \mathrm{E}-13$ \\
\hline OV.brown & HNSC.pink & $3.98 \mathrm{E}-19$ \\
\hline OV.brown & KIRC.blue & $4.73 \mathrm{E}-15$ \\
\hline OV.brown & UCEC.turquoise & $3.93 E-49$ \\
\hline OV.green & GBM.black & $1.52 \mathrm{E}-34$ \\
\hline OV.green & BRCA.turquoise & $1.31 \mathrm{E}-14$ \\
\hline OV.green & KIRC.yellow & $3.13 \mathrm{E}-19$ \\
\hline OV.green & BLCA.blue & 0.0086865 \\
\hline OV.green & UCEC.blue & $1.14 \mathrm{E}-24$ \\
\hline OV.turquoise & GBM.turquoise & $2.60 \mathrm{E}-71$ \\
\hline OV.turquoise & COADREAD.yellow & $1.46 \mathrm{E}-37$ \\
\hline OV.turquoise & LUSC.turquoise & $3.91 \mathrm{E}-49$ \\
\hline OV.turquoise & BRCA.yellow & 2.19E-71 \\
\hline
\end{tabular}


bioRxiv preprint doi: https://doi.org/10.1101/028415; this version posted October 5, 2015. The copyright holder for this preprint (which was not certified by peer review) is the author/funder, who has granted bioRxiv a license to display the preprint in perpetuity. It is made available under aCC-BY-NC-ND 4.0 International license.

\begin{tabular}{|c|c|c|}
\hline OV.turquoise & HNSC.yellow & $1.05 E-55$ \\
\hline OV.turquoise & KIRC.pink & $1.65 \mathrm{E}-56$ \\
\hline OV.turquoise & BLCA.turquoise & $3.06 \mathrm{E}-75$ \\
\hline OV.turquoise & UCEC.yellow & 2.07E-71 \\
\hline OV.yellow & GBM.tan & $2.51 \mathrm{E}-45$ \\
\hline OV.yellow & COADREAD.yellow & $5.45 \mathrm{E}-10$ \\
\hline OV.yellow & LUSC.yellow & 3.97E-19 \\
\hline OV.yellow & BRCA.black & $1.53 \mathrm{E}-57$ \\
\hline OV.yellow & HNSC.magenta & $2.96 \mathrm{E}-40$ \\
\hline OV.yellow & KIRC.green & 7.32E-08 \\
\hline OV.yellow & BLCA.pink & $2.47 \mathrm{E}-40$ \\
\hline OV.yellow & UCEC.magenta & 2.47E-43 \\
\hline COADREAD.black & HNSC.black & 0.007794982 \\
\hline COADREAD.black & KIRC.blue & 0.03646471 \\
\hline COADREAD.black & BLCA.green & 0.002211642 \\
\hline COADREAD.blue & GBM.turquoise & 0.00457559 \\
\hline COADREAD.blue & LUSC.brown & 0.01203316 \\
\hline COADREAD.blue & BRCA.red & 0.006733661 \\
\hline COADREAD.blue & HNSC.brown & 0.001154678 \\
\hline COADREAD.blue & KIRC.purple & 0.001713155 \\
\hline COADREAD.blue & UCEC.magenta & 0.000212338 \\
\hline COADREAD.brown & GBM.pink & 2.23E-09 \\
\hline COADREAD.brown & OV.blue & $9.77 \mathrm{E}-31$ \\
\hline COADREAD.brown & LUSC.blue & $2.15 \mathrm{E}-30$ \\
\hline COADREAD.brown & BRCA.blue & $9.80 \mathrm{E}-20$ \\
\hline COADREAD.brown & HNSC.blue & $6.42 \mathrm{E}-26$ \\
\hline COADREAD.brown & KIRC.red & $1.69 \mathrm{E}-08$ \\
\hline COADREAD.brown & BLCA.brown & $1.77 \mathrm{E}-23$ \\
\hline COADREAD.brown & UCEC.green & $9.80 \mathrm{E}-12$ \\
\hline COADREAD.green & GBM.turquoise & 5.53E-09 \\
\hline COADREAD.green & OV.turquoise & $3.01 \mathrm{E}-32$ \\
\hline COADREAD.green & LUSC.yellow & $2.40 \mathrm{E}-30$ \\
\hline COADREAD.green & BRCA.brown & $1.70 \mathrm{E}-40$ \\
\hline COADREAD.green & HNSC.turquoise & $3.86 \mathrm{E}-18$ \\
\hline
\end{tabular}


bioRxiv preprint doi: https://doi.org/10.1101/028415; this version posted October 5, 2015. The copyright holder for this preprint (which was not certified by peer review) is the author/funder, who has granted bioRxiv a license to display the preprint in perpetuity. It is made available under aCC-BY-NC-ND 4.0 International license.

\begin{tabular}{|c|c|c|}
\hline COADREAD.green & KIRC.green & $3.98 \mathrm{E}-26$ \\
\hline COADREAD.green & BLCA.turquoise & 7.34E-30 \\
\hline COADREAD.green & UCEC.brown & $2.15 \mathrm{E}-22$ \\
\hline COADREAD.magenta & OV.blue & $1.20 \mathrm{E}-11$ \\
\hline COADREAD.magenta & LUSC.blue & $1.61 \mathrm{E}-06$ \\
\hline COADREAD.magenta & BRCA.blue & $3.34 \mathrm{E}-08$ \\
\hline COADREAD.magenta & HNSC.green & $3.29 \mathrm{E}-11$ \\
\hline COADREAD.magenta & KIRC.greenyellow & 2.01E-17 \\
\hline COADREAD.magenta & BLCA.red & $1.89 \mathrm{E}-33$ \\
\hline COADREAD.magenta & UCEC.red & $8.68 \mathrm{E}-26$ \\
\hline COADREAD.pink & GBM.pink & $1.12 \mathrm{E}-06$ \\
\hline COADREAD.pink & OV.blue & $3.07 \mathrm{E}-12$ \\
\hline COADREAD.pink & LUSC.blue & $2.95 \mathrm{E}-19$ \\
\hline COADREAD.pink & BRCA.blue & 4.96E-17 \\
\hline COADREAD.pink & HNSC.blue & 3.96E-17 \\
\hline COADREAD.pink & KIRC.red & $8.40 \mathrm{E}-14$ \\
\hline COADREAD.pink & BLCA.brown & $3.28 \mathrm{E}-12$ \\
\hline COADREAD.pink & UCEC.green & $1.84 \mathrm{E}-10$ \\
\hline COADREAD.purple & GBM.green & $1.20 \mathrm{E}-36$ \\
\hline COADREAD.purple & OV.brown & 1.16E-08 \\
\hline COADREAD.purple & LUSC.black & $1.08 \mathrm{E}-30$ \\
\hline COADREAD.purple & HNSC.pink & $5.64 \mathrm{E}-35$ \\
\hline COADREAD.purple & KIRC.blue & $9.05 \mathrm{E}-40$ \\
\hline COADREAD.purple & UCEC.black & 2.63E-38 \\
\hline COADREAD.red & GBM.pink & 1.57E-06 \\
\hline COADREAD.red & OV.blue & $1.89 \mathrm{E}-13$ \\
\hline COADREAD.red & LUSC.blue & $1.36 \mathrm{E}-13$ \\
\hline COADREAD.red & BRCA.blue & 1.17E-21 \\
\hline COADREAD.red & HNSC.blue & $5.52 \mathrm{E}-20$ \\
\hline COADREAD.red & KIRC.red & $1.31 \mathrm{E}-07$ \\
\hline COADREAD.red & BLCA.brown & $8.38 \mathrm{E}-12$ \\
\hline
\end{tabular}


bioRxiv preprint doi: https://doi.org/10.1101/028415; this version posted October 5, 2015. The copyright holder for this preprint (which was not certified by peer review) is the author/funder, who has granted bioRxiv a license to display the preprint in perpetuity. It is made available under aCC-BY-NC-ND 4.0 International license.

\begin{tabular}{|c|c|c|}
\hline COADREAD.red & UCEC.green & $3.40 \mathrm{E}-11$ \\
\hline COADREAD.turquoise & BRCA.turquoise & $7.55 \mathrm{E}-08$ \\
\hline COADREAD.turquoise & KIRC.turquoise & $1.76 \mathrm{E}-06$ \\
\hline COADREAD.turquoise & BLCA.green & 0.002901911 \\
\hline COADREAD.turquoise & UCEC.turquoise & 0.01069324 \\
\hline COADREAD.yellow & GBM.turquoise & 1.67E-20 \\
\hline COADREAD.yellow & OV.turquoise & $1.12 \mathrm{E}-26$ \\
\hline COADREAD.yellow & LUSC.turquoise & $1.91 \mathrm{E}-19$ \\
\hline COADREAD.yellow & BRCA.yellow & $3.15 \mathrm{E}-31$ \\
\hline COADREAD.yellow & HNSC.yellow & $1.10 \mathrm{E}-24$ \\
\hline COADREAD.yellow & KIRC.pink & $6.02 \mathrm{E}-25$ \\
\hline COADREAD.yellow & BLCA.turquoise & 4.03E-31 \\
\hline COADREAD.yellow & UCEC.yellow & $1.08 \mathrm{E}-33$ \\
\hline LUSC.black & GBM.green & $3.12 \mathrm{E}-52$ \\
\hline LUSC.black & OV.brown & 1.19E-08 \\
\hline LUSC.black & COADREAD.purple & $1.80 \mathrm{E}-28$ \\
\hline LUSC.black & HNSC.pink & $1.25 \mathrm{E}-42$ \\
\hline LUSC.black & KIRC.blue & $3.82 \mathrm{E}-59$ \\
\hline LUSC.black & UCEC.black & $8.91 \mathrm{E}-50$ \\
\hline LUSC.blue & GBM.pink & $2.08 \mathrm{E}-29$ \\
\hline LUSC.blue & OV.blue & $1.21 \mathrm{E}-146$ \\
\hline LUSC.blue & COADREAD.brown & 2.03E-28 \\
\hline LUSC.blue & BRCA.blue & 4.53E-148 \\
\hline LUSC.blue & HNSC.blue & $3.68 \mathrm{E}-159$ \\
\hline LUSC.blue & KIRC.red & $4.83 \mathrm{E}-60$ \\
\hline LUSC.blue & BLCA.brown & $2.52 \mathrm{E}-95$ \\
\hline LUSC.blue & UCEC.green & $1.76 \mathrm{E}-69$ \\
\hline LUSC.brown & HNSC.red & $1.79 \mathrm{E}-18$ \\
\hline LUSC.brown & BLCA.green & $2.14 \mathrm{E}-28$ \\
\hline LUSC.green & KIRC.turquoise & 0.004866037 \\
\hline LUSC.green & BLCA.black & 2.00E-09 \\
\hline LUSC.pink & GBM.yellow & $2.10 \mathrm{E}-31$ \\
\hline
\end{tabular}


bioRxiv preprint doi: https://doi.org/10.1101/028415; this version posted October 5, 2015. The copyright holder for this preprint (which was not certified by peer review) is the author/funder, who has granted bioRxiv a license to display the preprint in perpetuity. It is made available under aCC-BY-NC-ND 4.0 International license.

\begin{tabular}{|c|c|c|}
\hline LUSC.pink & OV.brown & 4.44E-56 \\
\hline LUSC.pink & BRCA.turquoise & $2.90 \mathrm{E}-09$ \\
\hline LUSC.pink & HNSC.pink & 0.01970745 \\
\hline LUSC.pink & KIRC.turquoise & 0.0251461 \\
\hline LUSC.pink & UCEC.turquoise & $1.01 \mathrm{E}-31$ \\
\hline LUSC.red & BRCA.green & 0.01869355 \\
\hline LUSC.red & HNSC.green & 0.000642402 \\
\hline LUSC.red & KIRC.turquoise & 0.001324934 \\
\hline LUSC.red & BLCA.blue & 0.00032609 \\
\hline LUSC.turquoise & GBM.turquoise & $7.65 E-47$ \\
\hline LUSC.turquoise & OV.turquoise & $1.66 \mathrm{E}-60$ \\
\hline LUSC.turquoise & COADREAD.yellow & $7.80 \mathrm{E}-28$ \\
\hline LUSC.turquoise & BRCA.yellow & $1.29 E-76$ \\
\hline LUSC.turquoise & HNSC.yellow & $5.00 \mathrm{E}-110$ \\
\hline LUSC.turquoise & KIRC.pink & $7.22 \mathrm{E}-75$ \\
\hline LUSC.turquoise & BLCA.turquoise & $3.52 E-59$ \\
\hline LUSC.turquoise & UCEC.yellow & $7.86 \mathrm{E}-59$ \\
\hline LUSC.yellow & GBM.tan & $2.28 \mathrm{E}-34$ \\
\hline LUSC.yellow & OV.turquoise & $4.28 \mathrm{E}-21$ \\
\hline LUSC.yellow & COADREAD.green & $5.21 E-36$ \\
\hline LUSC.yellow & BRCA.brown & $1.74 \mathrm{E}-62$ \\
\hline LUSC.yellow & HNSC.turquoise & $9.20 \mathrm{E}-62$ \\
\hline LUSC.yellow & KIRC.green & $1.47 \mathrm{E}-112$ \\
\hline LUSC.yellow & BLCA.turquoise & $2.11 \mathrm{E}-23$ \\
\hline LUSC.yellow & UCEC.brown & $2.24 \mathrm{E}-48$ \\
\hline BRCA.black & GBM.tan & $5.95 \mathrm{E}-50$ \\
\hline BRCA.black & OV.yellow & $2.29 \mathrm{E}-56$ \\
\hline BRCA.black & COADREAD.yellow & 1.98E-09 \\
\hline BRCA.black & LUSC.yellow & 3.27E-23 \\
\hline BRCA.black & HNSC.magenta & $9.05 E-43$ \\
\hline BRCA.black & KIRC.green & $1.28 \mathrm{E}-11$ \\
\hline BRCA.black & BLCA.pink & $1.35 \mathrm{E}-41$ \\
\hline BRCA.black & UCEC.magenta & $5.76 \mathrm{E}-55$ \\
\hline BRCA.blue & GBM.pink & $8.15 \mathrm{E}-29$ \\
\hline
\end{tabular}


bioRxiv preprint doi: https://doi.org/10.1101/028415; this version posted October 5, 2015. The copyright holder for this preprint (which was not certified by peer review) is the author/funder, who has granted bioRxiv a license to display the preprint in perpetuity. It is made available under aCC-BY-NC-ND 4.0 International license.

\begin{tabular}{|c|c|c|}
\hline BRCA.blue & OV.blue & $5.32 \mathrm{E}-118$ \\
\hline BRCA.blue & COADREAD.brown & $7.69 \mathrm{E}-21$ \\
\hline BRCA.blue & LUSC.blue & $1.21 \mathrm{E}-145$ \\
\hline BRCA.blue & HNSC.blue & $4.59 \mathrm{E}-143$ \\
\hline BRCA.blue & KIRC.red & $1.05 \mathrm{E}-58$ \\
\hline BRCA.blue & BLCA.brown & $6.51 \mathrm{E}-90$ \\
\hline BRCA.blue & UCEC.green & $3.17 \mathrm{E}-60$ \\
\hline BRCA.brown & GBM.turquoise & $1.80 \mathrm{E}-16$ \\
\hline BRCA.brown & OV.turquoise & $1.35 \mathrm{E}-32$ \\
\hline BRCA.brown & COADREAD.green & $2.80 \mathrm{E}-44$ \\
\hline BRCA.brown & LUSC.yellow & $4.60 \mathrm{E}-59$ \\
\hline BRCA.brown & HNSC.turquoise & $7.13 E-54$ \\
\hline BRCA.brown & KIRC.green & 1.77E-67 \\
\hline BRCA.brown & BLCA.turquoise & $5.43 \mathrm{E}-36$ \\
\hline BRCA.brown & UCEC.brown & $3.56 \mathrm{E}-58$ \\
\hline BRCA.green & GBM.purple & 0.001997649 \\
\hline BRCA.green & OV.blue & $2.31 \mathrm{E}-12$ \\
\hline BRCA.green & COADREAD.brown & $6.27 \mathrm{E}-06$ \\
\hline BRCA.green & LUSC.turquoise & 0.003788179 \\
\hline BRCA.green & HNSC.green & $3.95 \mathrm{E}-20$ \\
\hline BRCA.green & KIRC.brown & $2.89 \mathrm{E}-33$ \\
\hline BRCA.green & BLCA.yellow & $9.53 \mathrm{E}-21$ \\
\hline BRCA.green & UCEC.green & $2.13 \mathrm{E}-09$ \\
\hline BRCA.red & COADREAD.blue & $1.76 \mathrm{E}-05$ \\
\hline BRCA.red & LUSC.brown & 0.01183595 \\
\hline BRCA.red & KIRC.purple & $2.86 \mathrm{E}-42$ \\
\hline BRCA.red & BLCA.blue & 0.00402368 \\
\hline BRCA.red & UCEC.pink & $4.11 \mathrm{E}-32$ \\
\hline BRCA.turquoise & GBM.black & $4.85 \mathrm{E}-42$ \\
\hline BRCA.turquoise & OV.green & $3.30 \mathrm{E}-15$ \\
\hline BRCA.turquoise & COADREAD.turquoise & $2.97 \mathrm{E}-05$ \\
\hline BRCA.turquoise & HNSC.brown & 3.97E-06 \\
\hline BRCA.turquoise & KIRC.yellow & 2.36E-35 \\
\hline
\end{tabular}


bioRxiv preprint doi: https://doi.org/10.1101/028415; this version posted October 5, 2015. The copyright holder for this preprint (which was not certified by peer review) is the author/funder, who has granted bioRxiv a license to display the preprint in perpetuity. It is made available under aCC-BY-NC-ND 4.0 International license.

\begin{tabular}{|c|c|c|}
\hline BRCA.turquoise & BLCA.blue & $7.58 \mathrm{E}-16$ \\
\hline BRCA.turquoise & UCEC.blue & $1.70 \mathrm{E}-27$ \\
\hline BRCA.yellow & GBM.turquoise & $8.66 \mathrm{E}-39$ \\
\hline BRCA.yellow & OV.turquoise & $2.09 E-68$ \\
\hline BRCA.yellow & COADREAD.yellow & $1.91 \mathrm{E}-38$ \\
\hline BRCA.yellow & LUSC.turquoise & $1.01 \mathrm{E}-75$ \\
\hline BRCA.yellow & HNSC.yellow & $2.95 \mathrm{E}-80$ \\
\hline BRCA.yellow & KIRC.pink & $1.02 \mathrm{E}-82$ \\
\hline BRCA.yellow & BLCA.turquoise & $3.71 \mathrm{E}-67$ \\
\hline BRCA.yellow & UCEC.yellow & $4.56 \mathrm{E}-86$ \\
\hline HNSC.black & COADREAD.magenta & $1.17 \mathrm{E}-05$ \\
\hline HNSC.black & BRCA.green & 0.004042421 \\
\hline HNSC.black & BLCA.red & $3.14 \mathrm{E}-11$ \\
\hline HNSC.black & UCEC.red & $1.02 \mathrm{E}-08$ \\
\hline HNSC.blue & GBM.pink & $7.18 \mathrm{E}-23$ \\
\hline HNSC.blue & OV.blue & $8.20 \mathrm{E}-83$ \\
\hline HNSC.blue & COADREAD.brown & $9.67 \mathrm{E}-23$ \\
\hline HNSC.blue & LUSC.blue & $8.04 \mathrm{E}-159$ \\
\hline HNSC.blue & BRCA.blue & $1.01 \mathrm{E}-138$ \\
\hline HNSC.blue & KIRC.red & $3.21 \mathrm{E}-49$ \\
\hline HNSC.blue & BLCA.brown & $5.41 \mathrm{E}-98$ \\
\hline HNSC.blue & UCEC.green & $5.20 \mathrm{E}-58$ \\
\hline HNSC.brown & GBM.brown & 0.003436834 \\
\hline HNSC.brown & LUSC.brown & $8.58 \mathrm{E}-20$ \\
\hline HNSC.brown & BRCA.turquoise & 0.000143654 \\
\hline HNSC.brown & BLCA.blue & $9.45 \mathrm{E}-07$ \\
\hline HNSC.brown & UCEC.turquoise & 4.01E-06 \\
\hline HNSC.green & GBM.purple & 0.008049011 \\
\hline HNSC.green & OV.blue & $7.14 \mathrm{E}-11$ \\
\hline HNSC.green & COADREAD.magenta & $8.67 \mathrm{E}-16$ \\
\hline HNSC.green & BRCA.green & $2.18 \mathrm{E}-22$ \\
\hline HNSC.green & KIRC.brown & $4.54 \mathrm{E}-09$ \\
\hline HNSC.green & BLCA.yellow & 1.03E-19 \\
\hline
\end{tabular}


bioRxiv preprint doi: https://doi.org/10.1101/028415; this version posted October 5, 2015. The copyright holder for this preprint (which was not certified by peer review) is the author/funder, who has granted bioRxiv a license to display the preprint in perpetuity. It is made available under aCC-BY-NC-ND 4.0 International license.

\begin{tabular}{|c|c|c|}
\hline HNSC.green & UCEC.green & $6.80 \mathrm{E}-09$ \\
\hline HNSC.magenta & GBM.tan & $3.15 \mathrm{E}-52$ \\
\hline HNSC.magenta & OV.yellow & $6.50 \mathrm{E}-41$ \\
\hline HNSC.magenta & COADREAD.yellow & $1.19 \mathrm{E}-09$ \\
\hline HNSC.magenta & LUSC.yellow & $7.11 \mathrm{E}-17$ \\
\hline HNSC.magenta & BRCA.black & $1.22 \mathrm{E}-43$ \\
\hline HNSC.magenta & KIRC.green & $1.20 \mathrm{E}-09$ \\
\hline HNSC.magenta & BLCA.pink & $4.48 \mathrm{E}-53$ \\
\hline HNSC.magenta & UCEC.magenta & $8.20 E-59$ \\
\hline HNSC.pink & GBM.green & $2.17 \mathrm{E}-47$ \\
\hline HNSC.pink & OV.brown & $2.72 \mathrm{E}-14$ \\
\hline HNSC.pink & COADREAD.purple & $5.69 E-35$ \\
\hline HNSC.pink & LUSC.black & $2.45 \mathrm{E}-43$ \\
\hline HNSC.pink & KIRC.blue & $3.49 \mathrm{E}-63$ \\
\hline HNSC.pink & BLCA.blue & 0.002532541 \\
\hline HNSC.pink & UCEC.black & $1.84 \mathrm{E}-37$ \\
\hline HNSC.red & LUSC.brown & $4.40 \mathrm{E}-22$ \\
\hline HNSC.red & KIRC.turquoise & $9.54 \mathrm{E}-05$ \\
\hline HNSC.red & BLCA.green & $3.78 \mathrm{E}-45$ \\
\hline HNSC.turquoise & GBM.red & $4.98 \mathrm{E}-12$ \\
\hline HNSC.turquoise & OV.turquoise & $8.27 \mathrm{E}-21$ \\
\hline HNSC.turquoise & COADREAD.green & $9.31 \mathrm{E}-29$ \\
\hline HNSC.turquoise & LUSC.yellow & $3.40 \mathrm{E}-61$ \\
\hline HNSC.turquoise & BRCA.brown & 4.85E-59 \\
\hline HNSC.turquoise & KIRC.green & 4.40E-49 \\
\hline HNSC.turquoise & BLCA.turquoise & $9.44 \mathrm{E}-24$ \\
\hline HNSC.turquoise & UCEC.brown & $6.20 \mathrm{E}-48$ \\
\hline HNSC.yellow & GBM.turquoise & $7.52 E-56$ \\
\hline HNSC.yellow & OV.turquoise & $1.84 \mathrm{E}-55$ \\
\hline HNSC.yellow & COADREAD.yellow & $9.35 \mathrm{E}-36$ \\
\hline HNSC.yellow & LUSC.turquoise & $2.69 \mathrm{E}-118$ \\
\hline HNSC.yellow & BRCA.yellow & $2.02 E-88$ \\
\hline HNSC.yellow & KIRC.pink & $2.43 \mathrm{E}-60$ \\
\hline HNSC.yellow & BLCA.turquoise & 4.43E-80 \\
\hline
\end{tabular}


bioRxiv preprint doi: https://doi.org/10.1101/028415; this version posted October 5, 2015. The copyright holder for this preprint (which was not certified by peer review) is the author/funder, who has granted bioRxiv a license to display the preprint in perpetuity. It is made available under aCC-BY-NC-ND 4.0 International license.

\begin{tabular}{|c|c|c|}
\hline HNSC.yellow & UCEC.yellow & 5.41E-98 \\
\hline KIRC.black & GBM.purple & $2.98 \mathrm{E}-08$ \\
\hline KIRC.black & OV.blue & $3.65 \mathrm{E}-18$ \\
\hline KIRC.black & COADREAD.brown & $8.80 \mathrm{E}-11$ \\
\hline KIRC.black & LUSC.blue & $2.13 \mathrm{E}-17$ \\
\hline KIRC.black & BRCA.blue & $4.00 \mathrm{E}-16$ \\
\hline KIRC.black & HNSC.blue & $6.43 E-18$ \\
\hline KIRC.black & BLCA.yellow & $8.16 \mathrm{E}-15$ \\
\hline KIRC.black & UCEC.green & $1.68 \mathrm{E}-18$ \\
\hline KIRC.blue & GBM.green & $1.08 \mathrm{E}-87$ \\
\hline KIRC.blue & OV.brown & $9.70 \mathrm{E}-13$ \\
\hline KIRC.blue & COADREAD.purple & $1.31 \mathrm{E}-48$ \\
\hline KIRC.blue & LUSC.black & $1.29 \mathrm{E}-68$ \\
\hline KIRC.blue & HNSC.pink & $2.36 \mathrm{E}-70$ \\
\hline KIRC.blue & UCEC.black & $1.41 \mathrm{E}-68$ \\
\hline KIRC.brown & GBM.purple & $1.16 \mathrm{E}-16$ \\
\hline KIRC.brown & OV.blue & $9.71 \mathrm{E}-14$ \\
\hline KIRC.brown & COADREAD.red & 0.002307719 \\
\hline KIRC.brown & LUSC.blue & $2.76 \mathrm{E}-05$ \\
\hline KIRC.brown & BRCA.green & $2.07 \mathrm{E}-43$ \\
\hline KIRC.brown & HNSC.green & $1.82 \mathrm{E}-09$ \\
\hline KIRC.brown & BLCA.yellow & $2.05 \mathrm{E}-17$ \\
\hline KIRC.brown & UCEC.green & $1.06 \mathrm{E}-15$ \\
\hline KIRC.green & GBM.turquoise & $7.48 \mathrm{E}-18$ \\
\hline KIRC.green & OV.turquoise & $1.58 \mathrm{E}-24$ \\
\hline KIRC.green & COADREAD.green & $8.60 \mathrm{E}-32$ \\
\hline KIRC.green & LUSC.yellow & 1.23E-96 \\
\hline KIRC.green & BRCA.brown & $2.13 E-71$ \\
\hline KIRC.green & HNSC.turquoise & $4.31 \mathrm{E}-40$ \\
\hline KIRC.green & BLCA.turquoise & $2.29 E-38$ \\
\hline KIRC.green & UCEC.brown & $1.98 \mathrm{E}-52$ \\
\hline KIRC.greenyellow & GBM.pink & 0.000250163 \\
\hline KIRC.greenyellow & OV.blue & $1.51 \mathrm{E}-08$ \\
\hline
\end{tabular}


bioRxiv preprint doi: https://doi.org/10.1101/028415; this version posted October 5, 2015. The copyright holder for this preprint (which was not certified by peer review) is the author/funder, who has granted bioRxiv a license to display the preprint in perpetuity. It is made available under aCC-BY-NC-ND 4.0 International license.

\begin{tabular}{|c|c|c|}
\hline KIRC.greenyellow & COADREAD.magenta & 3.77E-19 \\
\hline KIRC.greenyellow & LUSC.blue & $2.03 \mathrm{E}-06$ \\
\hline KIRC.greenyellow & BRCA.blue & $1.78 \mathrm{E}-10$ \\
\hline KIRC.greenyellow & HNSC.blue & $1.42 \mathrm{E}-07$ \\
\hline KIRC.greenyellow & BLCA.red & $2.90 \mathrm{E}-14$ \\
\hline KIRC.greenyellow & UCEC.red & $3.07 \mathrm{E}-22$ \\
\hline KIRC.magenta & GBM.turquoise & $7.35 \mathrm{E}-23$ \\
\hline KIRC.magenta & OV.turquoise & $2.81 \mathrm{E}-18$ \\
\hline KIRC.magenta & COADREAD.green & $2.34 \mathrm{E}-13$ \\
\hline KIRC.magenta & LUSC.turquoise & $1.29 \mathrm{E}-14$ \\
\hline KIRC.magenta & BRCA.yellow & $2.08 \mathrm{E}-13$ \\
\hline KIRC.magenta & HNSC.yellow & $2.05 \mathrm{E}-22$ \\
\hline KIRC.magenta & BLCA.turquoise & $4.39 \mathrm{E}-16$ \\
\hline KIRC.magenta & UCEC.yellow & $3.49 \mathrm{E}-31$ \\
\hline KIRC.pink & GBM.turquoise & $3.57 \mathrm{E}-24$ \\
\hline KIRC.pink & OV.turquoise & $4.24 \mathrm{E}-55$ \\
\hline KIRC.pink & COADREAD.yellow & $1.54 \mathrm{E}-32$ \\
\hline KIRC.pink & LUSC.turquoise & $6.76 \mathrm{E}-70$ \\
\hline KIRC.pink & BRCA.yellow & $8.40 \mathrm{E}-84$ \\
\hline KIRC.pink & HNSC.yellow & $3.28 \mathrm{E}-60$ \\
\hline KIRC.pink & BLCA.turquoise & $1.74 \mathrm{E}-44$ \\
\hline KIRC.pink & UCEC.yellow & $4.22 \mathrm{E}-57$ \\
\hline KIRC.purple & COADREAD.blue & 0.005537789 \\
\hline KIRC.purple & BRCA.red & 2.87E-37 \\
\hline KIRC.purple & UCEC.pink & $2.18 \mathrm{E}-37$ \\
\hline KIRC.red & GBM.pink & 4.34E-24 \\
\hline KIRC.red & OV.blue & $6.66 \mathrm{E}-43$ \\
\hline KIRC.red & COADREAD.pink & $1.04 \mathrm{E}-13$ \\
\hline KIRC.red & LUSC.blue & $1.26 \mathrm{E}-52$ \\
\hline KIRC.red & BRCA.blue & $1.66 \mathrm{E}-54$ \\
\hline KIRC.red & HNSC.blue & $3.72 E-45$ \\
\hline KIRC.red & BLCA.brown & 2.47E-33 \\
\hline KIRC.red & UCEC.green & 4.60E-29 \\
\hline
\end{tabular}


bioRxiv preprint doi: https://doi.org/10.1101/028415; this version posted October 5, 2015. The copyright holder for this preprint (which was not certified by peer review) is the author/funder, who has granted bioRxiv a license to display the preprint in perpetuity. It is made available under aCC-BY-NC-ND 4.0 International license.

\begin{tabular}{|c|c|c|}
\hline KIRC.turquoise & GBM.yellow & $5.32 \mathrm{E}-05$ \\
\hline KIRC.turquoise & LUSC.red & 0.001475322 \\
\hline KIRC.turquoise & BLCA.blue & 0.007362857 \\
\hline KIRC.yellow & GBM.black & $6.05 E-54$ \\
\hline KIRC.yellow & OV.green & $8.70 \mathrm{E}-20$ \\
\hline KIRC.yellow & BRCA.turquoise & $1.17 \mathrm{E}-22$ \\
\hline KIRC.yellow & BLCA.blue & 0.01085711 \\
\hline KIRC.yellow & UCEC.blue & $6.11 \mathrm{E}-20$ \\
\hline BLCA.black & HNSC.green & 0.000186086 \\
\hline BLCA.blue & LUSC.brown & $6.56 \mathrm{E}-16$ \\
\hline BLCA.blue & BRCA.turquoise & 8.33E-09 \\
\hline BLCA.blue & HNSC.brown & $3.84 \mathrm{E}-08$ \\
\hline BLCA.blue & KIRC.turquoise & 0.000131954 \\
\hline BLCA.brown & GBM.pink & $6.02 \mathrm{E}-16$ \\
\hline BLCA.brown & OV.blue & $3.58 \mathrm{E}-78$ \\
\hline BLCA.brown & COADREAD.brown & $7.84 \mathrm{E}-27$ \\
\hline BLCA.brown & LUSC.blue & $3.18 \mathrm{E}-97$ \\
\hline BLCA.brown & BRCA.blue & $1.09 \mathrm{E}-95$ \\
\hline BLCA.brown & HNSC.blue & $2.46 \mathrm{E}-96$ \\
\hline BLCA.brown & KIRC.red & $1.51 \mathrm{E}-37$ \\
\hline BLCA.brown & UCEC.green & $8.65 \mathrm{E}-48$ \\
\hline BLCA.green & LUSC.brown & $4.55 \mathrm{E}-29$ \\
\hline BLCA.green & HNSC.red & $4.56 \mathrm{E}-42$ \\
\hline BLCA.green & UCEC.turquoise & 0.007472986 \\
\hline BLCA.pink & GBM.tan & $1.43 \mathrm{E}-41$ \\
\hline BLCA.pink & OV.yellow & $2.27 \mathrm{E}-40$ \\
\hline BLCA.pink & COADREAD.yellow & $1.54 \mathrm{E}-10$ \\
\hline BLCA.pink & LUSC.yellow & $2.85 \mathrm{E}-21$ \\
\hline BLCA.pink & BRCA.black & $5.02 E-43$ \\
\hline BLCA.pink & HNSC.magenta & $2.29 \mathrm{E}-51$ \\
\hline BLCA.pink & KIRC.green & $1.92 \mathrm{E}-07$ \\
\hline BLCA.pink & UCEC.magenta & $6.37 E-55$ \\
\hline BLCA.red & OV.blue & $3.72 E-08$ \\
\hline
\end{tabular}


bioRxiv preprint doi: https://doi.org/10.1101/028415; this version posted October 5, 2015. The copyright holder for this preprint (which was not certified by peer review) is the author/funder, who has granted bioRxiv a license to display the preprint in perpetuity. It is made available under aCC-BY-NC-ND 4.0 International license.

\begin{tabular}{|c|c|c|}
\hline BLCA.red & COADREAD.magenta & $8.58 \mathrm{E}-40$ \\
\hline BLCA.red & LUSC.blue & $3.27 \mathrm{E}-14$ \\
\hline BLCA.red & BRCA.blue & 2.91E-09 \\
\hline BLCA.red & HNSC.black & $2.36 \mathrm{E}-09$ \\
\hline BLCA.red & KIRC.greenyellow & $1.22 \mathrm{E}-14$ \\
\hline BLCA.red & UCEC.red & $3.81 \mathrm{E}-30$ \\
\hline BLCA.turquoise & GBM.turquoise & 3.23E-52 \\
\hline BLCA.turquoise & OV.turquoise & $7.02 E-88$ \\
\hline BLCA.turquoise & COADREAD.yellow & $8.47 \mathrm{E}-45$ \\
\hline BLCA.turquoise & LUSC.turquoise & $7.53 \mathrm{E}-60$ \\
\hline BLCA.turquoise & BRCA.yellow & $4.51 E-73$ \\
\hline BLCA.turquoise & HNSC.yellow & $4.86 \mathrm{E}-74$ \\
\hline BLCA.turquoise & KIRC.pink & $2.37 \mathrm{E}-43$ \\
\hline BLCA.turquoise & UCEC.yellow & 7.90E-77 \\
\hline BLCA.yellow & GBM.brown & 0.000627877 \\
\hline BLCA.yellow & OV.blue & 0.000259226 \\
\hline BLCA.yellow & COADREAD.brown & 0.003223737 \\
\hline BLCA.yellow & LUSC.blue & $9.16 \mathrm{E}-05$ \\
\hline BLCA.yellow & BRCA.green & $8.26 \mathrm{E}-22$ \\
\hline BLCA.yellow & HNSC.green & $3.52 \mathrm{E}-23$ \\
\hline BLCA.yellow & KIRC.black & $9.87 \mathrm{E}-16$ \\
\hline BLCA.yellow & UCEC.green & $5.59 \mathrm{E}-10$ \\
\hline UCEC.black & GBM.green & $1.04 \mathrm{E}-57$ \\
\hline UCEC.black & OV.brown & 2.24E-08 \\
\hline UCEC.black & COADREAD.purple & 6.97E-38 \\
\hline UCEC.black & LUSC.black & $1.79 E-53$ \\
\hline UCEC.black & HNSC.pink & $5.16 \mathrm{E}-41$ \\
\hline UCEC.black & KIRC.blue & $1.97 \mathrm{E}-65$ \\
\hline UCEC.black & BLCA.blue & 0.01510793 \\
\hline UCEC.blue & GBM.black & $4.20 \mathrm{E}-27$ \\
\hline UCEC.blue & OV.green & $3.91 \mathrm{E}-24$ \\
\hline UCEC.blue & BRCA.turquoise & $8.61 \mathrm{E}-24$ \\
\hline UCEC.blue & KIRC.yellow & $1.37 \mathrm{E}-24$ \\
\hline
\end{tabular}


bioRxiv preprint doi: https://doi.org/10.1101/028415; this version posted October 5, 2015. The copyright holder for this preprint (which was not certified by peer review) is the author/funder, who has granted bioRxiv a license to display the preprint in perpetuity. It is made available under aCC-BY-NC-ND 4.0 International license.

\begin{tabular}{|c|c|c|}
\hline UCEC.blue & BLCA.blue & 0.000279847 \\
\hline UCEC.brown & GBM.turquoise & $1.72 \mathrm{E}-16$ \\
\hline UCEC.brown & OV.turquoise & $5.03 E-53$ \\
\hline UCEC.brown & COADREAD.green & $1.49 \mathrm{E}-28$ \\
\hline UCEC.brown & LUSC.yellow & $2.79 \mathrm{E}-47$ \\
\hline UCEC.brown & BRCA.brown & 2.73E-61 \\
\hline UCEC.brown & HNSC.turquoise & $1.87 \mathrm{E}-44$ \\
\hline UCEC.brown & KIRC.green & $1.52 \mathrm{E}-54$ \\
\hline UCEC.brown & BLCA.turquoise & $2.25 \mathrm{E}-43$ \\
\hline UCEC.green & GBM.pink & $1.08 \mathrm{E}-19$ \\
\hline UCEC.green & OV.blue & $6.98 \mathrm{E}-95$ \\
\hline UCEC.green & COADREAD.brown & $2.08 \mathrm{E}-12$ \\
\hline UCEC.green & LUSC.blue & $5.76 \mathrm{E}-69$ \\
\hline UCEC.green & BRCA.blue & $1.35 \mathrm{E}-59$ \\
\hline UCEC.green & HNSC.blue & $3.22 E-55$ \\
\hline UCEC.green & KIRC.red & $5.11 \mathrm{E}-24$ \\
\hline UCEC.green & BLCA.brown & $3.21 \mathrm{E}-45$ \\
\hline UCEC.magenta & GBM.tan & $1.52 \mathrm{E}-69$ \\
\hline UCEC.magenta & OV.yellow & $4.75 \mathrm{E}-43$ \\
\hline UCEC.magenta & COADREAD.yellow & $7.11 \mathrm{E}-11$ \\
\hline UCEC.magenta & LUSC.yellow & $1.81 \mathrm{E}-29$ \\
\hline UCEC.magenta & BRCA.black & $6.93 \mathrm{E}-57$ \\
\hline UCEC.magenta & HNSC.magenta & $1.85 \mathrm{E}-58$ \\
\hline UCEC.magenta & KIRC.green & $1.85 \mathrm{E}-13$ \\
\hline UCEC.magenta & BLCA.pink & $3.92 E-57$ \\
\hline UCEC.pink & BRCA.red & $9.08 \mathrm{E}-34$ \\
\hline UCEC.pink & KIRC.purple & $1.31 \mathrm{E}-38$ \\
\hline UCEC.pink & BLCA.blue & 0.007672225 \\
\hline UCEC.red & GBM.pink & 0.000169972 \\
\hline UCEC.red & OV.blue & $1.74 \mathrm{E}-24$ \\
\hline UCEC.red & COADREAD.magenta & 7.97E-28 \\
\hline UCEC.red & LUSC.blue & $1.26 \mathrm{E}-32$ \\
\hline UCEC.red & BRCA.blue & $1.08 \mathrm{E}-29$ \\
\hline
\end{tabular}


bioRxiv preprint doi: https://doi.org/10.1101/028415; this version posted October 5, 2015. The copyright holder for this preprint (which was not certified by peer review) is the author/funder, who has granted bioRxiv a license to display the preprint in perpetuity. It is made available under aCC-BY-NC-ND 4.0 International license.

\begin{tabular}{|l|l|l|}
\hline UCEC.red & HNSC.blue & $6.67 \mathrm{E}-22$ \\
\hline UCEC.red & KIRC.greenyellow & $5.87 \mathrm{E}-21$ \\
\hline UCEC.red & BLCA.red & $1.13 \mathrm{E}-25$ \\
\hline UCEC.turquoise & GBM.yellow & $6.82 \mathrm{E}-22$ \\
\hline UCEC.turquoise & OV.brown & $1.71 \mathrm{E}-40$ \\
\hline UCEC.turquoise & LUSC.pink & $3.89 \mathrm{E}-30$ \\
\hline UCEC.turquoise & BRCA.turquoise & $4.03 \mathrm{E}-12$ \\
\hline UCEC.turquoise & HNSC.brown & $1.79 \mathrm{E}-05$ \\
\hline UCEC.turquoise & KIRC.turquoise & $1.34 \mathrm{E}-07$ \\
\hline UCEC.yellow & GBM.turquoise & $5.63 \mathrm{E}-49$ \\
\hline UCEC.yellow & OV.turquoise & $1.21 \mathrm{E}-84$ \\
\hline UCEC.yellow & COADREAD.yellow & $8.05 \mathrm{E}-39$ \\
\hline UCEC.yellow & LUSC.turquoise & $1.85 \mathrm{E}-59$ \\
\hline UCEC.yellow & BRCA.yellow & $4.22 \mathrm{E}-88$ \\
\hline UCEC.yellow & HNSC.yellow & $1.93 \mathrm{E}-88$ \\
\hline UCEC.yellow & KIRC.pink & $4.17 \mathrm{E}-45$ \\
\hline UCEC.yellow & BLCA.turquoise & $3.73 \mathrm{E}-74$ \\
\hline
\end{tabular}


bioRxiv preprint doi: https://doi.org/10.1101/028415; this version posted October 5, 2015. The copyright holder for this preprint (which was not certified by peer review) is the author/funder, who has granted bioRxiv a license to display the preprint in perpetuity. It is made available under aCC-BY-NC-ND 4.0 International license.

\section{Zou_Suppl_Table_3}

\begin{tabular}{|c|c|c|c|}
\hline $\begin{array}{l}\text { module } \\
\text { name }\end{array}$ & $\begin{array}{l}\text { module } \\
\text { size }\end{array}$ & MSigDB.c5.bp (v3.1, Top10 is shown) & $\begin{array}{l}\text { hypergeometric } \\
\text { p-value }\end{array}$ \\
\hline GBM.M1 & 238 & CELL_CYCLE_GO_0007049 & $6.99 \mathrm{E}-22$ \\
\hline GBM.M1 & 238 & CELL_CYCLE_PROCESS & $4.50 \mathrm{E}-21$ \\
\hline GBM.M1 & 238 & M_PHASE & $3.78 \mathrm{E}-20$ \\
\hline GBM.M1 & 238 & M_PHASE_OF_MITOTIC_CELL_CYCLE & 4.87E-20 \\
\hline GBM.M1 & 238 & CELL_CYCLE_PHASE & $5.07 \mathrm{E}-20$ \\
\hline GBM.M1 & 238 & MITOTIC_CELL_CYCLE & $7.25 \mathrm{E}-20$ \\
\hline GBM.M1 & 238 & MITOSIS & $6.82 \mathrm{E}-19$ \\
\hline GBM.M1 & 238 & REGULATION_OF_MITOSIS & $4.47 \mathrm{E}-13$ \\
\hline GBM.M1 & 238 & REGULATION_OF_CELL_CYCLE & $1.51 \mathrm{E}-11$ \\
\hline GBM.M1 & 238 & CHROMOSOME_SEGREGATION & $1.40 \mathrm{E}-09$ \\
\hline GBM.M2 & 482 & NERVOUS_SYSTEM_DEVELOPMENT & $1.01 \mathrm{E}-14$ \\
\hline GBM.M2 & 482 & SYSTEM_DEVELOPMENT & $3.92 \mathrm{E}-12$ \\
\hline GBM.M2 & 482 & ANATOMICAL_STRUCTURE_DEVELOPMENT & $7.68 \mathrm{E}-12$ \\
\hline GBM.M2 & 482 & MULTICELLULAR_ORGANISMAL_DEVELOPMENT & $3.13 \mathrm{E}-11$ \\
\hline GBM.M2 & 482 & GLUTAMATE_SIGNALING_PATHWAY & $3.73 \mathrm{E}-08$ \\
\hline GBM.M2 & 482 & CENTRAL_NERVOUS_SYSTEM_DEVELOPMENT & 8.33E-08 \\
\hline GBM.M2 & 482 & NEURON_DIFFERENTIATION & $9.29 \mathrm{E}-08$ \\
\hline GBM.M2 & 482 & GENERATION_OF_NEURONS & 2.53E-07 \\
\hline GBM.M2 & 482 & AXONOGENESIS & $3.14 \mathrm{E}-07$ \\
\hline GBM.M2 & 482 & NEURON_DEVELOPMENT & 7.70E-07 \\
\hline GBM.M3 & 346 & TRANSMISSION_OF_NERVE_IMPULSE & $2.82 \mathrm{E}-18$ \\
\hline GBM.M3 & 346 & SYNAPTIC_TRANSMISSION & $3.86 \mathrm{E}-18$ \\
\hline GBM.M3 & 346 & CELL_CELL_SIGNALING & $1.78 \mathrm{E}-15$ \\
\hline GBM.M3 & 346 & NEUROLOGICAL_SYSTEM_PROCESS & $7.49 \mathrm{E}-11$ \\
\hline
\end{tabular}


bioRxiv preprint doi: https://doi.org/10.1101/028415; this version posted October 5, 2015. The copyright holder for this preprint (which was not certified by peer review) is the author/funder, who has granted bioRxiv a license to display the preprint in perpetuity. It is made available under aCC-BY-NC-ND 4.0 International license.

\begin{tabular}{|c|c|c|c|}
\hline $\begin{array}{l}\text { module } \\
\text { name }\end{array}$ & $\begin{array}{l}\text { module } \\
\text { size }\end{array}$ & MSigDB.c5.bp (v3.1, Top10 is shown) & $\begin{array}{l}\text { hypergeometric } \\
\text { p-value }\end{array}$ \\
\hline GBM.M3 & 346 & NERVOUS_SYSTEM_DEVELOPMENT & $5.40 \mathrm{E}-10$ \\
\hline GBM.M3 & 346 & SYSTEM_PROCESS & $2.55 \mathrm{E}-08$ \\
\hline GBM.M3 & 346 & MICROTUBULE_BASED_MOVEMENT & $1.02 \mathrm{E}-07$ \\
\hline GBM.M3 & 346 & CYTOSKELETON_DEPENDENT_INTRACELLULAR_TRANSPORT & $2.56 \mathrm{E}-06$ \\
\hline GBM.M3 & 346 & GENERATION_OF_A_SIGNAL_INVOLVED_IN_CELL_CELL_SIGNALING & 5.07E-06 \\
\hline GBM.M3 & 346 & TRANSPORT & $2.58 \mathrm{E}-05$ \\
\hline GBM.M4 & 268 & PROTEIN_HOMOOLIGOMERIZATION & 0.000132505 \\
\hline GBM.M4 & 268 & BODY_FLUID_SECRETION & 0.000201352 \\
\hline GBM.M4 & 268 & $\begin{array}{l}\text { CELL_SURFACE_RECEPTOR_LINKED_SIGNAL_TRANSDUCTION_GO_0007 } \\
166\end{array}$ & 0.000351599 \\
\hline GBM.M4 & 268 & PROTEIN_OLIGOMERIZATION & 0.001393972 \\
\hline GBM.M4 & 268 & REGULATION_OF_PROTEIN_STABILITY & 0.00149916 \\
\hline GBM.M4 & 268 & MEIOSIS_I & 0.00174793 \\
\hline GBM.M4 & 268 & SODIUM_ION_TRANSPORT & 0.002319194 \\
\hline GBM.M4 & 268 & FOCAL_ADHESION_FORMATION & 0.006237476 \\
\hline GBM.M4 & 268 & PEPTIDE_METABOLIC_PROCESS & 0.006237476 \\
\hline GBM.M4 & 268 & NEGATIVE_REGULATION_OF_MYELOID_CELL_DIFFERENTIATION & 0.006237476 \\
\hline GBM.M5 & 87 & PROTEIN_AMINO_ACID_PHOSPHORYLATION & $1.61 \mathrm{E}-06$ \\
\hline GBM.M5 & 87 & PHOSPHORYLATION & 4.13E-06 \\
\hline GBM.M5 & 87 & PROTEIN_AMINO_ACID_AUTOPHOSPHORYLATION & $6.62 \mathrm{E}-06$ \\
\hline GBM.M5 & 87 & PROTEIN_AUTOPROCESSING & 7.54E-06 \\
\hline GBM.M5 & 87 & POST_TRANSLATIONAL_PROTEIN_MODIFICATION & 1.85E-05 \\
\hline GBM.M5 & 87 & PROTEIN_PROCESSING & $4.22 \mathrm{E}-05$ \\
\hline GBM.M5 & 87 & POSITIVE_REGULATION_OF_TRANSCRIPTION_FACTOR_ACTIVITY & 0.000113847 \\
\hline GBM.M5 & 87 & POSITIVE_REGULATION_OF_DNA_BINDING & 0.000145412 \\
\hline
\end{tabular}


bioRxiv preprint doi: https://doi.org/10.1101/028415; this version posted October 5, 2015. The copyright holder for this preprint (which was not certified by peer review) is the author/funder, who has granted bioRxiv a license to display the preprint in perpetuity. It is made available under aCC-BY-NC-ND 4.0 International license.

\begin{tabular}{|c|c|c|c|}
\hline $\begin{array}{l}\text { module } \\
\text { name }\end{array}$ & $\begin{array}{l}\text { module } \\
\text { size }\end{array}$ & MSigDB.c5.bp (v3.1, Top10 is shown) & $\begin{array}{l}\text { hypergeometric } \\
\text { p-value }\end{array}$ \\
\hline GBM.M5 & 87 & POSITIVE_REGULATION_OF_BINDING & 0.000182175 \\
\hline GBM.M5 & 87 & PROTEIN_MODIFICATION_PROCESS & 0.000192739 \\
\hline GBM.M7 & 217 & NERVOUS_SYSTEM_DEVELOPMENT & 3.06E-07 \\
\hline GBM.M7 & 217 & REGULATION_OF_ACTION_POTENTIAL & $1.98 \mathrm{E}-05$ \\
\hline GBM.M7 & 217 & SYSTEM_DEVELOPMENT & $4.58 \mathrm{E}-05$ \\
\hline GBM.M7 & 217 & ANATOMICAL_STRUCTURE_DEVELOPMENT & $6.72 \mathrm{E}-05$ \\
\hline GBM.M7 & 217 & PERIPHERAL_NERVOUS_SYSTEM_DEVELOPMENT & 0.000194982 \\
\hline GBM.M7 & 217 & CENTRAL_NERVOUS_SYSTEM_DEVELOPMENT & 0.000222563 \\
\hline GBM.M7 & 217 & HEART_DEVELOPMENT & 0.000471087 \\
\hline GBM.M7 & 217 & ICOSANOID_METABOLIC_PROCESS & 0.000581111 \\
\hline GBM.M7 & 217 & MULTICELLULAR_ORGANISMAL_DEVELOPMENT & 0.000725646 \\
\hline GBM.M7 & 217 & EPIDERMAL_GROWTH_FACTOR_RECEPTOR_SIGNALING_PATHWAY & 0.001269072 \\
\hline GBM.M8 & 229 & ANATOMICAL_STRUCTURE_DEVELOPMENT & $7.58 \mathrm{E}-08$ \\
\hline GBM.M8 & 229 & SKELETAL_DEVELOPMENT & $1.24 \mathrm{E}-07$ \\
\hline GBM.M8 & 229 & MULTICELLULAR_ORGANISMAL_DEVELOPMENT & $5.29 \mathrm{E}-07$ \\
\hline GBM.M8 & 229 & ORGAN_DEVELOPMENT & $6.28 \mathrm{E}-07$ \\
\hline GBM.M8 & 229 & SYSTEM_DEVELOPMENT & $1.20 \mathrm{E}-06$ \\
\hline GBM.M8 & 229 & NEURON_DIFFERENTIATION & 0.000141844 \\
\hline GBM.M8 & 229 & NEGATIVE_REGULATION_OF_PHOSPHORYLATION & 0.000228472 \\
\hline GBM.M8 & 229 & GENERATION_OF_NEURONS & 0.00023054 \\
\hline GBM.M8 & 229 & NEGATIVE_REGULATION_OF_PHOSPHATE_METABOLIC_PROCESS & 0.000294735 \\
\hline GBM.M8 & 229 & REGULATION_OF_HORMONE_SECRETION & 0.000372241 \\
\hline GBM.M9 & 91 & RESPONSE_TO_WOUNDING & $9.42 \mathrm{E}-08$ \\
\hline GBM.M9 & 91 & REGULATION_OF_BODY_FLUID_LEVELS & $1.30 \mathrm{E}-07$ \\
\hline GBM.M9 & 91 & BLOOD_COAGULATION & $9.21 \mathrm{E}-07$ \\
\hline GBM.M9 & 91 & COAGULATION & $1.04 \mathrm{E}-06$ \\
\hline GBM.M9 & 91 & HEMOSTASIS & 1.61E-06 \\
\hline
\end{tabular}


bioRxiv preprint doi: https://doi.org/10.1101/028415; this version posted October 5, 2015. The copyright holder for this preprint (which was not certified by peer review) is the author/funder, who has granted bioRxiv a license to display the preprint in perpetuity. It is made available under aCC-BY-NC-ND 4.0 International license.

\begin{tabular}{|c|c|c|c|}
\hline $\begin{array}{l}\text { module } \\
\text { name }\end{array}$ & $\begin{array}{l}\text { module } \\
\text { size }\end{array}$ & MSigDB.c5.bp (v3.1, Top10 is shown) & $\begin{array}{l}\text { hypergeometric } \\
\text { p-value }\end{array}$ \\
\hline GBM.M9 & 91 & WOUND_HEALING & 2.92E-06 \\
\hline GBM.M9 & 91 & RESPONSE_TO_EXTERNAL_STIMULUS & $5.85 \mathrm{E}-06$ \\
\hline GBM.M9 & 91 & CYCLIC_NUCLEOTIDE_METABOLIC_PROCESS & $1.10 \mathrm{E}-05$ \\
\hline GBM.M9 & 91 & NEGATIVE_REGULATION_OF_ANGIOGENESIS & $1.90 \mathrm{E}-05$ \\
\hline GBM.M9 & 91 & ANATOMICAL_STRUCTURE_MORPHOGENESIS & $2.58 \mathrm{E}-05$ \\
\hline GBM.M10 & 241 & IMMUNE_SYSTEM_PROCESS & $5.31 E-16$ \\
\hline GBM.M10 & 241 & DEFENSE_RESPONSE & 3.33E-15 \\
\hline GBM.M10 & 241 & IMMUNE_RESPONSE & $1.65 \mathrm{E}-12$ \\
\hline GBM.M10 & 241 & RESPONSE_TO_EXTERNAL_STIMULUS & $5.34 \mathrm{E}-12$ \\
\hline GBM.M10 & 241 & LOCOMOTORY_BEHAVIOR & 7.54E-09 \\
\hline GBM.M10 & 241 & RESPONSE_TO_OTHER_ORGANISM & $2.49 \mathrm{E}-08$ \\
\hline GBM.M10 & 241 & RESPONSE_TO_WOUNDING & $2.50 \mathrm{E}-08$ \\
\hline GBM.M10 & 241 & RESPONSE_TO_BIOTIC_STIMULUS & $8.82 \mathrm{E}-08$ \\
\hline GBM.M10 & 241 & INTERFERON_GAMMA_PRODUCTION & $2.80 \mathrm{E}-07$ \\
\hline GBM.M10 & 241 & REGULATION_OF_IMMUNE_EFFECTOR_PROCESS & 4.16E-07 \\
\hline GBM.M11 & 56 & DEFENSE_RESPONSE & 2.53E-08 \\
\hline GBM.M11 & 56 & LOCOMOTORY_BEHAVIOR & 0.000100899 \\
\hline GBM.M11 & 56 & RESPONSE_TO_VIRUS & 0.000281284 \\
\hline GBM.M11 & 56 & IMMUNE_RESPONSE & 0.000326651 \\
\hline GBM.M11 & 56 & INFLAMMATORY_RESPONSE & 0.000327278 \\
\hline GBM.M11 & 56 & SENSORY_PERCEPTION_OF_TASTE & 0.000344898 \\
\hline GBM.M11 & 56 & APOPTOTIC_MITOCHONDRIAL_CHANGES & 0.000344898 \\
\hline GBM.M11 & 56 & DEFENSE_RESPONSE_TO_VIRUS & 0.000413201 \\
\hline GBM.M11 & 56 & PROTEIN_TARGETING_TO_MEMBRANE & 0.000413201 \\
\hline GBM.M11 & 56 & NEGATIVE_REGULATION_OF_HYDROLASE_ACTIVITY & 0.000567857 \\
\hline GBM.M12 & 700 & IMMUNE_SYSTEM_PROCESS & $1.58 \mathrm{E}-26$ \\
\hline
\end{tabular}


bioRxiv preprint doi: https://doi.org/10.1101/028415; this version posted October 5, 2015. The copyright holder for this preprint (which was not certified by peer review) is the author/funder, who has granted bioRxiv a license to display the preprint in perpetuity. It is made available under aCC-BY-NC-ND 4.0 International license.

\begin{tabular}{|c|c|c|c|}
\hline $\begin{array}{l}\text { module } \\
\text { name }\end{array}$ & $\begin{array}{l}\text { module } \\
\text { size }\end{array}$ & MSigDB.c5.bp (v3.1, Top10 is shown) & $\begin{array}{l}\text { hypergeometric } \\
\text { p-value }\end{array}$ \\
\hline GBM.M12 & 700 & IMMUNE_RESPONSE & $3.20 \mathrm{E}-25$ \\
\hline GBM.M12 & 700 & DEFENSE_RESPONSE & $2.28 \mathrm{E}-18$ \\
\hline GBM.M12 & 700 & SIGNAL_TRANSDUCTION & $5.56 \mathrm{E}-17$ \\
\hline GBM.M12 & 700 & RESPONSE_TO_EXTERNAL_STIMULUS & $1.02 \mathrm{E}-16$ \\
\hline GBM.M12 & 700 & NEGATIVE_REGULATION_OF_BIOLOGICAL_PROCESS & $7.91 \mathrm{E}-14$ \\
\hline GBM.M12 & 700 & CELL_DEVELOPMENT & $1.25 \mathrm{E}-13$ \\
\hline GBM.M12 & 700 & PROGRAMMED_CELL_DEATH & $8.16 \mathrm{E}-13$ \\
\hline GBM.M12 & 700 & NEGATIVE_REGULATION_OF_DEVELOPMENTAL_PROCESS & $1.10 \mathrm{E}-12$ \\
\hline GBM.M12 & 700 & RESPONSE_TO_WOUNDING & $2.47 \mathrm{E}-12$ \\
\hline GBM.M13 & 302 & AMINO_ACID_DERIVATIVE_BIOSYNTHETIC_PROCESS & $1.12 \mathrm{E}-07$ \\
\hline GBM.M13 & 302 & AMINO_ACID_DERIVATIVE_METABOLIC_PROCESS & $6.96 \mathrm{E}-07$ \\
\hline GBM.M13 & 302 & REGULATION_OF_NEUROTRANSMITTER_LEVELS & $1.62 \mathrm{E}-05$ \\
\hline GBM.M13 & 302 & AMINE_BIOSYNTHETIC_PROCESS & 4.22E-05 \\
\hline GBM.M13 & 302 & BIOGENIC_AMINE_METABOLIC_PROCESS & 7.19E-05 \\
\hline GBM.M13 & 302 & GLUCAN_METABOLIC_PROCESS & 0.000286139 \\
\hline GBM.M13 & 302 & SYSTEM_PROCESS & 0.00031423 \\
\hline GBM.M13 & 302 & DEVELOPMENTAL_GROWTH & 0.000389449 \\
\hline GBM.M13 & 302 & NITROGEN_COMPOUND_BIOSYNTHETIC_PROCESS & 0.00041 \\
\hline GBM.M13 & 302 & AROMATIC_COMPOUND_METABOLIC_PROCESS & 0.000476137 \\
\hline OV.M1 & 629 & MULTICELLULAR_ORGANISMAL_DEVELOPMENT & 1.57E-21 \\
\hline OV.M1 & 629 & ANATOMICAL_STRUCTURE_DEVELOPMENT & $1.12 \mathrm{E}-18$ \\
\hline OV.M1 & 629 & ORGAN_DEVELOPMENT & $2.75 \mathrm{E}-18$ \\
\hline OV.M1 & 629 & SYSTEM_DEVELOPMENT & $2.28 \mathrm{E}-17$ \\
\hline OV.M1 & 629 & SKELETAL_DEVELOPMENT & $1.25 \mathrm{E}-12$ \\
\hline OV.M1 & 629 & ANATOMICAL_STRUCTURE_MORPHOGENESIS & $1.02 \mathrm{E}-09$ \\
\hline OV.M1 & 629 & RESPONSE_TO_EXTERNAL_STIMULUS & 1.96E-09 \\
\hline OV.M1 & 629 & MUSCLE_DEVELOPMENT & 3.91E-07 \\
\hline OV.M1 & 629 & CELL_MATRIX_ADHESION & $9.36 \mathrm{E}-07$ \\
\hline
\end{tabular}


bioRxiv preprint doi: https://doi.org/10.1101/028415; this version posted October 5, 2015. The copyright holder for this preprint (which was not certified by peer review) is the author/funder, who has granted bioRxiv a license to display the preprint in perpetuity. It is made available under aCC-BY-NC-ND 4.0 International license.

\begin{tabular}{|c|c|c|c|}
\hline $\begin{array}{l}\text { module } \\
\text { name }\end{array}$ & $\begin{array}{l}\text { module } \\
\text { size }\end{array}$ & MSigDB.c5.bp (v3.1, Top10 is shown) & $\begin{array}{l}\text { hypergeometric } \\
\text { p-value }\end{array}$ \\
\hline OV.M1 & 629 & CELL_SUBSTRATE_ADHESION & $1.19 \mathrm{E}-06$ \\
\hline OV.M2 & 186 & SPERMATID_DEVELOPMENT & 0.003059772 \\
\hline OV.M2 & 186 & PEPTIDE_METABOLIC_PROCESS & 0.003059772 \\
\hline OV.M2 & 186 & REGULATION_OF_PROTEIN_POLYMERIZATION & 0.003718979 \\
\hline OV.M2 & 186 & SPERMATID_DIFFERENTIATION & 0.003718979 \\
\hline OV.M2 & 186 & MICROTUBULE_POLYMERIZATION_OR_DEPOLYMERIZATION & 0.003718979 \\
\hline OV.M2 & 186 & ISOPRENOID_METABOLIC_PROCESS & 0.004438039 \\
\hline OV.M2 & 186 & N_ACETYLGLUCOSAMINE_METABOLIC_PROCESS & 0.004438039 \\
\hline OV.M2 & 186 & NEUROTRANSMITTER_SECRETION & 0.005215905 \\
\hline OV.M2 & 186 & GLUCOSAMINE_METABOLIC_PROCESS & 0.005215905 \\
\hline OV.M2 & 186 & STRIATED_MUSCLE_CONTRACTION_GO_0006941 & 0.00605154 \\
\hline OV.M3 & 51 & CELL_CYCLE_CHECKPOINT_GO_0000075 & 4.62E-06 \\
\hline OV.M3 & 51 & REGULATION_OF_MITOTIC_CELL_CYCLE & $2.01 \mathrm{E}-05$ \\
\hline OV.M3 & 51 & MITOSIS & $3.92 \mathrm{E}-05$ \\
\hline OV.M3 & 51 & M_PHASE_OF_MITOTIC_CELL_CYCLE & $4.52 \mathrm{E}-05$ \\
\hline OV.M3 & 51 & REGULATION_OF_CELL_CYCLE & $6.33 \mathrm{E}-05$ \\
\hline OV.M3 & 51 & CELL_CYCLE_GO_0007049 & 8.60E-05 \\
\hline OV.M3 & 51 & REGULATION_OF_MITOSIS & 0.000117568 \\
\hline OV.M3 & 51 & REGULATION_OF_CYCLIN_DEPENDENT_PROTEIN_KINASE_ACTIVITY & 0.000135664 \\
\hline OV.M3 & 51 & M_PHASE & 0.000141626 \\
\hline OV.M3 & 51 & REGULATION_OF_DNA_METABOLIC_PROCESS & 0.000155481 \\
\hline OV.M5 & 1037 & IMMUNE_SYSTEM_PROCESS & $1.61 \mathrm{E}-35$ \\
\hline OV.M5 & 1037 & DEFENSE_RESPONSE & $2.22 \mathrm{E}-34$ \\
\hline OV.M5 & 1037 & IMMUNE_RESPONSE & $4.41 \mathrm{E}-33$ \\
\hline OV.M5 & 1037 & SIGNAL_TRANSDUCTION & $5.68 \mathrm{E}-26$ \\
\hline
\end{tabular}


bioRxiv preprint doi: https://doi.org/10.1101/028415; this version posted October 5, 2015. The copyright holder for this preprint (which was not certified by peer review) is the author/funder, who has granted bioRxiv a license to display the preprint in perpetuity. It is made available under aCC-BY-NC-ND 4.0 International license.

\begin{tabular}{|c|c|c|c|}
\hline $\begin{array}{l}\text { module } \\
\text { name }\end{array}$ & $\begin{array}{l}\text { module } \\
\text { size }\end{array}$ & MSigDB.c5.bp (v3.1, Top10 is shown) & $\begin{array}{l}\text { hypergeometric } \\
\text { p-value }\end{array}$ \\
\hline OV.M5 & 1037 & RESPONSE_TO_EXTERNAL_STIMULUS & $4.05 \mathrm{E}-18$ \\
\hline OV.M5 & 1037 & INFLAMMATORY_RESPONSE & $1.32 \mathrm{E}-17$ \\
\hline OV.M5 & 1037 & RESPONSE_TO_WOUNDING & $9.59 \mathrm{E}-16$ \\
\hline OV.M5 & 1037 & LOCOMOTORY_BEHAVIOR & $1.57 \mathrm{E}-13$ \\
\hline OV.M5 & 1037 & INTRACELLULAR_SIGNALING_CASCADE & $3.30 \mathrm{E}-13$ \\
\hline OV.M5 & 1037 & $\begin{array}{l}\text { CELL_SURFACE_RECEPTOR_LINKED_SIGNAL_TRANSDUCTION_GO_0007 } \\
166\end{array}$ & $9.72 \mathrm{E}-13$ \\
\hline OV.M6 & 62 & RESPONSE_TO_OTHER_ORGANISM & $1.25 \mathrm{E}-07$ \\
\hline OV.M6 & 62 & RESPONSE_TO_VIRUS & $2.90 \mathrm{E}-07$ \\
\hline OV.M6 & 62 & RESPONSE_TO_BIOTIC_STIMULUS & $1.11 \mathrm{E}-06$ \\
\hline OV.M6 & 62 & MULTI_ORGANISM_PROCESS & $7.06 \mathrm{E}-06$ \\
\hline OV.M6 & 62 & IMMUNE_SYSTEM_PROCESS & 0.000340928 \\
\hline OV.M6 & 62 & RESPONSE_TO_TOXIN & 0.000346569 \\
\hline OV.M6 & 62 & EPITHELIAL_CELL_DIFFERENTIATION & 0.000346569 \\
\hline OV.M6 & 62 & REGULATION_OF_INTERFERON_GAMMA_BIOSYNTHETIC_PROCESS & 0.000422815 \\
\hline OV.M6 & 62 & RESPONSE_TO_STEROID_HORMONE_STIMULUS & 0.000422815 \\
\hline OV.M6 & 62 & XENOBIOTIC_METABOLIC_PROCESS & 0.000422815 \\
\hline COADREAD.M1 & 136 & NEGATIVE_REGULATION_OF_TRANSCRIPTION_FACTOR_ACTIVITY & 9.96E-05 \\
\hline COADREAD.M1 & 136 & NEGATIVE_REGULATION_OF_DNA_BINDING & 0.000147466 \\
\hline COADREAD.M1 & 136 & NEGATIVE_REGULATION_OF_BINDING & 0.00017616 \\
\hline COADREAD.M1 & 136 & RNA_3END_PROCESSING & 0.001652514 \\
\hline COADREAD.M1 & 136 & S_PHASE_OF_MITOTIC_CELL_CYCLE & 0.001652514 \\
\hline COADREAD.M1 & 136 & REGULATION_OF_TRANSCRIPTION_FACTOR_ACTIVITY & 0.001931301 \\
\hline COADREAD.M1 & 136 & RESPONSE_TO_STEROID_HORMONE_STIMULUS & 0.002011569 \\
\hline COADREAD.M1 & 136 & VESICLE_LOCALIZATION & 0.002011569 \\
\hline COADREAD.M1 & 136 & NOTCH_SIGNALING_PATHWAY & 0.002404122 \\
\hline COADREAD.M1 & 136 & REGULATION_OF_DNA_BINDING & 0.00307146 \\
\hline
\end{tabular}


bioRxiv preprint doi: https://doi.org/10.1101/028415; this version posted October 5, 2015. The copyright holder for this preprint (which was not certified by peer review) is the author/funder, who has granted bioRxiv a license to display the preprint in perpetuity. It is made available under aCC-BY-NC-ND 4.0 International license.

\begin{tabular}{|c|c|c|c|}
\hline $\begin{array}{l}\text { module } \\
\text { name }\end{array}$ & $\begin{array}{l}\text { module } \\
\text { size }\end{array}$ & MSigDB.c5.bp (v3.1, Top10 is shown) & $\begin{array}{l}\text { hypergeometric } \\
\text { p-value }\end{array}$ \\
\hline COADREAD.M2 & 573 & CHROMOSOME_CONDENSATION & 8.44E-05 \\
\hline COADREAD.M2 & 573 & GLAND_DEVELOPMENT & 0.000269985 \\
\hline COADREAD.M2 & 573 & $\begin{array}{l}\text { TRANSMEMBRANE_RECEPTOR_PROTEIN_TYROSINE_KINASE_SIGNALIN } \\
\text { G_PATHWAY }\end{array}$ & 0.000307092 \\
\hline COADREAD.M2 & 573 & CELL_PROJECTION_BIOGENESIS & 0.000406198 \\
\hline COADREAD.M2 & 573 & ACTIN_CYTOSKELETON_ORGANIZATION_AND_BIOGENESIS & 0.000417593 \\
\hline COADREAD.M2 & 573 & $\begin{array}{l}\text { MICROTUBULE_ORGANIZING_CENTER_ORGANIZATION_AND_BIOGENESI } \\
\mathrm{S}\end{array}$ & 0.000645798 \\
\hline COADREAD.M2 & 573 & ORGANELLE_ORGANIZATION_AND_BIOGENESIS & 0.000714211 \\
\hline COADREAD.M2 & 573 & ACTIN_FILAMENT_BASED_PROCESS & 0.000856578 \\
\hline COADREAD.M2 & 573 & LIPID_BIOSYNTHETIC_PROCESS & 0.000968958 \\
\hline COADREAD.M2 & 573 & ESTABLISHMENT_OF_ORGANELLE_LOCALIZATION & 0.001041795 \\
\hline COADREAD.M3 & 321 & MULTICELLULAR_ORGANISMAL_DEVELOPMENT & $1.35 \mathrm{E}-13$ \\
\hline COADREAD.M3 & 321 & ANATOMICAL_STRUCTURE_DEVELOPMENT & $1.41 \mathrm{E}-13$ \\
\hline COADREAD.M3 & 321 & SYSTEM_DEVELOPMENT & 1.83E-12 \\
\hline COADREAD.M3 & 321 & ORGAN_DEVELOPMENT & $8.79 \mathrm{E}-11$ \\
\hline COADREAD.M3 & 321 & MUSCLE_DEVELOPMENT & $1.13 \mathrm{E}-07$ \\
\hline COADREAD.M3 & 321 & ANATOMICAL_STRUCTURE_MORPHOGENESIS & 1.81E-07 \\
\hline COADREAD.M3 & 321 & ORGAN_MORPHOGENESIS & $1.41 \mathrm{E}-06$ \\
\hline COADREAD.M3 & 321 & ACTIN_CYTOSKELETON_ORGANIZATION_AND_BIOGENESIS & $3.22 \mathrm{E}-06$ \\
\hline COADREAD.M3 & 321 & ACTIN_FILAMENT_BASED_PROCESS & 7.33E-06 \\
\hline COADREAD.M3 & 321 & POSITIVE_REGULATION_OF_DNA_METABOLIC_PROCESS & $1.35 \mathrm{E}-05$ \\
\hline COADREAD.M4 & 184 & IMMUNE_SYSTEM_PROCESS & $7.55 \mathrm{E}-14$ \\
\hline COADREAD.M4 & 184 & IMMUNE_RESPONSE & $1.39 \mathrm{E}-09$ \\
\hline COADREAD.M4 & 184 & LEUKOCYTE_ACTIVATION & $6.06 \mathrm{E}-09$ \\
\hline COADREAD.M4 & 184 & DEFENSE_RESPONSE & $9.19 \mathrm{E}-09$ \\
\hline COADREAD.M4 & 184 & CELL_ACTIVATION & 1.63E-08 \\
\hline COADREAD.M4 & 184 & LYMPHOCYTE_ACTIVATION & 4.15E-08 \\
\hline COADREAD.M4 & 184 & T_CELL_ACTIVATION & 7.53E-08 \\
\hline COADREAD.M4 & 184 & REGULATION_OF_IMMUNE_SYSTEM_PROCESS & 8.80E-08 \\
\hline
\end{tabular}


bioRxiv preprint doi: https://doi.org/10.1101/028415; this version posted October 5, 2015. The copyright holder for this preprint (which was not certified by peer review) is the author/funder, who has granted bioRxiv a license to display the preprint in perpetuity. It is made available under aCC-BY-NC-ND 4.0 International license.

\begin{tabular}{|c|c|c|c|}
\hline $\begin{array}{l}\text { module } \\
\text { name }\end{array}$ & $\begin{array}{l}\text { module } \\
\text { size }\end{array}$ & MSigDB.c5.bp (v3.1, Top10 is shown) & $\begin{array}{l}\text { hypergeometric } \\
\text { p-value }\end{array}$ \\
\hline COADREAD.M4 & 184 & SIGNAL_TRANSDUCTION & $2.21 \mathrm{E}-07$ \\
\hline COADREAD.M4 & 184 & RESPONSE_TO_BIOTIC_STIMULUS & $7.75 \mathrm{E}-07$ \\
\hline COADREAD.M6 & 75 & SMOOTH_MUSCLE_CONTRACTION_GO_0006939 & 8.19E-06 \\
\hline COADREAD.M6 & 75 & SYSTEM_PROCESS & $2.07 \mathrm{E}-05$ \\
\hline COADREAD.M6 & 75 & MYOBLAST_DIFFERENTIATION & $2.50 \mathrm{E}-05$ \\
\hline COADREAD.M6 & 75 & ACTIN_CYTOSKELETON_ORGANIZATION_AND_BIOGENESIS & $2.98 \mathrm{E}-05$ \\
\hline COADREAD.M6 & 75 & REGULATION_OF_MUSCLE_CONTRACTION & $3.55 \mathrm{E}-05$ \\
\hline COADREAD.M6 & 75 & ACTIN_FILAMENT_BASED_PROCESS & 4.61E-05 \\
\hline COADREAD.M6 & 75 & MUSCLE_CELL_DIFFERENTIATION & $5.59 \mathrm{E}-05$ \\
\hline COADREAD.M6 & 75 & CYTOSKELETON_ORGANIZATION_AND_BIOGENESIS & $7.78 \mathrm{E}-05$ \\
\hline COADREAD.M6 & 75 & SKELETAL_MUSCLE_DEVELOPMENT & 0.000159698 \\
\hline COADREAD.M6 & 75 & MUSCLE_DEVELOPMENT & 0.000289133 \\
\hline COADREAD.M7 & 104 & NEGATIVE_REGULATION_OF_PHOSPHORYLATION & $2.27 \mathrm{E}-07$ \\
\hline COADREAD.M7 & 104 & NEGATIVE_REGULATION_OF_PHOSPHATE_METABOLIC_PROCESS & $3.26 \mathrm{E}-07$ \\
\hline COADREAD.M7 & 104 & MULTICELLULAR_ORGANISMAL_DEVELOPMENT & $1.91 \mathrm{E}-06$ \\
\hline COADREAD.M7 & 104 & NEGATIVE_REGULATION_OF_CELL_CYCLE & $2.03 \mathrm{E}-06$ \\
\hline COADREAD.M7 & 104 & CELL_CYCLE_ARREST_GO_0007050 & $7.38 \mathrm{E}-06$ \\
\hline COADREAD.M7 & 104 & ANATOMICAL_STRUCTURE_DEVELOPMENT & $2.13 \mathrm{E}-05$ \\
\hline COADREAD.M7 & 104 & REGULATION_OF_NEUROGENESIS & $3.60 \mathrm{E}-05$ \\
\hline COADREAD.M7 & 104 & GENERATION_OF_NEURONS & 4.64E-05 \\
\hline COADREAD.M7 & 104 & AXONOGENESIS & $5.05 \mathrm{E}-05$ \\
\hline COADREAD.M7 & 104 & SYSTEM_DEVELOPMENT & $5.38 \mathrm{E}-05$ \\
\hline COADREAD.M8 & 58 & PEPTIDE_METABOLIC_PROCESS & 0.000303244 \\
\hline COADREAD.M8 & 58 & FATTY_ACID_BETA_OXIDATION & 0.000370003 \\
\hline COADREAD.M8 & 58 & REGULATION_OF_JNK_CASCADE & 0.000443252 \\
\hline
\end{tabular}


bioRxiv preprint doi: https://doi.org/10.1101/028415; this version posted October 5, 2015. The copyright holder for this preprint (which was not certified by peer review) is the author/funder, who has granted bioRxiv a license to display the preprint in perpetuity. It is made available under aCC-BY-NC-ND 4.0 International license.

\begin{tabular}{|c|c|c|c|}
\hline $\begin{array}{l}\text { module } \\
\text { name }\end{array}$ & $\begin{array}{l}\text { module } \\
\text { size }\end{array}$ & MSigDB.c5.bp (v3.1, Top10 is shown) & $\begin{array}{l}\text { hypergeometric } \\
\text { p-value }\end{array}$ \\
\hline COADREAD.M8 & 58 & MEIOTIC_RECOMBINATION & 0.000905659 \\
\hline COADREAD.M8 & 58 & FATTY_ACID_OXIDATION & 0.001017142 \\
\hline COADREAD.M8 & 58 & MEIOSIS_I & 0.001258847 \\
\hline COADREAD.M8 & 58 & REGULATION_OF_MAPKKK_CASCADE & 0.001258847 \\
\hline COADREAD.M8 & 58 & CHROMOSOME_SEGREGATION & 0.003220225 \\
\hline COADREAD.M8 & 58 & MEIOTIC_CELL_CYCLE & 0.003843446 \\
\hline COADREAD.M8 & 58 & CELLULAR_LIPID_CATABOLIC_PROCESS & 0.003843446 \\
\hline COADREAD.M9 & 149 & SYSTEM_DEVELOPMENT & $3.81 \mathrm{E}-09$ \\
\hline COADREAD.M9 & 149 & ANATOMICAL_STRUCTURE_DEVELOPMENT & $4.38 \mathrm{E}-09$ \\
\hline COADREAD.M9 & 149 & MULTICELLULAR_ORGANISMAL_DEVELOPMENT & 8.98E-09 \\
\hline COADREAD.M9 & 149 & ORGAN_DEVELOPMENT & 3.50E-07 \\
\hline COADREAD.M9 & 149 & CELL_CELL_SIGNALING & 2.06E-05 \\
\hline COADREAD.M9 & 149 & BONE_REMODELING & $4.21 \mathrm{E}-05$ \\
\hline COADREAD.M9 & 149 & TISSUE_DEVELOPMENT & 4.39E-05 \\
\hline COADREAD.M9 & 149 & TISSUE_REMODELING & 4.83E-05 \\
\hline COADREAD.M9 & 149 & VIRAL_INFECTIOUS_CYCLE & $6.27 \mathrm{E}-05$ \\
\hline COADREAD.M9 & 149 & REGULATION_OF_VIRAL_REPRODUCTION & 6.40E-05 \\
\hline COADREAD.M10 & 665 & SYNAPSE_ORGANIZATION_AND_BIOGENESIS & $4.78 \mathrm{E}-10$ \\
\hline COADREAD.M10 & 665 & SYNAPTOGENESIS & $7.61 \mathrm{E}-10$ \\
\hline COADREAD.M10 & 665 & EXTRACELLULAR_STRUCTURE_ORGANIZATION_AND_BIOGENESIS & $2.11 \mathrm{E}-08$ \\
\hline COADREAD.M10 & 665 & CELL_CELL_SIGNALING & 4.49E-05 \\
\hline COADREAD.M10 & 665 & $\begin{array}{l}\text { REGULATION_OF_CELLULAR_COMPONENT_ORGANIZATION_AND_BIOGE } \\
\text { NESIS }\end{array}$ & 0.000107599 \\
\hline COADREAD.M10 & 665 & GENERATION_OF_A_SIGNAL_INVOLVED_IN_CELL_CELL_SIGNALING & 0.000195535 \\
\hline COADREAD.M10 & 665 & TRANSMISSION_OF_NERVE_IMPULSE & 0.000211834 \\
\hline COADREAD.M10 & 665 & SYNAPTIC_TRANSMISSION & 0.000271751 \\
\hline COADREAD.M10 & 665 & SYSTEM_PROCESS & 0.000517515 \\
\hline COADREAD.M10 & 665 & REGULATION_OF_HORMONE_SECRETION & 0.000650164 \\
\hline
\end{tabular}


bioRxiv preprint doi: https://doi.org/10.1101/028415; this version posted October 5, 2015. The copyright holder for this preprint (which was not certified by peer review) is the author/funder, who has granted bioRxiv a license to display the preprint in perpetuity. It is made available under aCC-BY-NC-ND 4.0 International license.

\begin{tabular}{|c|c|c|c|}
\hline $\begin{array}{l}\text { module } \\
\text { name }\end{array}$ & $\begin{array}{l}\text { module } \\
\text { size }\end{array}$ & MSigDB.c5.bp (v3.1, Top10 is shown) & $\begin{array}{l}\text { hypergeometric } \\
\text { p-value }\end{array}$ \\
\hline COADREAD.M11 & 210 & IMMUNE_SYSTEM_PROCESS & $1.08 \mathrm{E}-20$ \\
\hline COADREAD.M11 & 210 & IMMUNE_RESPONSE & $5.78 \mathrm{E}-18$ \\
\hline COADREAD.M11 & 210 & DEFENSE_RESPONSE & $1.43 \mathrm{E}-16$ \\
\hline COADREAD.M11 & 210 & RESPONSE_TO_EXTERNAL_STIMULUS & $2.34 \mathrm{E}-11$ \\
\hline COADREAD.M11 & 210 & INFLAMMATORY_RESPONSE & $2.51 \mathrm{E}-11$ \\
\hline COADREAD.M11 & 210 & RESPONSE_TO_WOUNDING & 4.57E-10 \\
\hline COADREAD.M11 & 210 & RESPONSE_TO_VIRUS & $9.89 \mathrm{E}-10$ \\
\hline COADREAD.M11 & 210 & SIGNAL_TRANSDUCTION & $3.02 \mathrm{E}-09$ \\
\hline COADREAD.M11 & 210 & LOCOMOTORY_BEHAVIOR & $2.53 \mathrm{E}-08$ \\
\hline COADREAD.M11 & 210 & MULTI_ORGANISM_PROCESS & $6.56 \mathrm{E}-08$ \\
\hline LUSC.M1 & 131 & PEPTIDE_METABOLIC_PROCESS & 0.001534666 \\
\hline LUSC.M1 & 131 & FATTY_ACID_BETA_OXIDATION & 0.001868397 \\
\hline LUSC.M1 & 131 & DIGESTION & 0.002286341 \\
\hline LUSC.M1 & 131 & CELL_MATURATION & 0.003997835 \\
\hline LUSC.M1 & 131 & MEIOTIC_RECOMBINATION & 0.004513281 \\
\hline LUSC.M1 & 131 & POTASSIUM_ION_TRANSPORT & 0.005014208 \\
\hline LUSC.M1 & 131 & DEVELOPMENTAL_MATURATION & 0.005057728 \\
\hline LUSC.M1 & 131 & FATTY_ACID_OXIDATION & 0.005057728 \\
\hline LUSC.M1 & 131 & DETECTION_OF_CHEMICAL_STIMULUS & 0.005057728 \\
\hline LUSC.M1 & 131 & MEIOSIS_I & 0.006232196 \\
\hline LUSC.M2 & 646 & MULTICELLULAR_ORGANISMAL_DEVELOPMENT & $1.55 \mathrm{E}-23$ \\
\hline LUSC.M2 & 646 & ANATOMICAL_STRUCTURE_DEVELOPMENT & $2.51 \mathrm{E}-22$ \\
\hline LUSC.M2 & 646 & SYSTEM_DEVELOPMENT & 8.13E-22 \\
\hline LUSC.M2 & 646 & ORGAN_DEVELOPMENT & $4.13 \mathrm{E}-17$ \\
\hline LUSC.M2 & 646 & SKELETAL_DEVELOPMENT & $2.25 \mathrm{E}-13$ \\
\hline LUSC.M2 & 646 & NERVOUS_SYSTEM_DEVELOPMENT & $1.32 \mathrm{E}-08$ \\
\hline LUSC.M2 & 646 & ANATOMICAL_STRUCTURE_MORPHOGENESIS & $2.52 \mathrm{E}-08$ \\
\hline LUSC.M2 & 646 & MUSCLE_DEVELOPMENT & $5.38 \mathrm{E}-07$ \\
\hline
\end{tabular}


bioRxiv preprint doi: https://doi.org/10.1101/028415; this version posted October 5, 2015. The copyright holder for this preprint (which was not certified by peer review) is the author/funder, who has granted bioRxiv a license to display the preprint in perpetuity. It is made available under aCC-BY-NC-ND 4.0 International license.

\begin{tabular}{|c|c|c|c|}
\hline $\begin{array}{l}\text { module } \\
\text { name }\end{array}$ & $\begin{array}{l}\text { module } \\
\text { size }\end{array}$ & MSigDB.c5.bp (v3.1, Top10 is shown) & $\begin{array}{l}\text { hypergeometric } \\
\text { p-value }\end{array}$ \\
\hline LUSC.M2 & 646 & CELL_MATRIX_ADHESION & 1.17E-06 \\
\hline LUSC.M2 & 646 & CELL_SUBSTRATE_ADHESION & $1.48 \mathrm{E}-06$ \\
\hline LUSC.M3 & 622 & ECTODERM_DEVELOPMENT & $5.98 \mathrm{E}-21$ \\
\hline LUSC.M3 & 622 & TISSUE_DEVELOPMENT & $1.96 \mathrm{E}-17$ \\
\hline LUSC.M3 & 622 & EPIDERMIS_DEVELOPMENT & $2.01 \mathrm{E}-17$ \\
\hline LUSC.M3 & 622 & ANATOMICAL_STRUCTURE_DEVELOPMENT & $4.59 \mathrm{E}-12$ \\
\hline LUSC.M3 & 622 & ORGAN_DEVELOPMENT & $6.38 \mathrm{E}-11$ \\
\hline LUSC.M3 & 622 & SYSTEM_DEVELOPMENT & $3.47 \mathrm{E}-10$ \\
\hline LUSC.M3 & 622 & MULTICELLULAR_ORGANISMAL_DEVELOPMENT & $4.04 \mathrm{E}-10$ \\
\hline LUSC.M3 & 622 & KERATINOCYTE_DIFFERENTIATION & 2.01E-06 \\
\hline LUSC.M3 & 622 & $\begin{array}{l}\text { CELL_SURFACE_RECEPTOR_LINKED_SIGNAL_TRANSDUCTION_GO_0007 } \\
166\end{array}$ & 2.83E-06 \\
\hline LUSC.M3 & 622 & MORPHOGENESIS_OF_AN_EPITHELIUM & $3.13 \mathrm{E}-06$ \\
\hline LUSC.M4 & 219 & CARBOXYLIC_ACID_METABOLIC_PROCESS & $1.80 \mathrm{E}-06$ \\
\hline LUSC.M4 & 219 & COENZYME_BIOSYNTHETIC_PROCESS & $1.91 \mathrm{E}-06$ \\
\hline LUSC.M4 & 219 & ORGANIC_ACID_METABOLIC_PROCESS & $2.00 \mathrm{E}-06$ \\
\hline LUSC.M4 & 219 & RESPONSE_TO_CHEMICAL_STIMULUS & 3.47E-06 \\
\hline LUSC.M4 & 219 & GLUCOSE_METABOLIC_PROCESS & 7.61E-06 \\
\hline LUSC.M4 & 219 & CARBOHYDRATE_METABOLIC_PROCESS & $1.36 \mathrm{E}-05$ \\
\hline LUSC.M4 & 219 & RESPONSE_TO_HORMONE_STIMULUS & $1.77 \mathrm{E}-05$ \\
\hline LUSC.M4 & 219 & MYOBLAST_DIFFERENTIATION & $2.05 \mathrm{E}-05$ \\
\hline LUSC.M4 & 219 & MONOCARBOXYLIC_ACID_METABOLIC_PROCESS & $2.82 \mathrm{E}-05$ \\
\hline LUSC.M4 & 219 & COENZYME_METABOLIC_PROCESS & $3.59 \mathrm{E}-05$ \\
\hline LUSC.M6 & 69 & NEUROTRANSMITTER_SECRETION & 0.000739482 \\
\hline LUSC.M6 & 69 & REGULATED_SECRETORY_PATHWAY & 0.000991429 \\
\hline LUSC.M6 & 69 & REGULATION_OF_NEUROTRANSMITTER_LEVELS & 0.002558979 \\
\hline
\end{tabular}


bioRxiv preprint doi: https://doi.org/10.1101/028415; this version posted October 5, 2015. The copyright holder for this preprint (which was not certified by peer review) is the author/funder, who has granted bioRxiv a license to display the preprint in perpetuity. It is made available under aCC-BY-NC-ND 4.0 International license.

\begin{tabular}{|c|c|c|c|}
\hline $\begin{array}{l}\text { module } \\
\text { name }\end{array}$ & $\begin{array}{l}\text { module } \\
\text { size }\end{array}$ & MSigDB.c5.bp (v3.1, Top10 is shown) & $\begin{array}{l}\text { hypergeometric } \\
\text { p-value }\end{array}$ \\
\hline LUSC.M6 & 69 & REGULATION_OF_HEART_CONTRACTION & 0.002775878 \\
\hline LUSC.M6 & 69 & GENERATION_OF_A_SIGNAL_INVOLVED_IN_CELL_CELL_SIGNALING & 0.003726435 \\
\hline LUSC.M6 & 69 & DIGESTION & 0.008423994 \\
\hline LUSC.M6 & 69 & SEXUAL_REPRODUCTION & 0.009543131 \\
\hline LUSC.M6 & 69 & REPRODUCTION & 0.00964598 \\
\hline LUSC.M6 & 69 & FEMALE_PREGNANCY & 0.012050729 \\
\hline LUSC.M6 & 69 & POTASSIUM_ION_TRANSPORT & 0.014311191 \\
\hline LUSC.M7 & 136 & EXCRETION & $2.71 \mathrm{E}-06$ \\
\hline LUSC.M7 & 136 & ESTABLISHMENT_OF_LOCALIZATION & $2.71 \mathrm{E}-05$ \\
\hline LUSC.M7 & 136 & TRANSPORT & 3.34E-05 \\
\hline LUSC.M7 & 136 & RESPIRATORY_GASEOUS_EXCHANGE & $8.00 \mathrm{E}-05$ \\
\hline LUSC.M7 & 136 & ION_TRANSPORT & 0.00015554 \\
\hline LUSC.M7 & 136 & INORGANIC_ANION_TRANSPORT & 0.00017616 \\
\hline LUSC.M7 & 136 & CALCIUM_INDEPENDENT_CELL_CELL_ADHESION & 0.000326495 \\
\hline LUSC.M7 & 136 & RESPONSE_TO_DRUG & 0.000326495 \\
\hline LUSC.M7 & 136 & INNATE_IMMUNE_RESPONSE & 0.000373776 \\
\hline LUSC.M7 & 136 & REGULATION_OF_HEART_CONTRACTION & 0.000481055 \\
\hline LUSC.M8 & 675 & DEFENSE_RESPONSE & $2.15 \mathrm{E}-31$ \\
\hline LUSC.M8 & 675 & IMMUNE_SYSTEM_PROCESS & $4.32 \mathrm{E}-29$ \\
\hline LUSC.M8 & 675 & IMMUNE_RESPONSE & 7.35E-27 \\
\hline LUSC.M8 & 675 & RESPONSE_TO_EXTERNAL_STIMULUS & $3.52 \mathrm{E}-26$ \\
\hline LUSC.M8 & 675 & RESPONSE_TO_WOUNDING & $2.37 \mathrm{E}-21$ \\
\hline LUSC.M8 & 675 & INFLAMMATORY_RESPONSE & $2.48 \mathrm{E}-18$ \\
\hline LUSC.M8 & 675 & SIGNAL_TRANSDUCTION & $6.51 \mathrm{E}-17$ \\
\hline LUSC.M8 & 675 & LOCOMOTORY_BEHAVIOR & $7.09 \mathrm{E}-17$ \\
\hline LUSC.M8 & 675 & BEHAVIOR & $1.72 \mathrm{E}-13$ \\
\hline LUSC.M8 & 675 & $\begin{array}{l}\text { CELL_SURFACE_RECEPTOR_LINKED_SIGNAL_TRANSDUCTION_GO_0007 } \\
166\end{array}$ & $2.14 \mathrm{E}-11$ \\
\hline
\end{tabular}


bioRxiv preprint doi: https://doi.org/10.1101/028415; this version posted October 5, 2015. The copyright holder for this preprint (which was not certified by peer review) is the author/funder, who has granted bioRxiv a license to display the preprint in perpetuity. It is made available under aCC-BY-NC-ND 4.0 International license.

\begin{tabular}{|c|c|c|c|}
\hline $\begin{array}{l}\text { module } \\
\text { name }\end{array}$ & $\begin{array}{l}\text { module } \\
\text { size }\end{array}$ & MSigDB.c5.bp (v3.1, Top10 is shown) & $\begin{array}{l}\text { hypergeometric } \\
\text { p-value }\end{array}$ \\
\hline LUSC.M9 & 427 & IMMUNE_SYSTEM_PROCESS & $8.15 \mathrm{E}-31$ \\
\hline LUSC.M9 & 427 & IMMUNE_RESPONSE & $5.43 \mathrm{E}-24$ \\
\hline LUSC.M9 & 427 & DEFENSE_RESPONSE & 7.93E-21 \\
\hline LUSC.M9 & 427 & LYMPHOCYTE_ACTIVATION & $2.80 \mathrm{E}-14$ \\
\hline LUSC.M9 & 427 & SIGNAL_TRANSDUCTION & $3.13 \mathrm{E}-14$ \\
\hline LUSC.M9 & 427 & LEUKOCYTE_ACTIVATION & $2.29 \mathrm{E}-13$ \\
\hline LUSC.M9 & 427 & T_CELL_ACTIVATION & $1.39 \mathrm{E}-12$ \\
\hline LUSC.M9 & 427 & CELL_ACTIVATION & $1.42 \mathrm{E}-12$ \\
\hline LUSC.M9 & 427 & CELLULAR_DEFENSE_RESPONSE & $6.61 \mathrm{E}-11$ \\
\hline LUSC.M9 & 427 & LOCOMOTORY_BEHAVIOR & $4.38 \mathrm{E}-10$ \\
\hline BRCA.M1 & 40 & RESPONSE_TO_VIRUS & 2.03E-06 \\
\hline BRCA.M1 & 40 & IMMUNE_RESPONSE & 3.95E-06 \\
\hline BRCA.M1 & 40 & RESPONSE_TO_OTHER_ORGANISM & $1.55 \mathrm{E}-05$ \\
\hline BRCA.M1 & 40 & IMMUNE_SYSTEM_PROCESS & 2.81E-05 \\
\hline BRCA.M1 & 40 & I_KAPPAB_KINASE_NF_KAPPAB_CASCADE & $5.41 \mathrm{E}-05$ \\
\hline BRCA.M1 & 40 & RESPONSE_TO_BIOTIC_STIMULUS & $6.61 \mathrm{E}-05$ \\
\hline BRCA.M1 & 40 & DEFENSE_RESPONSE & 0.000124237 \\
\hline BRCA.M1 & 40 & SENSORY_PERCEPTION_OF_TASTE & 0.000175453 \\
\hline BRCA.M1 & 40 & APOPTOTIC_MITOCHONDRIAL_CHANGES & 0.000175453 \\
\hline BRCA.M1 & 40 & APOPTOTIC_PROGRAM & 0.000177326 \\
\hline BRCA.M2 & 641 & ANATOMICAL_STRUCTURE_DEVELOPMENT & $5.38 \mathrm{E}-22$ \\
\hline BRCA.M2 & 641 & MULTICELLULAR_ORGANISMAL_DEVELOPMENT & 1.63E-21 \\
\hline BRCA.M2 & 641 & SYSTEM_DEVELOPMENT & $1.08 \mathrm{E}-19$ \\
\hline BRCA.M2 & 641 & ORGAN_DEVELOPMENT & $1.19 \mathrm{E}-16$ \\
\hline BRCA.M2 & 641 & SKELETAL_DEVELOPMENT & $1.89 \mathrm{E}-15$ \\
\hline BRCA.M2 & 641 & SYNAPTOGENESIS & $1.68 \mathrm{E}-08$ \\
\hline BRCA.M2 & 641 & ANATOMICAL_STRUCTURE_MORPHOGENESIS & 7.02E-08 \\
\hline
\end{tabular}


bioRxiv preprint doi: https://doi.org/10.1101/028415; this version posted October 5, 2015. The copyright holder for this preprint (which was not certified by peer review) is the author/funder, who has granted bioRxiv a license to display the preprint in perpetuity. It is made available under aCC-BY-NC-ND 4.0 International license.

\begin{tabular}{|c|c|c|c|}
\hline $\begin{array}{l}\text { module } \\
\text { name }\end{array}$ & $\begin{array}{l}\text { module } \\
\text { size }\end{array}$ & MSigDB.c5.bp (v3.1, Top10 is shown) & $\begin{array}{l}\text { hypergeometric } \\
\text { p-value }\end{array}$ \\
\hline BRCA.M2 & 641 & TISSUE_DEVELOPMENT & $1.13 \mathrm{E}-07$ \\
\hline BRCA.M2 & 641 & CELL_CELL_SIGNALING & $1.15 \mathrm{E}-07$ \\
\hline BRCA.M2 & 641 & SYNAPSE_ORGANIZATION_AND_BIOGENESIS & $1.66 \mathrm{E}-07$ \\
\hline BRCA.M3 & 385 & IMMUNE_SYSTEM_PROCESS & $6.47 \mathrm{E}-31$ \\
\hline BRCA.M3 & 385 & IMMUNE_RESPONSE & 4.64E-30 \\
\hline BRCA.M3 & 385 & DEFENSE_RESPONSE & $1.37 \mathrm{E}-17$ \\
\hline BRCA.M3 & 385 & LOCOMOTORY_BEHAVIOR & $1.04 \mathrm{E}-10$ \\
\hline BRCA.M3 & 385 & INFLAMMATORY_RESPONSE & $1.13 \mathrm{E}-10$ \\
\hline BRCA.M3 & 385 & RESPONSE_TO_WOUNDING & $1.61 \mathrm{E}-10$ \\
\hline BRCA.M3 & 385 & CELLULAR_DEFENSE_RESPONSE & $3.01 \mathrm{E}-10$ \\
\hline BRCA.M3 & 385 & RESPONSE_TO_EXTERNAL_STIMULUS & $3.06 \mathrm{E}-10$ \\
\hline BRCA.M3 & 385 & SIGNAL_TRANSDUCTION & $3.51 \mathrm{E}-10$ \\
\hline BRCA.M3 & 385 & CELLULAR_CATION_HOMEOSTASIS & 4.91E-09 \\
\hline BRCA.M4 & 170 & REGULATION_OF_BODY_FLUID_LEVELS & $2.78 \mathrm{E}-07$ \\
\hline BRCA.M4 & 170 & BLOOD_COAGULATION & $9.37 \mathrm{E}-07$ \\
\hline BRCA.M4 & 170 & COAGULATION & $1.08 \mathrm{E}-06$ \\
\hline BRCA.M4 & 170 & HEMOSTASIS & $1.83 \mathrm{E}-06$ \\
\hline BRCA.M4 & 170 & RESPONSE_TO_WOUNDING & $2.34 \mathrm{E}-06$ \\
\hline BRCA.M4 & 170 & WOUND_HEALING & 3.70E-06 \\
\hline BRCA.M4 & 170 & RESPONSE_TO_EXTERNAL_STIMULUS & $5.95 \mathrm{E}-06$ \\
\hline BRCA.M4 & 170 & MULTICELLULAR_ORGANISMAL_DEVELOPMENT & $2.04 \mathrm{E}-05$ \\
\hline BRCA.M4 & 170 & ORGAN_DEVELOPMENT & $3.91 \mathrm{E}-05$ \\
\hline BRCA.M4 & 170 & GENERATION_OF_PRECURSOR_METABOLITES_AND_ENERGY & 4.87E-05 \\
\hline BRCA.M6 & 128 & CERAMIDE_METABOLIC_PROCESS & 3.07E-05 \\
\hline BRCA.M6 & 128 & GLYCOSPHINGOLIPID_METABOLIC_PROCESS & 4.07E-05 \\
\hline BRCA.M6 & 128 & SPHINGOID_METABOLIC_PROCESS & 4.07E-05 \\
\hline
\end{tabular}


bioRxiv preprint doi: https://doi.org/10.1101/028415; this version posted October 5, 2015. The copyright holder for this preprint (which was not certified by peer review) is the author/funder, who has granted bioRxiv a license to display the preprint in perpetuity. It is made available under aCC-BY-NC-ND 4.0 International license.

\begin{tabular}{|c|c|c|c|}
\hline $\begin{array}{l}\text { module } \\
\text { name }\end{array}$ & $\begin{array}{l}\text { module } \\
\text { size }\end{array}$ & MSigDB.c5.bp (v3.1, Top10 is shown) & $\begin{array}{l}\text { hypergeometric } \\
\text { p-value }\end{array}$ \\
\hline BRCA.M6 & 128 & GLYCOLIPID_METABOLIC_PROCESS & 0.000101926 \\
\hline BRCA.M6 & 128 & REGULATION_OF_NUCLEOCYTOPLASMIC_TRANSPORT & 0.000273233 \\
\hline BRCA.M6 & 128 & REGULATION_OF_INTRACELLULAR_TRANSPORT & 0.000402906 \\
\hline BRCA.M6 & 128 & SPHINGOLIPID_METABOLIC_PROCESS & 0.000629316 \\
\hline BRCA.M6 & 128 & REGULATION_OF_TRANSPORT & 0.000631171 \\
\hline BRCA.M6 & 128 & PROTEIN_AMINO_ACID_AUTOPHOSPHORYLATION & 0.000767618 \\
\hline BRCA.M6 & 128 & PROTEIN_AUTOPROCESSING & 0.000843442 \\
\hline BRCA.M7 & 1173 & MITOTIC_CELL_CYCLE & $1.30 \mathrm{E}-16$ \\
\hline BRCA.M7 & 1173 & CELL_CYCLE_GO_0007049 & $1.44 \mathrm{E}-15$ \\
\hline BRCA.M7 & 1173 & CELL_CYCLE_PROCESS & $1.97 \mathrm{E}-14$ \\
\hline BRCA.M7 & 1173 & M_PHASE_OF_MITOTIC_CELL_CYCLE & $1.47 \mathrm{E}-13$ \\
\hline BRCA.M7 & 1173 & CELL_CYCLE_PHASE & $1.67 \mathrm{E}-13$ \\
\hline BRCA.M7 & 1173 & M_PHASE & $1.70 \mathrm{E}-13$ \\
\hline BRCA.M7 & 1173 & MITOSIS & $4.68 \mathrm{E}-13$ \\
\hline BRCA.M7 & 1173 & REGULATION_OF_CELL_CYCLE & $2.32 \mathrm{E}-09$ \\
\hline BRCA.M7 & 1173 & REGULATION_OF_MITOSIS & $1.26 \mathrm{E}-08$ \\
\hline BRCA.M7 & 1173 & RESPONSE_TO_STEROID_HORMONE_STIMULUS & $3.29 \mathrm{E}-07$ \\
\hline BRCA.M8 & 320 & IMMUNE_SYSTEM_PROCESS & $5.08 \mathrm{E}-22$ \\
\hline BRCA.M8 & 320 & DEFENSE_RESPONSE & $5.56 \mathrm{E}-19$ \\
\hline BRCA.M8 & 320 & IMMUNE_RESPONSE & $1.11 \mathrm{E}-16$ \\
\hline BRCA.M8 & 320 & SIGNAL_TRANSDUCTION & $6.27 \mathrm{E}-15$ \\
\hline BRCA.M8 & 320 & RESPONSE_TO_EXTERNAL_STIMULUS & $3.69 \mathrm{E}-11$ \\
\hline BRCA.M8 & 320 & INFLAMMATORY_RESPONSE & $6.69 \mathrm{E}-10$ \\
\hline BRCA.M8 & 320 & CYTOKINE_PRODUCTION & $8.29 \mathrm{E}-09$ \\
\hline BRCA.M8 & 320 & RESPONSE_TO_WOUNDING & 2.03E-08 \\
\hline BRCA.M8 & 320 & MULTI_ORGANISM_PROCESS & $1.43 \mathrm{E}-07$ \\
\hline BRCA.M8 & 320 & POSITIVE_REGULATION_OF_BIOLOGICAL_PROCESS & $1.90 \mathrm{E}-07$ \\
\hline HNSC.M1 & 137 & STRIATED_MUSCLE_CONTRACTION_GO_0006941 & $1.51 \mathrm{E}-10$ \\
\hline
\end{tabular}


bioRxiv preprint doi: https://doi.org/10.1101/028415; this version posted October 5, 2015. The copyright holder for this preprint (which was not certified by peer review) is the author/funder, who has granted bioRxiv a license to display the preprint in perpetuity. It is made available under aCC-BY-NC-ND 4.0 International license.

\begin{tabular}{|c|c|c|c|}
\hline $\begin{array}{l}\text { module } \\
\text { name }\end{array}$ & $\begin{array}{l}\text { module } \\
\text { size }\end{array}$ & MSigDB.c5.bp (v3.1, Top10 is shown) & $\begin{array}{l}\text { hypergeometric } \\
\text { p-value }\end{array}$ \\
\hline HNSC.M1 & 137 & MUSCLE_DEVELOPMENT & $6.67 \mathrm{E}-09$ \\
\hline HNSC.M1 & 137 & SYSTEM_PROCESS & $1.41 \mathrm{E}-08$ \\
\hline HNSC.M1 & 137 & ION_TRANSPORT & 0.000162766 \\
\hline HNSC.M1 & 137 & ANATOMICAL_STRUCTURE_DEVELOPMENT & 0.000190506 \\
\hline HNSC.M1 & 137 & REGULATION_OF_MUSCLE_CONTRACTION & 0.000212791 \\
\hline HNSC.M1 & 137 & CARBOHYDRATE_TRANSPORT & 0.000212791 \\
\hline HNSC.M1 & 137 & ESTABLISHMENT_AND_OR_MAINTENANCE_OF_CELL_POLARITY & 0.000212791 \\
\hline HNSC.M1 & 137 & ORGAN_DEVELOPMENT & 0.000243776 \\
\hline HNSC.M1 & 137 & CATION_TRANSPORT & 0.000321926 \\
\hline HNSC.M2 & 683 & ANATOMICAL_STRUCTURE_DEVELOPMENT & $1.47 \mathrm{E}-19$ \\
\hline HNSC.M2 & 683 & MULTICELLULAR_ORGANISMAL_DEVELOPMENT & $1.42 \mathrm{E}-18$ \\
\hline HNSC.M2 & 683 & SYSTEM_DEVELOPMENT & $1.65 \mathrm{E}-17$ \\
\hline HNSC.M2 & 683 & ORGAN_DEVELOPMENT & 3.70E-13 \\
\hline HNSC.M2 & 683 & SKELETAL_DEVELOPMENT & $6.85 \mathrm{E}-13$ \\
\hline HNSC.M2 & 683 & NERVOUS_SYSTEM_DEVELOPMENT & $1.57 \mathrm{E}-08$ \\
\hline HNSC.M2 & 683 & MUSCLE_DEVELOPMENT & $1.71 \mathrm{E}-07$ \\
\hline HNSC.M2 & 683 & ANATOMICAL_STRUCTURE_MORPHOGENESIS & $2.92 \mathrm{E}-07$ \\
\hline HNSC.M2 & 683 & GENERATION_OF_A_SIGNAL_INVOLVED_IN_CELL_CELL_SIGNALING & $1.99 \mathrm{E}-06$ \\
\hline HNSC.M2 & 683 & REGULATION_OF_HORMONE_SECRETION & 2.13E-06 \\
\hline HNSC.M3 & 399 & ECTODERM_DEVELOPMENT & $1.69 \mathrm{E}-10$ \\
\hline HNSC.M3 & 399 & EPIDERMIS_DEVELOPMENT & $5.24 \mathrm{E}-09$ \\
\hline HNSC.M3 & 399 & TISSUE_DEVELOPMENT & $3.34 \mathrm{E}-08$ \\
\hline HNSC.M3 & 399 & ORGAN_DEVELOPMENT & $2.21 \mathrm{E}-07$ \\
\hline HNSC.M3 & 399 & SYSTEM_DEVELOPMENT & 4.53E-07 \\
\hline HNSC.M3 & 399 & MULTICELLULAR_ORGANISMAL_DEVELOPMENT & $5.64 \mathrm{E}-07$ \\
\hline HNSC.M3 & 399 & ANATOMICAL_STRUCTURE_DEVELOPMENT & 3.58E-06 \\
\hline HNSC.M3 & 399 & FATTY_ACID_BIOSYNTHETIC_PROCESS & $9.24 \mathrm{E}-05$ \\
\hline HNSC.M3 & 399 & CYTOPLASM_ORGANIZATION_AND_BIOGENESIS & 0.000124158 \\
\hline
\end{tabular}


bioRxiv preprint doi: https://doi.org/10.1101/028415; this version posted October 5, 2015. The copyright holder for this preprint (which was not certified by peer review) is the author/funder, who has granted bioRxiv a license to display the preprint in perpetuity. It is made available under aCC-BY-NC-ND 4.0 International license.

\begin{tabular}{|c|c|c|c|}
\hline $\begin{array}{l}\text { module } \\
\text { name }\end{array}$ & $\begin{array}{l}\text { module } \\
\text { size }\end{array}$ & MSigDB.c5.bp (v3.1, Top10 is shown) & $\begin{array}{l}\text { hypergeometric } \\
\text { p-value }\end{array}$ \\
\hline HNSC.M3 & 399 & INTERLEUKIN_2_PRODUCTION & 0.000876675 \\
\hline HNSC.M4 & 233 & ANATOMICAL_STRUCTURE_DEVELOPMENT & $1.04 \mathrm{E}-05$ \\
\hline HNSC.M4 & 233 & SYSTEM_DEVELOPMENT & $1.62 \mathrm{E}-05$ \\
\hline HNSC.M4 & 233 & MULTICELLULAR_ORGANISMAL_DEVELOPMENT & 1.93E-05 \\
\hline HNSC.M4 & 233 & CELL_CELL_ADHESION & $3.61 \mathrm{E}-05$ \\
\hline HNSC.M4 & 233 & ORGAN_DEVELOPMENT & 4.09E-05 \\
\hline HNSC.M4 & 233 & SKELETAL_DEVELOPMENT & 0.000114245 \\
\hline HNSC.M4 & 233 & HETEROPHILIC_CELL_ADHESION & 0.000133208 \\
\hline HNSC.M4 & 233 & INTERCELLULAR_JUNCTION_ASSEMBLY & 0.000181729 \\
\hline HNSC.M4 & 233 & N_ACETYLGLUCOSAMINE_METABOLIC_PROCESS & 0.000240413 \\
\hline HNSC.M4 & 233 & SMOOTH_MUSCLE_CONTRACTION_GO_0006939 & 0.000240413 \\
\hline HNSC.M6 & 113 & RESPONSE_TO_VIRUS & $2.12 \mathrm{E}-07$ \\
\hline HNSC.M6 & 113 & RESPONSE_TO_OTHER_ORGANISM & 4.40E-06 \\
\hline HNSC.M6 & 113 & DEFENSE_RESPONSE & $1.09 \mathrm{E}-05$ \\
\hline HNSC.M6 & 113 & MULTI_ORGANISM_PROCESS & 2.33E-05 \\
\hline HNSC.M6 & 113 & RESPONSE_TO_BIOTIC_STIMULUS & $3.65 \mathrm{E}-05$ \\
\hline HNSC.M6 & 113 & I_KAPPAB_KINASE_NF_KAPPAB_CASCADE & 0.000307631 \\
\hline HNSC.M6 & 113 & IMMUNE_SYSTEM_PROCESS & 0.000320374 \\
\hline HNSC.M6 & 113 & ION_HOMEOSTASIS & 0.00054269 \\
\hline HNSC.M6 & 113 & REGULATION_OF_CELL_ADHESION & 0.000902707 \\
\hline HNSC.M6 & 113 & CELLULAR_HOMEOSTASIS & 0.000978858 \\
\hline HNSC.M7 & 127 & REGULATION_OF_MEMBRANE_POTENTIAL & 8.13E-05 \\
\hline HNSC.M7 & 127 & SPERMATID_DEVELOPMENT & 0.001443428 \\
\hline HNSC.M7 & 127 & PEPTIDE_METABOLIC_PROCESS & 0.001443428 \\
\hline HNSC.M7 & 127 & FATTY_ACID_BETA_OXIDATION & 0.00175753 \\
\hline HNSC.M7 & 127 & SPERMATID_DIFFERENTIATION & 0.00175753 \\
\hline
\end{tabular}


bioRxiv preprint doi: https://doi.org/10.1101/028415; this version posted October 5, 2015. The copyright holder for this preprint (which was not certified by peer review) is the author/funder, who has granted bioRxiv a license to display the preprint in perpetuity. It is made available under aCC-BY-NC-ND 4.0 International license.

\begin{tabular}{|c|c|c|c|}
\hline $\begin{array}{l}\text { module } \\
\text { name }\end{array}$ & $\begin{array}{l}\text { module } \\
\text { size }\end{array}$ & MSigDB.c5.bp (v3.1, Top10 is shown) & $\begin{array}{l}\text { hypergeometric } \\
\text { p-value }\end{array}$ \\
\hline HNSC.M7 & 127 & REGULATION_OF_ACTION_POTENTIAL & 0.004248538 \\
\hline HNSC.M7 & 127 & BASE_EXCISION_REPAIR & 0.004248538 \\
\hline HNSC.M7 & 127 & EMBRYONIC_DEVELOPMENT & 0.004599437 \\
\hline HNSC.M7 & 127 & FATTY_ACID_OXIDATION & 0.004761619 \\
\hline HNSC.M7 & 127 & DETECTION_OF_CHEMICAL_STIMULUS & 0.004761619 \\
\hline HNSC.M8 & 212 & KERATINOCYTE_DIFFERENTIATION & $1.61 \mathrm{E}-17$ \\
\hline HNSC.M8 & 212 & EPIDERMIS_DEVELOPMENT & $1.52 \mathrm{E}-13$ \\
\hline HNSC.M8 & 212 & ECTODERM_DEVELOPMENT & $7.63 \mathrm{E}-13$ \\
\hline HNSC.M8 & 212 & TISSUE_DEVELOPMENT & 7.13E-11 \\
\hline HNSC.M8 & 212 & TISSUE_MORPHOGENESIS & $7.78 \mathrm{E}-06$ \\
\hline HNSC.M8 & 212 & EMBRYO_IMPLANTATION & $7.78 \mathrm{E}-06$ \\
\hline HNSC.M8 & 212 & OVULATION_CYCLE & $7.78 \mathrm{E}-06$ \\
\hline HNSC.M8 & 212 & CYTOKINE_AND_CHEMOKINE_MEDIATED_SIGNALING_PATHWAY & $6.43 \mathrm{E}-05$ \\
\hline HNSC.M8 & 212 & MULTICELLULAR_ORGANISMAL_DEVELOPMENT & 7.96E-05 \\
\hline HNSC.M8 & 212 & EPITHELIAL_CELL_DIFFERENTIATION & 0.000100716 \\
\hline HNSC.M9 & 745 & IMMUNE_SYSTEM_PROCESS & $7.51 \mathrm{E}-33$ \\
\hline HNSC.M9 & 745 & IMMUNE_RESPONSE & $1.16 \mathrm{E}-28$ \\
\hline HNSC.M9 & 745 & DEFENSE_RESPONSE & $7.06 \mathrm{E}-16$ \\
\hline HNSC.M9 & 745 & T_CELL_ACTIVATION & $4.39 \mathrm{E}-13$ \\
\hline HNSC.M9 & 745 & LEUKOCYTE_ACTIVATION & 8.74E-13 \\
\hline HNSC.M9 & 745 & SIGNAL_TRANSDUCTION & $5.42 \mathrm{E}-12$ \\
\hline HNSC.M9 & 745 & CELL_ACTIVATION & $7.44 \mathrm{E}-12$ \\
\hline HNSC.M9 & 745 & LYMPHOCYTE_ACTIVATION & 1.13E-11 \\
\hline HNSC.M9 & 745 & RESPONSE_TO_CHEMICAL_STIMULUS & $1.82 \mathrm{E}-10$ \\
\hline HNSC.M9 & 745 & LOCOMOTORY_BEHAVIOR & $3.72 \mathrm{E}-10$ \\
\hline HNSC.M10 & 392 & IMMUNE_SYSTEM_PROCESS & 1.64E-25 \\
\hline HNSC.M10 & 392 & IMMUNE_RESPONSE & 3.63E-21 \\
\hline
\end{tabular}


bioRxiv preprint doi: https://doi.org/10.1101/028415; this version posted October 5, 2015. The copyright holder for this preprint (which was not certified by peer review) is the author/funder, who has granted bioRxiv a license to display the preprint in perpetuity. It is made available under aCC-BY-NC-ND 4.0 International license.

\begin{tabular}{|c|c|c|c|}
\hline $\begin{array}{l}\text { module } \\
\text { name }\end{array}$ & $\begin{array}{l}\text { module } \\
\text { size }\end{array}$ & MSigDB.c5.bp (v3.1, Top10 is shown) & $\begin{array}{l}\text { hypergeometric } \\
\text { p-value }\end{array}$ \\
\hline HNSC.M10 & 392 & DEFENSE_RESPONSE & $3.26 \mathrm{E}-19$ \\
\hline HNSC.M10 & 392 & SIGNAL_TRANSDUCTION & $7.11 \mathrm{E}-14$ \\
\hline HNSC.M10 & 392 & RESPONSE_TO_EXTERNAL_STIMULUS & $4.46 \mathrm{E}-10$ \\
\hline HNSC.M10 & 392 & $\begin{array}{l}\text { CELL_SURFACE_RECEPTOR_LINKED_SIGNAL_TRANSDUCTION_GO_0007 } \\
166\end{array}$ & 4.99E-09 \\
\hline HNSC.M10 & 392 & INFLAMMATORY_RESPONSE & $1.05 \mathrm{E}-08$ \\
\hline HNSC.M10 & 392 & HUMORAL_IMMUNE_RESPONSE & $6.85 \mathrm{E}-08$ \\
\hline HNSC.M10 & 392 & CELLULAR_DEFENSE_RESPONSE & 7.01E-08 \\
\hline HNSC.M10 & 392 & RESPONSE_TO_WOUNDING & $1.73 \mathrm{E}-06$ \\
\hline KIRC.M1 & 214 & ANATOMICAL_STRUCTURE_DEVELOPMENT & 4.10E-09 \\
\hline KIRC.M1 & 214 & SYSTEM_DEVELOPMENT & $8.79 \mathrm{E}-08$ \\
\hline KIRC.M1 & 214 & MULTICELLULAR_ORGANISMAL_DEVELOPMENT & $1.19 \mathrm{E}-07$ \\
\hline KIRC.M1 & 214 & NERVOUS_SYSTEM_DEVELOPMENT & $1.27 \mathrm{E}-06$ \\
\hline KIRC.M1 & 214 & CELLULAR_CATION_HOMEOSTASIS & 9.37E-06 \\
\hline KIRC.M1 & 214 & CATION_HOMEOSTASIS & $1.15 \mathrm{E}-05$ \\
\hline KIRC.M1 & 214 & EXTRACELLULAR_STRUCTURE_ORGANIZATION_AND_BIOGENESIS & $1.35 \mathrm{E}-05$ \\
\hline KIRC.M1 & 214 & CELLULAR_HOMEOSTASIS & $1.42 \mathrm{E}-05$ \\
\hline KIRC.M1 & 214 & MYOBLAST_DIFFERENTIATION & $1.88 \mathrm{E}-05$ \\
\hline KIRC.M1 & 214 & CELL_MATRIX_ADHESION & $3.21 \mathrm{E}-05$ \\
\hline KIRC.M2 & 451 & STRIATED_MUSCLE_CONTRACTION_GO_0006941 & 0.002632494 \\
\hline KIRC.M2 & 451 & CELL_MATURATION & 0.003928635 \\
\hline KIRC.M2 & 451 & MYOBLAST_DIFFERENTIATION & 0.004698584 \\
\hline KIRC.M2 & 451 & MEIOTIC_RECOMBINATION & 0.004698584 \\
\hline KIRC.M2 & 451 & DEVELOPMENTAL_MATURATION & 0.005553409 \\
\hline KIRC.M2 & 451 & MEIOSIS_I & 0.007526941 \\
\hline KIRC.M2 & 451 & MUSCLE_CELL_DIFFERENTIATION & 0.009865225 \\
\hline KIRC.M2 & 451 & SPERMATID_DEVELOPMENT & 0.016922323 \\
\hline
\end{tabular}


bioRxiv preprint doi: https://doi.org/10.1101/028415; this version posted October 5, 2015. The copyright holder for this preprint (which was not certified by peer review) is the author/funder, who has granted bioRxiv a license to display the preprint in perpetuity. It is made available under aCC-BY-NC-ND 4.0 International license.

\begin{tabular}{|c|c|c|c|}
\hline $\begin{array}{l}\text { module } \\
\text { name }\end{array}$ & $\begin{array}{l}\text { module } \\
\text { size }\end{array}$ & MSigDB.c5.bp (v3.1, Top10 is shown) & $\begin{array}{l}\text { hypergeometric } \\
\text { p-value }\end{array}$ \\
\hline KIRC.M2 & 451 & S_PHASE_OF_MITOTIC_CELL_CYCLE & 0.016922323 \\
\hline KIRC.M2 & 451 & AMINE_CATABOLIC_PROCESS & 0.017378794 \\
\hline KIRC.M3 & 440 & ANATOMICAL_STRUCTURE_DEVELOPMENT & $5.45 \mathrm{E}-11$ \\
\hline KIRC.M3 & 440 & SIGNAL_TRANSDUCTION & $6.63 \mathrm{E}-11$ \\
\hline KIRC.M3 & 440 & SYSTEM_DEVELOPMENT & $4.99 \mathrm{E}-10$ \\
\hline KIRC.M3 & 440 & MULTICELLULAR_ORGANISMAL_DEVELOPMENT & $5.75 \mathrm{E}-10$ \\
\hline KIRC.M3 & 440 & NERVOUS_SYSTEM_DEVELOPMENT & $1.14 \mathrm{E}-09$ \\
\hline KIRC.M3 & 440 & SYNAPSE_ORGANIZATION_AND_BIOGENESIS & $9.05 \mathrm{E}-09$ \\
\hline KIRC.M3 & 440 & $\begin{array}{l}\text { CELL_SURFACE_RECEPTOR_LINKED_SIGNAL_TRANSDUCTION_GO_0007 } \\
166\end{array}$ & 2.93E-08 \\
\hline KIRC.M3 & 440 & G_PROTEIN_COUPLED_RECEPTOR_PROTEIN_SIGNALING_PATHWAY & $2.96 \mathrm{E}-08$ \\
\hline KIRC.M3 & 440 & SYNAPTOGENESIS & $3.21 \mathrm{E}-08$ \\
\hline KIRC.M3 & 440 & CELL_CELL_SIGNALING & $5.33 \mathrm{E}-08$ \\
\hline KIRC.M4 & 291 & IMMUNE_SYSTEM_PROCESS & $1.77 \mathrm{E}-23$ \\
\hline KIRC.M4 & 291 & IMMUNE_RESPONSE & $7.86 \mathrm{E}-20$ \\
\hline KIRC.M4 & 291 & DEFENSE_RESPONSE & $3.11 \mathrm{E}-15$ \\
\hline KIRC.M4 & 291 & T_CELL_ACTIVATION & $3.31 \mathrm{E}-13$ \\
\hline KIRC.M4 & 291 & LYMPHOCYTE_ACTIVATION & $1.08 \mathrm{E}-12$ \\
\hline KIRC.M4 & 291 & SIGNAL_TRANSDUCTION & $3.61 \mathrm{E}-12$ \\
\hline KIRC.M4 & 291 & LEUKOCYTE_ACTIVATION & $5.79 \mathrm{E}-12$ \\
\hline KIRC.M4 & 291 & CELL_ACTIVATION & $2.50 \mathrm{E}-11$ \\
\hline KIRC.M4 & 291 & REGULATION_OF_IMMUNE_SYSTEM_PROCESS & 7.18E-11 \\
\hline KIRC.M4 & 291 & REGULATION_OF_LYMPHOCYTE_ACTIVATION & $5.72 \mathrm{E}-10$ \\
\hline KIRC.M5 & 79 & NEUROTRANSMITTER_SECRETION & $1.07 \mathrm{E}-07$ \\
\hline KIRC.M5 & 79 & REGULATED_SECRETORY_PATHWAY & $2.04 \mathrm{E}-07$ \\
\hline KIRC.M5 & 79 & REGULATION_OF_MUSCLE_CONTRACTION & 5.73E-07 \\
\hline KIRC.M5 & 79 & REGULATION_OF_NEUROTRANSMITTER_LEVELS & $1.55 \mathrm{E}-06$ \\
\hline KIRC.M5 & 79 & GENERATION_OF_A_SIGNAL_INVOLVED_IN_CELL_CELL_SIGNALING & $3.42 \mathrm{E}-06$ \\
\hline KIRC.M5 & 79 & SYSTEM_PROCESS & $5.24 \mathrm{E}-06$ \\
\hline
\end{tabular}


bioRxiv preprint doi: https://doi.org/10.1101/028415; this version posted October 5, 2015. The copyright holder for this preprint (which was not certified by peer review) is the author/funder, who has granted bioRxiv a license to display the preprint in perpetuity. It is made available under aCC-BY-NC-ND 4.0 International license.

\begin{tabular}{|c|c|c|c|}
\hline $\begin{array}{l}\text { module } \\
\text { name }\end{array}$ & $\begin{array}{l}\text { module } \\
\text { size }\end{array}$ & MSigDB.c5.bp (v3.1, Top10 is shown) & $\begin{array}{l}\text { hypergeometric } \\
\text { p-value }\end{array}$ \\
\hline KIRC.M5 & 79 & REGULATION_OF_MULTICELLULAR_ORGANISMAL_PROCESS & 1.74E-05 \\
\hline KIRC.M5 & 79 & POTASSIUM_ION_TRANSPORT & 5.64E-05 \\
\hline KIRC.M5 & 79 & REGULATION_OF_TRANSPORT & $9.94 \mathrm{E}-05$ \\
\hline KIRC.M5 & 79 & SECRETORY_PATHWAY & 0.000238941 \\
\hline KIRC.M7 & 213 & DEFENSE_RESPONSE & $9.45 \mathrm{E}-09$ \\
\hline KIRC.M7 & 213 & PHAGOCYTOSIS & 4.57E-07 \\
\hline KIRC.M7 & 213 & HUMORAL_IMMUNE_RESPONSE & $5.64 \mathrm{E}-07$ \\
\hline KIRC.M7 & 213 & IMMUNE_SYSTEM_PROCESS & $9.23 \mathrm{E}-07$ \\
\hline KIRC.M7 & 213 & IMMUNE_RESPONSE & 3.35E-06 \\
\hline KIRC.M7 & 213 & CELLULAR_DEFENSE_RESPONSE & 2.04E-05 \\
\hline KIRC.M7 & 213 & SIGNAL_TRANSDUCTION & $4.54 \mathrm{E}-05$ \\
\hline KIRC.M7 & 213 & $\begin{array}{l}\text { CELL_SURFACE_RECEPTOR_LINKED_SIGNAL_TRANSDUCTION_GO_0007 } \\
166\end{array}$ & $5.60 \mathrm{E}-05$ \\
\hline KIRC.M7 & 213 & POSITIVE_REGULATION_OF_BIOLOGICAL_PROCESS & 6.47E-05 \\
\hline KIRC.M7 & 213 & $\begin{array}{l}\text { G_PROTEIN_SIGNALING_COUPLED_TO_IP3_SECOND_MESSENGERPHOS } \\
\text { PHOLIPASE_C_ACTIVATING }\end{array}$ & 7.24E-05 \\
\hline KIRC.M8 & 213 & DEFENSE_RESPONSE & $2.61 \mathrm{E}-24$ \\
\hline KIRC.M8 & 213 & IMMUNE_SYSTEM_PROCESS & $2.11 \mathrm{E}-18$ \\
\hline KIRC.M8 & 213 & RESPONSE_TO_EXTERNAL_STIMULUS & 4.61E-18 \\
\hline KIRC.M8 & 213 & IMMUNE_RESPONSE & $1.04 \mathrm{E}-16$ \\
\hline KIRC.M8 & 213 & LOCOMOTORY_BEHAVIOR & $2.09 \mathrm{E}-14$ \\
\hline KIRC.M8 & 213 & SIGNAL_TRANSDUCTION & $7.08 \mathrm{E}-13$ \\
\hline KIRC.M8 & 213 & INFLAMMATORY_RESPONSE & $2.12 \mathrm{E}-12$ \\
\hline KIRC.M8 & 213 & RESPONSE_TO_WOUNDING & $5.13 \mathrm{E}-12$ \\
\hline KIRC.M8 & 213 & BEHAVIOR & $2.57 \mathrm{E}-11$ \\
\hline KIRC.M8 & 213 & CELLULAR_DEFENSE_RESPONSE & 4.46E-09 \\
\hline KIRC.M9 & 189 & REGULATION_OF_PEPTIDYL_TYROSINE_PHOSPHORYLATION & 1.47E-05 \\
\hline KIRC.M9 & 189 & REGULATION_OF_PHOSPHORYLATION & $6.23 \mathrm{E}-05$ \\
\hline KIRC.M9 & 189 & REGULATION_OF_TYROSINE_PHOSPHORYLATION_OF_STAT_PROTEIN & 7.16E-05 \\
\hline
\end{tabular}


bioRxiv preprint doi: https://doi.org/10.1101/028415; this version posted October 5, 2015. The copyright holder for this preprint (which was not certified by peer review) is the author/funder, who has granted bioRxiv a license to display the preprint in perpetuity. It is made available under aCC-BY-NC-ND 4.0 International license.

\begin{tabular}{|c|c|c|c|}
\hline $\begin{array}{l}\text { module } \\
\text { name }\end{array}$ & $\begin{array}{l}\text { module } \\
\text { size }\end{array}$ & MSigDB.c5.bp (v3.1, Top10 is shown) & $\begin{array}{l}\text { hypergeometric } \\
\text { p-value }\end{array}$ \\
\hline KIRC.M9 & 189 & POSITIVE_REGULATION_OF_EPITHELIAL_CELL_PROLIFERATION & 7.16E-05 \\
\hline KIRC.M9 & 189 & POSITIVE_REGULATION_OF_CELL_MIGRATION & 7.16E-05 \\
\hline KIRC.M9 & 189 & REGULATION_OF_TRANSFERASE_ACTIVITY & 7.84E-05 \\
\hline KIRC.M9 & 189 & PEPTIDYL_TYROSINE_PHOSPHORYLATION & 7.93E-05 \\
\hline KIRC.M9 & 189 & CELL_CELL_ADHESION & $9.87 \mathrm{E}-05$ \\
\hline KIRC.M9 & 189 & POSITIVE_REGULATION_OF_TRANSFERASE_ACTIVITY & 9.87E-05 \\
\hline KIRC.M9 & 189 & PEPTIDYL_TYROSINE_MODIFICATION & 0.000105926 \\
\hline KIRC.M10 & 221 & MULTICELLULAR_ORGANISMAL_DEVELOPMENT & $2.40 \mathrm{E}-11$ \\
\hline KIRC.M10 & 221 & ORGAN_DEVELOPMENT & $2.66 \mathrm{E}-11$ \\
\hline KIRC.M10 & 221 & ANATOMICAL_STRUCTURE_DEVELOPMENT & $1.56 \mathrm{E}-10$ \\
\hline KIRC.M10 & 221 & SYSTEM_DEVELOPMENT & $1.71 \mathrm{E}-10$ \\
\hline KIRC.M10 & 221 & SKELETAL_DEVELOPMENT & $9.81 \mathrm{E}-07$ \\
\hline KIRC.M10 & 221 & HEART_DEVELOPMENT & $3.28 \mathrm{E}-05$ \\
\hline KIRC.M10 & 221 & MUSCLE_DEVELOPMENT & 4.28E-05 \\
\hline KIRC.M10 & 221 & TISSUE_DEVELOPMENT & $7.92 \mathrm{E}-05$ \\
\hline KIRC.M10 & 221 & EPIDERMIS_DEVELOPMENT & $7.98 \mathrm{E}-05$ \\
\hline KIRC.M10 & 221 & EPITHELIAL_TO_MESENCHYMAL_TRANSITION & 0.000113915 \\
\hline KIRC.M11 & 581 & VITAMIN_TRANSPORT & $4.84 \mathrm{E}-07$ \\
\hline KIRC.M11 & 581 & CARBOXYLIC_ACID_TRANSPORT & $9.68 \mathrm{E}-07$ \\
\hline KIRC.M11 & 581 & ORGANIC_ACID_TRANSPORT & $1.20 \mathrm{E}-06$ \\
\hline KIRC.M11 & 581 & MONOCARBOXYLIC_ACID_TRANSPORT & $2.85 \mathrm{E}-06$ \\
\hline KIRC.M11 & 581 & ESTABLISHMENT_OF_LOCALIZATION & $3.05 \mathrm{E}-06$ \\
\hline KIRC.M11 & 581 & RESPONSE_TO_DRUG & $1.72 \mathrm{E}-05$ \\
\hline KIRC.M11 & 581 & TRANSPORT & $1.76 \mathrm{E}-05$ \\
\hline KIRC.M11 & 581 & NITROGEN_COMPOUND_METABOLIC_PROCESS & $6.55 \mathrm{E}-05$ \\
\hline KIRC.M11 & 581 & CARBOXYLIC_ACID_METABOLIC_PROCESS & $8.06 \mathrm{E}-05$ \\
\hline KIRC.M11 & 581 & ORGANIC_ACID_METABOLIC_PROCESS & $9.14 \mathrm{E}-05$ \\
\hline KIRC.M12 & 341 & CELL_CYCLE_PROCESS & 3.38E-18 \\
\hline
\end{tabular}


bioRxiv preprint doi: https://doi.org/10.1101/028415; this version posted October 5, 2015. The copyright holder for this preprint (which was not certified by peer review) is the author/funder, who has granted bioRxiv a license to display the preprint in perpetuity. It is made available under aCC-BY-NC-ND 4.0 International license.

\begin{tabular}{|c|c|c|c|}
\hline $\begin{array}{l}\text { module } \\
\text { name }\end{array}$ & $\begin{array}{l}\text { module } \\
\text { size }\end{array}$ & MSigDB.c5.bp (v3.1, Top10 is shown) & $\begin{array}{l}\text { hypergeometric } \\
\text { p-value }\end{array}$ \\
\hline KIRC.M12 & 341 & M_PHASE & $3.91 \mathrm{E}-18$ \\
\hline KIRC.M12 & 341 & CELL_CYCLE_GO_0007049 & $4.59 \mathrm{E}-18$ \\
\hline KIRC.M12 & 341 & MITOTIC_CELL_CYCLE & $1.75 \mathrm{E}-17$ \\
\hline KIRC.M12 & 341 & CELL_CYCLE_PHASE & $1.82 \mathrm{E}-17$ \\
\hline KIRC.M12 & 341 & M_PHASE_OF_MITOTIC_CELL_CYCLE & $4.22 \mathrm{E}-17$ \\
\hline KIRC.M12 & 341 & MITOSIS & $4.06 \mathrm{E}-16$ \\
\hline KIRC.M12 & 341 & REGULATION_OF_MITOSIS & $5.14 \mathrm{E}-10$ \\
\hline KIRC.M12 & 341 & REGULATION_OF_CELL_CYCLE & $3.92 \mathrm{E}-09$ \\
\hline KIRC.M12 & 341 & CELL_CYCLE_CHECKPOINT_GO_0000075 & $4.58 \mathrm{E}-08$ \\
\hline BLCA.M1 & 111 & COENZYME_BIOSYNTHETIC_PROCESS & $1.46 \mathrm{E}-05$ \\
\hline BLCA.M1 & 111 & COFACTOR_BIOSYNTHETIC_PROCESS & 0.000155596 \\
\hline BLCA.M1 & 111 & COENZYME_METABOLIC_PROCESS & 0.000927251 \\
\hline BLCA.M1 & 111 & RESPONSE_TO_TOXIN & 0.001105661 \\
\hline BLCA.M1 & 111 & NEGATIVE_REGULATION_OF_MYELOID_CELL_DIFFERENTIATION & 0.001105661 \\
\hline BLCA.M1 & 111 & XENOBIOTIC_METABOLIC_PROCESS & 0.001346913 \\
\hline BLCA.M1 & 111 & APOPTOTIC_MITOCHONDRIAL_CHANGES & 0.001346913 \\
\hline BLCA.M1 & 111 & TRICARBOXYLIC_ACID_CYCLE_INTERMEDIATE_METABOLIC_PROCESS & 0.001346913 \\
\hline BLCA.M1 & 111 & RESPONSE_TO_XENOBIOTIC_STIMULUS & 0.001610975 \\
\hline BLCA.M1 & 111 & RESPONSE_TO_CARBOHYDRATE_STIMULUS & 0.001610975 \\
\hline BLCA.M2 & 697 & EMBRYONIC_DEVELOPMENT & $1.75 \mathrm{E}-06$ \\
\hline BLCA.M2 & 697 & LIPID_METABOLIC_PROCESS & 1.87E-06 \\
\hline BLCA.M2 & 697 & CYTOPLASM_ORGANIZATION_AND_BIOGENESIS & $3.88 \mathrm{E}-06$ \\
\hline BLCA.M2 & 697 & CELLULAR_LIPID_METABOLIC_PROCESS & $7.24 \mathrm{E}-06$ \\
\hline BLCA.M2 & 697 & ANATOMICAL_STRUCTURE_DEVELOPMENT & $1.04 \mathrm{E}-05$ \\
\hline
\end{tabular}


bioRxiv preprint doi: https://doi.org/10.1101/028415; this version posted October 5, 2015. The copyright holder for this preprint (which was not certified by peer review) is the author/funder, who has granted bioRxiv a license to display the preprint in perpetuity. It is made available under aCC-BY-NC-ND 4.0 International license.

\begin{tabular}{|c|c|c|c|}
\hline $\begin{array}{l}\text { module } \\
\text { name }\end{array}$ & $\begin{array}{l}\text { module } \\
\text { size }\end{array}$ & MSigDB.c5.bp (v3.1, Top10 is shown) & $\begin{array}{l}\text { hypergeometric } \\
\text { p-value }\end{array}$ \\
\hline BLCA.M2 & 697 & CYCLIC_NUCLEOTIDE_METABOLIC_PROCESS & $1.24 \mathrm{E}-05$ \\
\hline BLCA.M2 & 697 & MULTICELLULAR_ORGANISMAL_DEVELOPMENT & $2.84 \mathrm{E}-05$ \\
\hline BLCA.M2 & 697 & INTERCELLULAR_JUNCTION_ASSEMBLY_AND_MAINTENANCE & $3.28 \mathrm{E}-05$ \\
\hline BLCA.M2 & 697 & EPIDERMAL_GROWTH_FACTOR_RECEPTOR_SIGNALING_PATHWAY & 4.78E-05 \\
\hline BLCA.M2 & 697 & SYSTEM_DEVELOPMENT & 5.92E-05 \\
\hline BLCA.M3 & 437 & MULTICELLULAR_ORGANISMAL_DEVELOPMENT & $1.31 \mathrm{E}-14$ \\
\hline BLCA.M3 & 437 & ANATOMICAL_STRUCTURE_DEVELOPMENT & $3.35 \mathrm{E}-14$ \\
\hline BLCA.M3 & 437 & SYSTEM_DEVELOPMENT & $1.16 \mathrm{E}-11$ \\
\hline BLCA.M3 & 437 & ORGAN_DEVELOPMENT & 4.29E-09 \\
\hline BLCA.M3 & 437 & SKELETAL_DEVELOPMENT & 1.67E-08 \\
\hline BLCA.M3 & 437 & MUSCLE_DEVELOPMENT & $3.16 \mathrm{E}-07$ \\
\hline BLCA.M3 & 437 & ANATOMICAL_STRUCTURE_MORPHOGENESIS & $6.00 \mathrm{E}-07$ \\
\hline BLCA.M3 & 437 & NERVOUS_SYSTEM_DEVELOPMENT & $3.28 \mathrm{E}-05$ \\
\hline BLCA.M3 & 437 & GENERATION_OF_NEURONS & 3.97E-05 \\
\hline BLCA.M3 & 437 & CELL_MATRIX_ADHESION & $9.56 \mathrm{E}-05$ \\
\hline BLCA.M4 & 256 & KERATINOCYTE_DIFFERENTIATION & $5.60 \mathrm{E}-07$ \\
\hline BLCA.M4 & 256 & EPIDERMIS_DEVELOPMENT & $1.70 \mathrm{E}-06$ \\
\hline BLCA.M4 & 256 & ECTODERM_DEVELOPMENT & $4.24 \mathrm{E}-06$ \\
\hline BLCA.M4 & 256 & TISSUE_DEVELOPMENT & 3.53E-05 \\
\hline BLCA.M4 & 256 & CALCIUM_INDEPENDENT_CELL_CELL_ADHESION & 0.000111075 \\
\hline BLCA.M4 & 256 & EPITHELIAL_CELL_DIFFERENTIATION & 0.00017591 \\
\hline BLCA.M4 & 256 & RESPONSE_TO_STEROID_HORMONE_STIMULUS & 0.000239798 \\
\hline BLCA.M4 & 256 & REGULATION_OF_ACTIN_FILAMENT_LENGTH & 0.000408544 \\
\hline BLCA.M4 & 256 & CELL_CELL_ADHESION & 0.000505858 \\
\hline BLCA.M4 & 256 & POSITIVE_REGULATION_OF_TRANSFERASE_ACTIVITY & 0.000505858 \\
\hline BLCA.M6 & 89 & DEFENSE_RESPONSE & $1.39 \mathrm{E}-05$ \\
\hline BLCA.M6 & 89 & RESPONSE_TO_OTHER_ORGANISM & $2.19 \mathrm{E}-05$ \\
\hline BLCA.M6 & 89 & RESPONSE_TO_VIRUS & $5.00 \mathrm{E}-05$ \\
\hline
\end{tabular}


bioRxiv preprint doi: https://doi.org/10.1101/028415; this version posted October 5, 2015. The copyright holder for this preprint (which was not certified by peer review) is the author/funder, who has granted bioRxiv a license to display the preprint in perpetuity. It is made available under aCC-BY-NC-ND 4.0 International license.

\begin{tabular}{|c|c|c|c|}
\hline $\begin{array}{l}\text { module } \\
\text { name }\end{array}$ & $\begin{array}{l}\text { module } \\
\text { size }\end{array}$ & MSigDB.c5.bp (v3.1, Top10 is shown) & $\begin{array}{l}\text { hypergeometric } \\
\text { p-value }\end{array}$ \\
\hline BLCA.M6 & 89 & I_KAPPAB_KINASE_NF_KAPPAB_CASCADE & 0.000100388 \\
\hline BLCA.M6 & 89 & RESPONSE_TO_BIOTIC_STIMULUS & 0.000127869 \\
\hline BLCA.M6 & 89 & EPIDERMIS_DEVELOPMENT & 0.0001977 \\
\hline BLCA.M6 & 89 & ECTODERM_DEVELOPMENT & 0.000313021 \\
\hline BLCA.M6 & 89 & IMMUNE_SYSTEM_PROCESS & 0.000399913 \\
\hline BLCA.M6 & 89 & LEUKOCYTE_DIFFERENTIATION & 0.000487311 \\
\hline BLCA.M6 & 89 & MULTI_ORGANISM_PROCESS & 0.000557908 \\
\hline BLCA.M7 & 183 & MUSCLE_DEVELOPMENT & $3.29 \mathrm{E}-10$ \\
\hline BLCA.M7 & 183 & SKELETAL_MUSCLE_DEVELOPMENT & $1.89 \mathrm{E}-07$ \\
\hline BLCA.M7 & 183 & MYOBLAST_DIFFERENTIATION & $2.15 \mathrm{E}-07$ \\
\hline BLCA.M7 & 183 & ORGAN_DEVELOPMENT & $3.21 \mathrm{E}-07$ \\
\hline BLCA.M7 & 183 & MUSCLE_CELL_DIFFERENTIATION & $8.85 \mathrm{E}-07$ \\
\hline BLCA.M7 & 183 & STRIATED_MUSCLE_DEVELOPMENT & $9.26 \mathrm{E}-07$ \\
\hline BLCA.M7 & 183 & REGULATION_OF_HEART_CONTRACTION & $1.75 \mathrm{E}-06$ \\
\hline BLCA.M7 & 183 & SYSTEM_DEVELOPMENT & $1.05 \mathrm{E}-05$ \\
\hline BLCA.M7 & 183 & SYSTEM_PROCESS & $2.06 \mathrm{E}-05$ \\
\hline BLCA.M7 & 183 & MULTICELLULAR_ORGANISMAL_DEVELOPMENT & $2.15 \mathrm{E}-05$ \\
\hline BLCA.M8 & 916 & IMMUNE_SYSTEM_PROCESS & $6.01 \mathrm{E}-56$ \\
\hline BLCA.M8 & 916 & IMMUNE_RESPONSE & $1.35 \mathrm{E}-45$ \\
\hline BLCA.M8 & 916 & SIGNAL_TRANSDUCTION & $2.56 \mathrm{E}-36$ \\
\hline BLCA.M8 & 916 & DEFENSE_RESPONSE & $1.51 \mathrm{E}-30$ \\
\hline BLCA.M8 & 916 & RESPONSE_TO_EXTERNAL_STIMULUS & $1.37 \mathrm{E}-23$ \\
\hline BLCA.M8 & 916 & LOCOMOTORY_BEHAVIOR & 7.57E-20 \\
\hline BLCA.M8 & 916 & $\begin{array}{l}\text { CELL_SURFACE_RECEPTOR_LINKED_SIGNAL_TRANSDUCTION_GO_0007 } \\
166\end{array}$ & $3.36 \mathrm{E}-19$ \\
\hline BLCA.M8 & 916 & RESPONSE_TO_WOUNDING & $1.40 \mathrm{E}-17$ \\
\hline BLCA.M8 & 916 & LEUKOCYTE_ACTIVATION & $1.61 \mathrm{E}-17$ \\
\hline
\end{tabular}


bioRxiv preprint doi: https://doi.org/10.1101/028415; this version posted October 5, 2015. The copyright holder for this preprint (which was not certified by peer review) is the author/funder, who has granted bioRxiv a license to display the preprint in perpetuity. It is made available under aCC-BY-NC-ND 4.0 International license.

\begin{tabular}{|c|c|c|c|}
\hline $\begin{array}{l}\text { module } \\
\text { name }\end{array}$ & $\begin{array}{l}\text { module } \\
\text { size }\end{array}$ & MSigDB.c5.bp (v3.1, Top10 is shown) & $\begin{array}{l}\text { hypergeometric } \\
\text { p-value }\end{array}$ \\
\hline BLCA.M8 & 916 & INFLAMMATORY_RESPONSE & $1.63 \mathrm{E}-16$ \\
\hline BLCA.M9 & 309 & EXTRACELLULAR_STRUCTURE_ORGANIZATION_AND_BIOGENESIS & 4.87E-06 \\
\hline BLCA.M9 & 309 & SYSTEM_PROCESS & $5.22 \mathrm{E}-05$ \\
\hline BLCA.M9 & 309 & SYNAPTOGENESIS & $1.00 \mathrm{E}-04$ \\
\hline BLCA.M9 & 309 & NERVOUS_SYSTEM_DEVELOPMENT & 0.000120749 \\
\hline BLCA.M9 & 309 & POSITIVE_REGULATION_OF_SECRETION & 0.000154822 \\
\hline BLCA.M9 & 309 & SYNAPTIC_TRANSMISSION & 0.000183308 \\
\hline BLCA.M9 & 309 & SYSTEM_DEVELOPMENT & 0.000222238 \\
\hline BLCA.M9 & 309 & RESPONSE_TO_DRUG & 0.000228631 \\
\hline BLCA.M9 & 309 & ESTABLISHMENT_OF_LOCALIZATION & 0.00026093 \\
\hline BLCA.M9 & 309 & SYNAPSE_ORGANIZATION_AND_BIOGENESIS & 0.000273718 \\
\hline UCEC.M1 & 155 & PEPTIDE_METABOLIC_PROCESS & 0.002138568 \\
\hline UCEC.M1 & 155 & FATTY_ACID_BETA_OXIDATION & 0.002601739 \\
\hline UCEC.M1 & 155 & TRICARBOXYLIC_ACID_CYCLE_INTERMEDIATE_METABOLIC_PROCESS & 0.002601739 \\
\hline UCEC.M1 & 155 & VITAMIN_TRANSPORT & 0.00365578 \\
\hline UCEC.M1 & 155 & PROTEIN_TETRAMERIZATION & 0.004245421 \\
\hline UCEC.M1 & 155 & NEGATIVE_REGULATION_OF_HYDROLASE_ACTIVITY & 0.004245421 \\
\hline UCEC.M1 & 155 & NEUROPEPTIDE_SIGNALING_PATHWAY & 0.004245421 \\
\hline UCEC.M1 & 155 & STRIATED_MUSCLE_CONTRACTION_GO_0006941 & 0.004245421 \\
\hline UCEC.M1 & 155 & AEROBIC_RESPIRATION & 0.004875999 \\
\hline UCEC.M1 & 155 & LIPID_HOMEOSTASIS & 0.005546917 \\
\hline UCEC.M2 & 429 & MITOTIC_CELL_CYCLE & $2.84 \mathrm{E}-13$ \\
\hline UCEC.M2 & 429 & CELL_CYCLE_PHASE & $2.52 \mathrm{E}-12$ \\
\hline UCEC.M2 & 429 & CELL_CYCLE_PROCESS & $4.55 \mathrm{E}-12$ \\
\hline UCEC.M2 & 429 & M_PHASE_OF_MITOTIC_CELL_CYCLE & $7.61 \mathrm{E}-12$ \\
\hline UCEC.M2 & 429 & MITOSIS & $5.32 \mathrm{E}-11$ \\
\hline UCEC.M2 & 429 & CELL CYCLE GO 0007049 & $7.24 \mathrm{E}-10$ \\
\hline
\end{tabular}


bioRxiv preprint doi: https://doi.org/10.1101/028415; this version posted October 5, 2015. The copyright holder for this preprint (which was not certified by peer review) is the author/funder, who has granted bioRxiv a license to display the preprint in perpetuity. It is made available under aCC-BY-NC-ND 4.0 International license.

\begin{tabular}{|c|c|c|c|}
\hline $\begin{array}{l}\text { module } \\
\text { name }\end{array}$ & $\begin{array}{l}\text { module } \\
\text { size }\end{array}$ & MSigDB.c5.bp (v3.1, Top10 is shown) & $\begin{array}{l}\text { hypergeometric } \\
\text { p-value }\end{array}$ \\
\hline UCEC.M2 & 429 & M_PHASE & $7.45 \mathrm{E}-10$ \\
\hline UCEC.M2 & 429 & REGULATION_OF_MITOSIS & $1.06 \mathrm{E}-06$ \\
\hline UCEC.M2 & 429 & CHROMOSOME_SEGREGATION & $2.25 \mathrm{E}-06$ \\
\hline UCEC.M2 & 429 & INTERPHASE_OF_MITOTIC_CELL_CYCLE & 3.05E-06 \\
\hline UCEC.M3 & 349 & IMMUNE_SYSTEM_PROCESS & $1.03 \mathrm{E}-20$ \\
\hline UCEC.M3 & 349 & IMMUNE_RESPONSE & $1.15 \mathrm{E}-17$ \\
\hline UCEC.M3 & 349 & SIGNAL_TRANSDUCTION & $1.37 \mathrm{E}-15$ \\
\hline UCEC.MЗ & 349 & T_CELL_ACTIVATION & 2.81E-12 \\
\hline UCEC.M3 & 349 & DEFENSE_RESPONSE & $1.08 \mathrm{E}-11$ \\
\hline UCEC.M3 & 349 & LEUKOCYTE_ACTIVATION & $5.60 \mathrm{E}-11$ \\
\hline UCEC.M3 & 349 & LYMPHOCYTE_ACTIVATION & $1.83 \mathrm{E}-10$ \\
\hline UCEC.M3 & 349 & CELL_ACTIVATION & $2.38 \mathrm{E}-10$ \\
\hline UCEC.M3 & 349 & REGULATION_OF_MULTICELLULAR_ORGANISMAL_PROCESS & $1.93 \mathrm{E}-08$ \\
\hline UCEC.M3 & 349 & CELLULAR_DEFENSE_RESPONSE & $2.36 \mathrm{E}-08$ \\
\hline UCEC.M4 & 300 & MULTICELLULAR_ORGANISMAL_DEVELOPMENT & $1.04 \mathrm{E}-18$ \\
\hline UCEC.M4 & 300 & ANATOMICAL_STRUCTURE_DEVELOPMENT & $5.11 \mathrm{E}-18$ \\
\hline UCEC.M4 & 300 & SYSTEM_DEVELOPMENT & $8.12 \mathrm{E}-17$ \\
\hline UCEC.M4 & 300 & ORGAN_DEVELOPMENT & $1.16 \mathrm{E}-13$ \\
\hline UCEC.M4 & 300 & BLOOD_COAGULATION & 2.47E-10 \\
\hline UCEC.M4 & 300 & COAGULATION & $3.15 \mathrm{E}-10$ \\
\hline UCEC.M4 & 300 & HEMOSTASIS & $7.92 \mathrm{E}-10$ \\
\hline UCEC.M4 & 300 & SKELETAL_DEVELOPMENT & $1.55 \mathrm{E}-09$ \\
\hline UCEC.M4 & 300 & WOUND_HEALING & $2.70 \mathrm{E}-09$ \\
\hline UCEC.M4 & 300 & REGULATION_OF_BODY_FLUID_LEVELS & 4.69E-09 \\
\hline UCEC.M6 & 97 & RESPONSE_TO_VIRUS & $2.72 \mathrm{E}-06$ \\
\hline UCEC.M6 & 97 & DEFENSE_RESPONSE & $3.08 \mathrm{E}-06$ \\
\hline UCEC.M6 & 97 & IMMUNE_RESPONSE & $9.60 \mathrm{E}-06$ \\
\hline UCEC.M6 & 97 & I_KAPPAB_KINASE_NF_KAPPAB_CASCADE & $1.14 \mathrm{E}-05$ \\
\hline
\end{tabular}


bioRxiv preprint doi: https://doi.org/10.1101/028415; this version posted October 5, 2015. The copyright holder for this preprint (which was not certified by peer review) is the author/funder, who has granted bioRxiv a license to display the preprint in perpetuity. It is made available under aCC-BY-NC-ND 4.0 International license.

\begin{tabular}{|c|c|c|c|}
\hline $\begin{array}{l}\text { module } \\
\text { name }\end{array}$ & $\begin{array}{l}\text { module } \\
\text { size }\end{array}$ & MSigDB.c5.bp (v3.1, Top10 is shown) & $\begin{array}{l}\text { hypergeometric } \\
\text { p-value }\end{array}$ \\
\hline UCEC.M6 & 97 & APOPTOTIC_MITOCHONDRIAL_CHANGES & $1.34 \mathrm{E}-05$ \\
\hline UCEC.M6 & 97 & IMMUNE_SYSTEM_PROCESS & $1.62 \mathrm{E}-05$ \\
\hline UCEC.M6 & 97 & RESPONSE_TO_OTHER_ORGANISM & 3.32E-05 \\
\hline UCEC.M6 & 97 & POSITIVE_REGULATION_OF_I_KAPPAB_KINASE_NF_KAPPAB_CASCADE & 4.17E-05 \\
\hline UCEC.M6 & 97 & PROTEIN_KINASE_CASCADE & 4.66E-05 \\
\hline UCEC.M6 & 97 & REGULATION_OF_I_KAPPAB_KINASE_NF_KAPPAB_CASCADE & $5.74 \mathrm{E}-05$ \\
\hline UCEC.M7 & 123 & REGULATION_OF_NUCLEOCYTOPLASMIC_TRANSPORT & $6.30 \mathrm{E}-06$ \\
\hline UCEC.M7 & 123 & REGULATION_OF_INTRACELLULAR_TRANSPORT & 1.07E-05 \\
\hline UCEC.M7 & 123 & ENZYME_LINKED_RECEPTOR_PROTEIN_SIGNALING_PATHWAY & $1.40 \mathrm{E}-05$ \\
\hline UCEC.M7 & 123 & SPHINGOLIPID_BIOSYNTHETIC_PROCESS & $1.99 \mathrm{E}-05$ \\
\hline UCEC.M7 & 123 & PROTEIN_EXPORT_FROM_NUCLEUS & $3.62 \mathrm{E}-05$ \\
\hline UCEC.M7 & 123 & PHOSPHORYLATION & $6.78 \mathrm{E}-05$ \\
\hline UCEC.M7 & 123 & $\begin{array}{l}\text { TRANSMEMBRANE_RECEPTOR_PROTEIN_TYROSINE_KINASE_SIGNALIN } \\
\text { G_PATHWAY }\end{array}$ & 0.000103166 \\
\hline UCEC.M7 & 123 & PROTEIN_AMINO_ACID_PHOSPHORYLATION & 0.000177072 \\
\hline UCEC.M7 & 123 & EPIDERMAL_GROWTH_FACTOR_RECEPTOR_SIGNALING_PATHWAY & 0.000242999 \\
\hline UCEC.M7 & 123 & PEPTIDYL_AMINO_ACID_MODIFICATION & 0.000429533 \\
\hline UCEC.M8 & 167 & CELL_MATRIX_ADHESION & 3.95E-07 \\
\hline UCEC.M8 & 167 & CELL_SUBSTRATE_ADHESION & 4.64E-07 \\
\hline UCEC.M8 & 167 & SKELETAL_DEVELOPMENT & $1.20 \mathrm{E}-06$ \\
\hline UCEC.M8 & 167 & REGULATION_OF_MULTICELLULAR_ORGANISMAL_PROCESS & 2.37E-06 \\
\hline UCEC.M8 & 167 & MULTICELLULAR_ORGANISMAL_DEVELOPMENT & 4.69E-06 \\
\hline UCEC.M8 & 167 & SYSTEM_PROCESS & $6.47 \mathrm{E}-06$ \\
\hline UCEC.M8 & 167 & ANATOMICAL_STRUCTURE_DEVELOPMENT & 8.94E-06 \\
\hline UCEC.M8 & 167 & SYSTEM_DEVELOPMENT & 8.97E-06 \\
\hline UCEC.M8 & 167 & REGULATION_OF_MUSCLE_CONTRACTION & $1.14 \mathrm{E}-05$ \\
\hline UCEC.M8 & 167 & ORGAN_DEVELOPMENT & $3.18 \mathrm{E}-05$ \\
\hline
\end{tabular}


bioRxiv preprint doi: https://doi.org/10.1101/028415; this version posted October 5, 2015. The copyright holder for this preprint (which was not certified by peer review) is the author/funder, who has granted bioRxiv a license to display the preprint in perpetuity. It is made available under aCC-BY-NC-ND 4.0 International license.

\begin{tabular}{|c|c|c|c|}
\hline $\begin{array}{l}\text { module } \\
\text { name }\end{array}$ & $\begin{array}{l}\text { module } \\
\text { size }\end{array}$ & MSigDB.c5.bp (v3.1, Top10 is shown) & $\begin{array}{l}\text { hypergeometric } \\
\text { p-value }\end{array}$ \\
\hline UCEC.M9 & 607 & PROTEIN_AMINO_ACID_O_LINKED_GLYCOSYLATION & $1.00 \mathrm{E}-04$ \\
\hline UCEC.M9 & 607 & SEXUAL_REPRODUCTION & 0.000482434 \\
\hline UCEC.M9 & 607 & GAMETE_GENERATION & 0.001236102 \\
\hline UCEC.M9 & 607 & DIGESTION & 0.001245424 \\
\hline UCEC.M9 & 607 & BODY_FLUID_SECRETION & 0.002169668 \\
\hline UCEC.M9 & 607 & CALCIUM_INDEPENDENT_CELL_CELL_ADHESION & 0.002825644 \\
\hline UCEC.M9 & 607 & COFACTOR_TRANSPORT & 0.002922453 \\
\hline UCEC.M9 & 607 & N_ACETYLGLUCOSAMINE_METABOLIC_PROCESS & 0.00381725 \\
\hline UCEC.M9 & 607 & SECRETION & 0.003992735 \\
\hline UCEC.M9 & 607 & G2_M_TRANSITION_OF_MITOTIC_CELL_CYCLE & 0.004861511 \\
\hline UCEC.M10 & 324 & IMMUNE_SYSTEM_PROCESS & $6.86 \mathrm{E}-27$ \\
\hline UCEC.M10 & 324 & IMMUNE_RESPONSE & $1.12 \mathrm{E}-21$ \\
\hline UCEC.M10 & 324 & DEFENSE_RESPONSE & $7.55 \mathrm{E}-18$ \\
\hline UCEC.M10 & 324 & RESPONSE_TO_EXTERNAL_STIMULUS & $3.25 \mathrm{E}-15$ \\
\hline UCEC.M10 & 324 & INFLAMMATORY_RESPONSE & $5.50 \mathrm{E}-14$ \\
\hline UCEC.M10 & 324 & RESPONSE_TO_WOUNDING & $7.33 \mathrm{E}-12$ \\
\hline UCEC.M10 & 324 & HUMORAL_IMMUNE_RESPONSE & $1.57 \mathrm{E}-08$ \\
\hline UCEC.M10 & 324 & SIGNAL_TRANSDUCTION & $2.70 \mathrm{E}-07$ \\
\hline UCEC.M10 & 324 & CDC42_PROTEIN_SIGNAL_TRANSDUCTION & 4.89E-07 \\
\hline UCEC.M10 & 324 & LOCOMOTORY_BEHAVIOR & $1.40 \mathrm{E}-06$ \\
\hline
\end{tabular}


bioRxiv preprint doi: https://doi.orq/10.1101/028415: this version posted October 5.2015 . The copvright holder for this preprint (which was not certified by peer review) is the author/funder, who has granted bioRxiv a license to display the preprint in perpetuity. It is made available under aCC-BY-NC-ND 4.0 International license.

\section{Zou_Suppl_Table_4}

\section{Core module genes of the conserved CGMs}

\section{\# 1:black modules}

\# function class: cell cycle

\# core genes are present in at least three different cancer types

BIRC5 BRIP1 CENPA CLSPN DEPDC1 DEPDC1B E2F7 HMMR MCM10 MYBL2 PBK APOBEC3B ASPM AURKB BRCA2 BUB1 CASC5 CCNE1 CCNE2 CDC25C CDC45 CDCA2 CENPE CENPF CKAP2L DIAPH3 DLGAP5 E2F8 ESCO2 ESPL1 EX01 FAM111B FAM64A FAM83D FOXM1 GGH GSG2 IQGAP3 KIF14 KIF15 LDHD MELK NCAPG NDC80 NEIL3 NUF2 PIF1 POLQ RRM2 SGOL1 SKA1 TOP2A TROAP TTK UBE2C VASH2 WDR62 ANLN APLP1 ARHGAP11B ARHGEF37 ASF1B ATP8B3 BUB1B C15orf42 C17orf96 C19orf57 C9orf140 CCDC150 CCNB2 CDC20 CDC25A CDCA7 CDK1 CDKN3 CDT1 CENPI CENPK CENPM CENPV CENPW CEP55 DTL E2F2 ERCC6L FAM54A FAM72D FANCA FBXO43 GPRIN1 GTSE1 HJURP IGF2BP3 KIAA0101 KIF18A KIF18B KIF20A KIF23 KIF2C KIF4A KIFC1 LRP8 MFSD4 MKI67 MLLT11 MND1 MYBL1 NCAPH NEK2 OIP5 ORC1L PLK1 PTTG1 RAD54L RECQL4 RPL39L RTKN2 SKA3 SLC7A5 SPC24 SPC25 STEAP3 TK1 TMEM38B TMSB15B TPX2 UHRF1 XRCC2 ZNF695

\section{\# 2:turquoise modules}

\# function class: adaptive immune

\# core genes are present in at least 8 different cancer types

ALOX5AP CD163 CD53 CPVL FCGR3A FGL2 FPR3 HLA-DOA HLA-DPA1 HLA-DPB1 HLA-DQA1 HLA-DRA SIGLEC10 SLAMF8 VSIG4 APOC1 BTK C1QA C1QB C1QC C3AR1 CD300A CD86 CLEC7A CMKLR1 CTSS CYBB FCGR2B FPR1 GPR183 HLA-DMB HLA-DRB1 HLA-DRB5 IL10RA LAIR1 LILRB4 LYZ MPEG1 MS4A4A MSR1 NCKAP1L PLEK SDS SRGN

\section{\# 3:orange modules}

\# function class: adaptive immune

\# core genes are present in at least 4 different cancer types

ACAP1 ADAM6 CD27 CD3E CD6 DERL3 IGJ IL12RB1 IL2RB ITGAL JAK3 LAG3 LCK LOC96610 MAP4K1 NKG7 PSTPIP1 PTPN7 RASAL3 TBC1D10C TMC8 AGAP2 APOBEC3D APOBEC3G ARHGAP9 BATF BIRC3 CCL5 CCR5 CCR7 CD2 CD247 CD3D CD5 CD52 CD79B CD96 CIITA CORO1A CST7 CTSW CXCL9 CXCR6 CYTIP ERAP2 FAIM3 FOXP3 GBP4 GPR132 HCST IDO1 IL2RG IPCEF1 ITGB7 KIF21B LAT LRMP LSP1 MMP25 MYO1G P2RY8 PPP1R16B PRF1 PTPRCAP RAB37 RAC2 SEPT1 SLAMF7 SP140 SPN SPOCK2 TRAF3IP3 UBD ACSL5 ANKRD22 APOL4 ASB2 BATF3 BIN2 C16orf54 C4A CD37 CD48 CD69 CD7 CD79A CD8A CPNE5 CXCL10 ETV7 FAM113B FAM46C FAM65B GBP5 GIMAP1 GIMAP7 GJD3 GNG7 GRAP2 GZMA GZMB IKZF1 IL15 IL34 ISG20 KLHDC7B LOC606724 LTB MCOLN2 MEI1 MGAT3 POU2F2 PTGDS RASGRP1 RASGRP2 RUNX3 SARDH SASH3 SELL SLA2 SOCS1 ST8SIA1 TCF7 TLR9 TMEM156 TNFAIP2 TNFRSF4 TRIM69 TYMP WAS ZAP70

\section{\# 4:red modules}

\# function class: innate immune

\# core genes are present in at least 3 different cancer types

BST2 CMPK2 HERC5 HERC6 IFI27 IFI44L IFI6 IFIH1 IFIT1 IFIT3 IFITM1 ISG15 MX1 MX2 OAS1 OAS2 OASL RSAD2 XAF1 DDX60 EPSTI1 IFI35 IFI44 IFIT2 IRF7 LY6E OAS3 RTP4 SAMD9 SAMD9L BATF2 DDX60L HCG26 HCP5 HLA-F HSH2D LAMP3 PSMB9 STAT1 TRIM22 USP18 APOL1 APOL6 DDX58 GBP1 HLA-B HLA-H HLA-L IFI16 TAP1 TNFSF10 
bioRxiv preprint doi: https://doi.org/10.1101/028415; this version posted October 5, 2015. The copyright holder for this preprint (which was not certified by peer review) is the author/funder, who has granted bioRxiv a license to display the preprint in perpetuity. It is made available under aCC-BY-NC-ND 4.0 International license.

\section{Core module genes of the conserved CGMs}

COL12A1 COL1A1 COL1A2 COL3A1 COL5A1 COL5A2 COL6A1 COL6A2 COL6A3 CTSK DCN EMILIN1 FBN1 FN1 ISLR LUM MMP11 MMP2 OLFML2B PCOLCE POSTN ADAM12 ADAMTS12 ADAMTS2 ADAMTS4 ADAMTS7 CDH11 COL5A3 CRISPLD2 CTGF DACT1 EDNRA FAM26E FBLN2 GLT8D2 HTRA3 ITGA11 KIF26B LEPREL2 MXRA5 NDN OLFML1 PRRX1 PXDN RCN3 SERPINE1 SGIP1 SPON2 SSC5D THBS2 VCAN WISP1 ZNF469 ADAMTS14 AEBP1 AG2 ALDH1A3 ASPN BGN C13orf33 C1QTNF1 CACNA1C CCDC80 CD248 CHSY3 COL8A1 CPZ CYR61 ECM1 ECM2 FAP FBLN1 FNDC1 FNDC4 GAS1 HEPH INHBA KCNE4 LOXL2 LTBP2 MRC2 P4HA3 PDGFRA PID1 PMEPA1 PRICKLE1 SERPINF1 SFRP4 SPOCK1 SRPX2 SULF1 SVEP1 TGFB3 THBS1 TMEM200B TNC TWIST1 AKAP12 AKT3 APCDD1 ASAM C10orf72 CACNA1H COL16A1 COLEC12 COX7A1 CPXM1 CSPG4 CTHRC1 DDR2 DIO2 DNM1 DPYSL3 DSEL EGFLAM ETV1 FGF1 FLRT2 GPC6 HHIPL1 HMCN1 IGDCC4 ISM1 LAMA2 MEX3B MFAP2 MSRB3 MXRA8 NID2 NOX4 NRP2 NTM OLFM2 PAMR1 PCDH18 PDGFRL PDPN PDZRN3 PODNL1 RARRES2 RBMS3 SCARF2 SDC2 SLC24A3 SNAI2 SPARC SRPX THY1 TMEM119 TMEM158 TMEM200A TSHZ3 VGLL3 WNT5A ABCC9 ACAN ACTA2 ACTG2 ADAMTS10 ANGPTL2 ATP10A BASP1 BEND6 BNC2 C12orf68 CCDC8 CDC42EP5 CDH23 CHRD CLEC11A CNN1 COL14A1 COL8A2 CPE CREB3L1 CSMD2 DAAM2 DENND2A EDIL3 EFEMP1 EGR2 EPHA3 FAM19A5 FAT4 FBLN7 FILIP1L FLNC FMOD FOXL1 GALNTL2 GEM GGT5 GJA5 GLI3 HIC1 HTRA1 IGF2 ITGB3 ITGBL1 KDELR3 LOC399959 LOX LOXL1 LRCH2 LRRC17 LTBP1 LZTS1 MAP1B MATN3 MDGA1 MEG3 MEIS3 MMP23B MOXD1 MRVI1 MSC NACAD NAV3 NKD2 OLFML3 PAPPA PCDH7 PCDHGB7 PDGFRB PLAU PMP22 PNMAL2 PODN PPAPDC3 PROS1 PRR16 PTGIS RASD2 RASGRF2 RGS4 ROR2 RPLPOP2 RUNX2 SH3RF3 SLIT3 SNED1 STC1 STMN3 SULF2 TAGLN TGFBI TIMP3 TPM2 TRPC1 TSPAN11 WTIP XYLT1 ZFHX4 ZFPM2 ZNF521

\section{\# 6::purple modules}

\# function class: angiogenesis

\# core genes are present in at least two different cancer types

APLNR CLEC3B EDNRB EMCN HSPA12B JAM2 NPR1 PDE7B RASD1 SOX17 SPARCL1 ST6GALNAC3 TAL1 TEK ABCG2 ADAMTS9 AVPR1A CACHD1 CETP CLDN11 CLDN5 COL15A1 EBF1 EBF3 ECSCR F2RL3 FAM124B FGD5 GJA5 ITIH5 LHX6 LPL NR5A2 PCDH17 PDE1A PDE2A PDE8B PDGFD PDK4 PGM5 PTPRB RASL11A RBP7 RGS5 RUNDC3B SEMA3G SHE SLCO2A1 TMTC1 TRPC6 A2M ABCB1 ADAMTS5 ADCY1 ADCY4 AGT ALPL ANK2 ANO2 AOC3 APOD APOLD1 AQP1 ARHGAP28 ATOH8 ATP1B2 BEND7 BMP6 BTNL9 C14orf49 C17orf72 C2CD4C CABLES1 CADM1 CALCRL CCDC85A CD36 CDH6 CDKN1C CFD CLEC1A CLIC5 COL14A1 CXCL12 CYYR1 DACH1 DCHS1 DENND2A DUSP1 EGR1 EGR3 EMID1 ENPP2 ESR1 FAM107A FAM13C FAM155A FAM171A1 FAM38B FILIP1 FLT4 FOLH1 FOS FOSB FOXF1 GABRD GATA2 GJA4 GNA14 GNG7 GPC3 GPR85 GPRASP1 GPRC5B GPX3 GRRP1 GYG2 HIGD1B HOXD9 ID1 ID4 IGF1 INHBB ITGA10 ITGA9 ITM2A JPH4 KBTBD11 KCNAB1 KDR KIAA0754 KIF26A KL KLF2 KLF4 LIPE LOC100190938 LOC158376 LOC339524 LXN LYVE1 MPPED2 MYH11 MYOM1 NGFR NLGN4X NOSTRIN NR4A1 NRXN2 NYNRIN OR51E1 PALMD PAMR1 PARK2 PARM1 PCDH19 PCDHB15 PCDHB3 PCDHB4 PDE1B PDE5A PEAR1 PKD1L1 PLAC9 PLCB1 PLCB4 QPRT RARB RASGRF2 RASIP1 RASL12 RGAG4 S1PR1 SAMD5 SCN4B SDPR SEMA6B SEMA6D SEPP1 SERPINI1 SH3BGRL2 SHROOM4 SLC35F1 SNED1 SOCS2 SORBS2 SOX18 SPRY1 SPTBN4 TFPI TGFBR3 TM4SF18 TMEM150C TMEM88 TNXB USHBP1 VWF WSCD1 ZFP36 ZNF423 ZNF521 ZNF788

\section{\# 7:magenta modules}

\# function class: muscle development

\# core genes are present in at least two different cancer types

FHL1 HSPB6 JPH2 PDLIM3 SYNM SYNPO2 ACTA2 ACTG2 AOC3 CNN1 DES ELN FBLN5 FLNC FXYD6 HSPB7 INMT ITGA7 KCNMB1 LIMS2 LMOD1 MFAP4 MRGPRF MYH11 MYL9 MYLK NCAM1 PODN PRELP RASL12 SORBS1 TAGLN TPM2 ACACB AKAP6 ATOH8 BOC C5orf4 CLIP3 CPXM2 CRYAB DACT3 DTNA EBF4 EFHD1 FAM134B FBXL22 FBXO32 FOXF1 FRZB HSPB2 HSPB8 IGF2 IGFBP5 LOC728264 LOXL1 MGP MYH3 MYOM1 NEXN PGM5 PHYHIP PKNOX2 PLA2G16 POPDC2 PPAPDC3 PPP1R14A PSD RAI2 REEP1 RERG SLC2A4 SMOC2 SRL STON1 SYN1 SYNC TIMP3 TNS1 TSPAN18 TSPAN2 WFDC1

\section{\# 8:brown modules}

\# function class: differentiation

\# core genes are present in at least two different cancer types 
bioRxiv preprint doi: https://doi.org/10.1101/028415; this version posted October 5, 2015. The copyright holder for this preprint (which was not certified by peer review) is the author/funder, who has granted bioRxiv a license to display the preprint in perpetuity. It is made available under aCC-BY-NC-ND 4.0 International license.

\section{Core module genes of the conserved CGMs}

ACPP AIM1L ALDH3B2 ALS2CL BNIPL C1orf170 CSTA EHF EPHA1 EPHB3 EPS8L1 EVPL FGFR2 FUT2 GJB2 GJB6 GRHL1 GRHL3 IFFO2 IL1RN KCNJ15 KCNS3 KLF8 KRT13 KRT17 KRT80 LYPD3 MALL NCCRP1 NIPAL1 NIPAL4 OCLN P2RY2 PLAC2 PPL PROM2 PRSS27 PTK6 RAET1G RAPGEFL1 RHOV SDCBP2 SERINC2 SLC2A9 SLC37A2 TMEM154 TMEM184A TMEM45B TNS4 TTC22 TTC39A ZNF185 ZNF750 A4GALT ABCA12 ACBD7 ACSS1 ADAMTS17 ADAMTSL5 AHNAK2 ALOX12 ANKLE1 ANKRD22 ANKRD35 ANXA1 ANXA8 AQP3 ARHGEF37 ARHGEF4 ATP10B B4GALT6 BCL11A BNC1 BSPRY BTBD11 C12orf34 C15orf62 C16orf74 C17orf104 C19orf33 C1orf106 C1orf116 C20orf54 C3orf58 C6orf114 C6orf132 C7orf13 C8orf73 CA12 CABYR CARD14 CAV1 CBS CCDC64B CD24 CDH26 CDH3 CDHR1 CEACAM19 CEACAM6 CGN CHST7 CITED4 CLDN1 CLDN4 CLDN7 CLIC3 CNFN COCH COL17A1 CRABP2 CTSL2 CXADR CXCL14 CXCR2 DHRS3 DHRS9 DMKN DSC2 DSG3 DSP DUOX1 DUOX2 DUOXA1 E2F5 EMP1 EPB49 EPCAM EPN3 EPPK1 EXPH5 F2RL1 F3 FABP5 FAM43A FAM53A FAM81A FAM83A GBP6 GJA1 GJB3 GKAP1 GLB1L2 GPR109A GPR109B GPR157 HBEGF HES2 HLF HOMER2 HOOK1 HOPX HOXA10 HSPB1 HTR7 IL17RB IL1A IL1B IL20RB IL22RA1 ILDR1 INPP4B ITGA6 ITGB4 ITGB6 KCNK1 KIAA1543 KLF4 KLF5 KLK10 KRT15 KRT16 KRT19 KRT5 KRT6A KRT6B KRT6C LAD1 LAMA3 LCN2 LMTK3 LTB4R LTB4R2 LY6D MACC1 MAL2 MDK MICALCL MNS1 MPP7 MPZL2 MYO5B NEBL NELL2 NRCAM NTRK2 OVOL1 P2RY1 PARD6A PHLDA2 PI3 PKP1 PLA2G4F PLCD3 PLCH2 PLEKHG6 PLEKHN1 PODXL2 POU2F3 PPM1E PPP1R14C PRKX PRRG4 PRSS22 PRSS8 PSCA PTCH1 PTGES PVRL1 PVRL4 RAB11FIP1 RAB25 RAB38 RASL10B RASSF9 RHBDL2 RHOD RNF165 RNF39 RNFT2 S100A14 S100A8 S100A9 S100P S1PR5 SCEL SDC1 SEC14L2 SERPINB2 SERPINB5 SFN SGPP2 SH3TC2 SLPI SOX15 SOX2 SPINK5 SPRR1A ST6GALNAC1 ST6GALNAC2 STAR STARD5 STEAP1 STOX1 STOX2 SULT2B1 SUSD4 SV2A SYCP2 SYT8 TACSTD2 TFAP2C TG TGM1 THBD THRB THSD1 TMC4 TMEM40 TMEM79 TMPRSS4 TP63 TPRG1 TRIM2 TRIM29 TRPV4 TSPAN1 TTC9 ULBP2 WNT4 WNT7B XDH ZNF117 ZNF239

\section{\# 9::green modules}

\# function class: metabolism

\# core genes are present in at least two different cancer types

ATHL1 CPT1B GOLGA2B GOLGA8A HSF4 MST1 NCRNA00105 NEAT1 PABPC1L RNF207 SEC31B ADAMTS13 AHSA2 C9orf45 CELF6 CHKB-CPT1B KCNQ1OT1 L3MBTL LOC100190986 LOC100272228 LOC162632 MST1P2 MYO15B PRICKLE4 SEC16B WDR52 AGAP8 AGER AOC2 ARHGAP33 AVIL CAPN3 CEACAM19 DNAH1 DNHD1 FAM13AOS FLJ42627 GABBR1 GABRE GOLGA6L9 GOLGA8B GSDMB HERC2P2 KIAA1683 LOC100132247 LOC100132287 LOC220594 LOC221442 LOC338799 LOC400931 LOC91316 LRP5L MALAT1 MAMDC4 MTMR9L NCRNA00201 NPIPL3 OVGP1 PAQR6 PILRB PLGLB2 PPIEL SLC25A27 SPTBN5 TNFRSF25 TTLL3 ? ADHFE1 AMT AMY2B ATAD3C BZRAP1 C1orf104 C6orf26 C7orf53 CAPN12 CG030 COL27A1 COLQ CRYGS DFNB59 EGFL8 FER1L4 FLJ45445 FOXD4 KCNIP2 KLRA1 LENG8 LOC100131434 LOC100133161 LOC100133331 LOC100270804 LOC388692 LOC613037 LRRC56 MST1P9 NCRNA00174 NCRNA00176 NEIL1 NSUN5P1 NSUN5P2 PCSK4 PI4KAP2 PNPLA7 PRR22 PRRT2 QRICH2 REC8 RPL36A SLC6A16 SLC9A5 UNC5CL ZMAT1 ZNF177 ZNF404 ZNF662 ABCA7 ACCS ACRC AGAP11 AGAP7 ALS2CL ANKRD24 ANKRD36 ANKRD36B ANO9 AURKAPS1 C14orf181 C16orf79 C1orf126 C1orf175 C1orf213 C20orf46 C2orf63 C6orf164 C9orf68 CACNB1 CAPS CARD14 CCDC150 CDHR3 CDK3 CHRNA10 CNTD1 CROCCL2 CTRL CYP2D7P1 DNAH17 DNASE1L2 DNM1P35 DPY19L2P2 FAM95B1 FLJ13197 FLJ45244 FLJ45340 GNB3 GOLGA6L10 GOLGA6L5 GPC2 HCG27 HIST4H4 HSD17B7P2 INE1 ITIH4 KCNAB3 KCP KIAA1529 KIFC2 KLHL3 LCAT LOC100128288 LOC100128842 LOC100272146 LOC100272217 LOC100302650 LOC143666 LOC202181 LOC253039 LOC283314 LOC283663 LOC286367 LOC349114 LOC728264 LPIN3 LRRC37A2 LTB4R LY6G5B MAPK8IP3 MC1R MEGF6 MGC16121 MIR17HG MPP3 MSH5 MSTO2P MYH3 NBPF16 NCRNA00085 NPFF NPIP NTN5 OBSCN OXER1 PBX4 PDXDC2 PI4KAP1 PLEKHG4 PLEKHH2 PLIN4 PMS2L11 PPFIA4 PRSS53 PTK6 PVT1 RGL3 RHPN1 RRN3P1 RRP7B SCNN1D SGK494 SLFNL1 SNHG12 SNHG4 SPDYE6 SPIRE2 SYCP2 TBC1D3B TCTE3 TFAP2E TRPV1 TSSK6 TTC18 TTC21A TTN UCKL1AS WDR27 WDR90 YJEFN3 ZNF135 ZNF233 ZNF37B ZNF577 ZNF833

\section{\# 10:pink modules}


bioRxiv preprint doi: https://doi.org/10.1101/028415; this version posted October 5, 2015. The copyright holder for this preprint (which was not certified by peer review) is the author/funder, who has granted bioRxiv a license to display the preprint in perpetuity. It is made available under aCC-BY-NC-ND 4.0 International license.

\section{Core module genes of the conserved CGMs}

BAIAP3 C17orf72 C19orf51 C6orf97 C9orf98 CAPS CCDC11 CCDC40 DNALI1 FHAD1 KIAA1377 LOC646851 LRRC34 LRRC46 PPIL6 RSPH1 TPPP3 TTC18 TTC25 WDR78 ZMYND12 AK7 C10orf79 C11orf63 C11orf66 C14orf174 C16orf71 C1orf192 C1orf228 C1orf88 C2orf77 C6orf27 C7orf63 C9orf117 C9orf24 CASC1 CCDC103 CCDC114 CCDC146 CCDC153 CCDC19 CCDC39 CCDC65 CCDC74B CCDC81 DNAH3 DNAH7 EFCAB10 FAM164C FAM47E FANK1 FBXO15 FOXJ1 HYDIN KCNRG LRP2BP LRRC48 LRRC6 MAP6 MDH1B NHLRC4 PIH1D2 RAB36 RIBC1 SPA17 SPAG8 SPATA17 SPEF1 UBXN10 WDR66 ZMYND10 ? AGBL2 ANKRD35 ANKRD45 ATG9B BCO2 BEST4 C10orf95 C11orf70 C2orf88 C3orf15 C6orf154 C6orf165 C6orf217 C9orf116 CADPS2 CAPS2 CCDC113 CCDC17 CCDC74A CCDC78 CCDC89 CCDC96 CCNO CDHR3 CERKL CHST5 CHST6 CTXN1 DLEC1 DNAH9 DPY19L2P2 DYX1C1 DZIP1L EFHC2 ENKUR EPHX2 F3 FAM167A FAM179A FAM189A2 GALNT3 GATM GLIS3 GPR135 GPR162 HAGHL IGF2BP2 INHBB IQCD KIF17 LRRC10B LRRC56 MAK MAOB MAPK15 MNS1 MORN3 MUC5B MYB NME5 NUDT7 PCSK4 PLCH1 PRRT2 RFX2 RSPH4A SERINC2 SH3BGR SLC15A2 SPAG1 SPATA18 SPEF2 STK33 STOX1 TCF7 TCTEX1D1 TFF3 TMEM220 TPPP TSNAXIP1 TSPAN1 TTC16 TTC21A TTLL9 TXNDC6 UCKL1AS WDR93 ZNF204P ZNF214

\section{\# 11:yellow modules}

\# function class: phosphorylation/signaling

\# core genes are present in at least three different cancer types

CCNT1 CDYL2 IL6ST IPMK MGAT5 UHMK1 ZNF704 AMIGO1 ANKRD36BP1 DDI2 DKFZp686O24166 ERN1 FRRS1 KIAA0754 KIAA1161 KIAA1244 KIRREL KLHL11 LCOR LOC150381 MAN2A1 MAP3K13 MAST4 N4BP2 NCOA2 NOS1AP PPM1L RAD54L2 RALGAPA2 ROR1 RUNDC2A SERINC5 SGK196 SLC9A7 SOCS7 TAOK1 ZDHHC20 ZNF221 ACER2 ASXL2 ATP11A C6orf204 C9orf129 CBX6 CITED4 CXADR DENND1B DGKH EGFR ETV3 EXOC6B FAM160A1 GLI4 GSR GTF2A1 HIST1H4J IL6R ITGB3 KIAA1958 KLHL23 LMTK2 LNPEP LOC202181 LOC387646 LOC650623 LONRF3 MBNL3 MFHAS1 NACC2 NBEAL1 NBPF10 NIPAL2 NUPR1 OSMR PARD3B PDE3A POTEF PRKAR2A PTPLB REL RNF152 RPL13AP3 RPL22L1 RPPH1 SERTAD4 SESN3 SGPP2 SLC12A2 SMAD9 SNHG9 SPATA13 STOX2 THSD7A TSPAN5 UGCG WDR31 ZC3HAV1L ZNF462 ZNF486 
bioRxiv preprint doi: https://doi.org/10.1101/028415; this version posted October 5, 2015. The copyright holder for this preprint (which was not certified by peer review) is the author/funder, who has granted bioRxiv a license to display the preprint in perpetuity. It is made available under aCC-BY-NC-ND 4.0 International license.

\section{Zou_Suppl_Table_5}

\begin{tabular}{|l|l|}
\hline & \multicolumn{1}{|c|}{ predicted module drivers } \\
\hline $\begin{array}{l}\text { overlap with } \\
\text { significantly } \\
\text { mutated genes } \\
\text { (MutSig) }\end{array}$ & $\begin{array}{l}\text { TP53 BRCA1 BUB1B CDKN1A RB1 PTPN11 PIK3R1 JAK2 } \\
\text { PIK3CA EGFR CTNNB1 RAC1 RASA1 AKT1 HRAS EP300 }\end{array}$ \\
\hline MYH9 ERAA CCND1 SMAD4 CDH1 SMAD2 NCOA3 DMD \\
\hline $\begin{array}{l}\text { overlap with } \\
\text { cancer } \\
\text { consensus } \\
\text { genes }\end{array}$ & $\begin{array}{l}\text { TP53 BRCA1 BUB1B XPO1 MYC RB1 CD74 LCK } \\
\end{array}$ \\
& PTPN11 CBL JAK1 ITK CD79B CD79A PIK3R1 JAK2 \\
& EP300 CREBBP CYLD CCND1 ELN KDR TCF3 CDH1 \\
& NCOA1 PDGFRB MYH9 ERBB2 MET FGFR3 JAK3 ERCC2 \\
\hline
\end{tabular}

